Universidade de SÃo Paulo

Faculdade de Filosofia, Ciências e letras de Ribeirão Preto Pós-GraduaÇÃo em Física Aplicada À Medicina e Biologia

\title{
Algoritmos de Monte Carlo generalizados e criticalidade no modelo de Ising dipolar e em proteínas descritas por um modelo mínimo
}

\author{
LEANDRO GUTIERREZ RIZZI
}

Ribeirão Preto - SP

2013 


\section{LeAndro Gutierrez Rizzi}

\section{Algoritmos de Monte Carlo generalizados e criticalidade no modelo de Ising dipolar e em proteínas descritas por um modelo mínimo}

Tese apresentada à Faculdade de Filosofia, Ciências e Letras de Ribeirão Preto da Universidade de São Paulo, como parte das exigências para a obtenção do título de Doutor em Ciências

Área de Concentração:

Física Aplicada à Medicina e Biologia

Orientador:

Prof. Dr. Nelson Augusto Alves

Versão corrigida

Ribeirão Preto - SP

2013 
AUTORIZO A REPRODUÇÃO E DIVULGAÇÃO TOTAL OU PARCIAL DESTE TRABALHO, POR QUALQUER MEIO CONVENCIONAL OU ELETRÔNICO, PARA FINS DE ESTUdO E PESQUISA, DESDE QUE CITADA A FONTE.

Rizzi, Leandro Gutierrez.

Algoritmos de Monte Carlo generalizados e criticalidade no modelo de Ising dipolar e em proteínas descritas por um modelo mínimo/ Leandro Gutierrez Rizzi; orientador Prof. Dr. Nelson Augusto Alves. Ribeirão Preto, 2013. 134 p.

Tese (Doutorado - Programa de Pós-Graduação em Física Aplicada à Medicina e Biologia) - Faculdade de Filosofia, Ciências e Letras de Ribeirão Preto da Universidade de São Paulo.

1. algoritmos de Monte Carlo generalizados. 2. transições de fase.

3. modelo de Ising dipolar. 4. modelo mínimo de proteínas. 


\section{DEDICATÓRIA}

Dedico esta Tese aos meus pais Antônio Carlos Rizzi e Odette Gutierrez Rizzi e aos meus sobrinhos, Vicente e Clara. 


\section{AGRADECIMENTOS}

Em primeiro lugar, agradeço ao Prof. Dr. Nelson A. Alves, pela ampla gama de ensinamentos que me transmitiu e pela enorme dedicação com que orientou meus estudos durante todos esses anos. Sempre terá o meu respeito e minha admiração.

Gostaria também de agradecer:

Ao Prof. Dr. Marcelo Mulato, coordenador do curso de pós-graduação FAMB, por todo o apoio e pelas discussões realizadas nesses últimos anos.

Aos Professores das disciplinas que cursei na FCFRP durante o Doutorado, Prof. Dr. Antonio Caliri, Prof. Dr. Fernando Luis B. da Silva e Prof. Dr. Marco Antônio A. da Silva.

À secretária do programa de pós-graduação Nilza Maria L. Marino, por toda a dedicação e auxílio prestado.

À secretária do Departamento de Física (DF) da FFCLRP, Sonia A. N. de Paula; aos funcionários do Serviço de pós-graduação da FFCLRP, Denise Aparecida Silveira, Cesar P. Brites, Maria Inês Joaquim e Maria Fabiana C. Tavares. Aos funcionários do DF, José L. Aziani, Julio Cezar, Leonardo M. de Oliveira, Lourenço Rocha, Marcilio Mano Jr. e Ricardo G. F. dos Santos; e da (ex-)Seção de Informática, Dr. Adriano Holanda, Everton Bertolai, Fábio Moretti, Matheus Machado e Tiago Carrer, pelo auxílio prestado.

À Dra. Cynthia M. C. P. Manso pelas revisões nos textos publicados em inglês.

Ao $\mathrm{CNPq}$, pela bolsa de estudos e à CAPES e FAPESP pelo auxílio à pesquisa.

Ao Laboratório de Computação Científica Avançada (LCCA) da USP, pelos recursos computacionais disponibilizados. Em particular, ao administrador Ettore E. D. Ligorio, pelos esclarecimentos.

Aos meus colaboradores, amigos e companheiros do Laboratório de Simulação Computacional em Sistemas Complexos, Doutores Luiz Carlos B. Mostaço-Guidolin 
e Rafael B. Frigori, e Mestres Jacyana S. M. Fonseca e Matheus R. de Mendonça. Aos amigos e colegas do Laboratório de Modelagem de Sistemas Complexos, Prof. Dr. Alexandre S. Martinez, Doutores Brenno C. T. Cabella, Marcelo A. Pereira e Rodrigo S. González, e Mestres Lindomar S. dos Santos, Natália Destefano, Olavo H. Menin e Tiago José Arruda.

Aos incontáveis amigos que criei por causa da minha paixão pela Física, os quais de uma forma ou de outra me apoiaram. Em particular, agradeço aos amigos Adalberto Anderlini, Carlos Eduardo C. Rolim, Carlos Augusto Morbiolo, Diogo Melo, Diogo P. C. Vieira, Dr. Erbe P. Rodrigues, Dr. Eslley S. Gonçalves, Felipe M. Escanhoela, Gabriel B. Cintra, Luis Fernando Laguna, Dr. João Paulo Dal Molin, Marcos Souto, Paulo H. Friso, Ricardo O. S. Soares, Victor Raphael C. M. Roque e Welton Gomes.

À Ana Carolina Mourão Roque, minha companheira, pelo apoio, compreensão e amizade, além de todo o "ódio" compartilhado.

Ao pessoal das bandas "Asator": Gabriel Lucas, Carol Toledo e Carlos "Vordevil"; e "Signs of the Beast": Rafael "Miojo" Moretto, Danillo "Torresmo", Vinícius Zaneti, Betinho Zampieri e Angelo Bordin; pela música, minha outra paixão. 
Where we start is where we end

We step out sweetly, with nothing planned

Along by the river we feed bread to the swans

And then over the footbridge to the woods beyond

We walk ourselves weary, you and I

There's just this moment 


\section{RESUMO}

RIZZI, L. G. Algoritmos de Monte Carlo generalizados e criticalidade no modelo de Ising dipolar e em proteínas descritas por um modelo mínimo. 134 p. Tese (Doutorado) - Faculdade de Filosofia, Ciências e Letras de Ribeirão Preto, Universidade de São Paulo, Ribeirão Preto, 2013.

Sistemas complexos que apresentam interações competitivas são ubíquos na natureza. Obter descrições adequadas das propriedades termodinâmicas desses sistemas é um desafio para o entendimento de uma série de processos químicos e físicos. Soluções analíticas em termos da Mecânica Estatística são extremamente difíceis de serem obtidas para esses sistemas. Isso faz com que o uso de simulações numéricas seja, na maioria dos casos, a única abordagem possível. Nesta Tese avaliamos o desempenho de duas classes de algoritmos de Monte Carlo generalizados empregados na determinação da natureza das transições de fase em dois sistemas complexos: o modelo de Ising dipolar bidimensional (2D) e um modelo mínimo para descrever proteínas. Na primeira classe, a qual representa os algoritmos seriais, incluimos os algoritmos multicanônico (MUCA) e de amostragem entrópica (ES), também conhecidos como algoritmos de amostragem uniforme. Na segunda classe, que diz respeito aos algoritmos paralelizáveis, incluimos o algoritmo canônico de Metropolis associado ao método de troca entre réplicas (REM). Para ambas as classes introduzimos contribuições metodológicas visando o aumento da eficiência na obtenção das propriedades canônicas e microcanônicas dos modelos. No caso dos algoritmos de amostragem uniforme, caracterizamos protocolos baseados na contagem de viagens de ida e volta que otimizam a determinação dos pesos de amostragem, e dessa maneira, aumentam a eficiência na obtenção da densidades de estados. Com relação ao uso de simulações canônicas implementadas com o REM, introduzimos o método ST-WHAM-MUCA como uma nova maneira de calcular a entropia microcanônica, 
associando o inverso da temperatura estatística obtida via ST-WHAM às equações de recorrência do algoritmo MUCA. A partir de simulações canônicas para os dois modelos estudados, mostramos que a termoestatística microcanônica obtida via STWHAM é equivalente àquela obtida pelo algoritmo MUCA, mesmo para a região onde ocorrem transições de fase de primeira ordem e uma não concavidade é observada na entropia microcanônica. Além dos estudos sobre a metodologia empregada na implementação dos algoritmos, realizamos contribuições para o entendimento da criticalidade nos modelos. Em particular, determinamos os aspectos críticos no modelo de Ising dipolar 2D para dois cenários distintos. Para o Cenário I, onde apenas uma transição entre as fases de faixas e tetragonal é observada, empregamos o algoritmo MUCA aliado à metodologia de obtenção dos zeros complexos da função de partição canônica. Nesse caso, foi possível determinar a natureza contínua da transição de fase faixas-tetragonal, excluindo um possível ponto trícritico, como sugerido na literatura para a região $h=1$ do diagrama de fases. Para o Cenário II, o qual descreve uma região que apresenta duas transições de fase em decorrência do aparecimento de uma fase nemática entre as fases de faixas e tetragonal, mostramos que o algoritmo MUCA apresenta problemas mesmo para redes pequenas. Utilizando o algoritmo de Metropolis associado ao REM, realizamos simulações para uma rede de tamanho $L=72$. A partir da análise via ST-WHAM dessas simulações, obtivemos estimativas para o inverso da temperatura microcanônica, as quais sugerem que ambas transições de fase, faixas-nemática e nemática-tetragonal, sejam de primeira ordem, excluindo a possibilidade de uma transição de Kosterlitz-Thouless (KT). Também realizamos simulações utilizando o algoritmo de Metropolis associado ao REM para estudar a criticalidade em proteínas descritas por um modelo mínimo. Nesse estudo caracterizamos a termoestatística microcanônica das transições de enovelamento de quatro cadeias polipeptídicas com conhecida propensidade à formação de agregados. Nossos resultados sugerem que a ausência de barreiras na energia livre favorece a presença de conformações parcialmente desenoveladas, o que facilitaria a agregação das proteínas. Por fim, introduzimos o raio de giração hidrofóbico como parâmetro de ordem para a transição de enovelamento. Além de fornecer resultados condizentes com a descrição microcanônica, essa quantidade pode ser utilizada mesmo que não existam informações sobre o estado nativo. 


\section{ABSTRACT}

RIZZI, L. G. Generalized Monte Carlo algorithms and criticality in the dipolar Ising model and in proteins described by a minimal model. $134 \mathrm{p}$. Thesis (Ph.D.) - Faculdade de Filosofia, Ciências e Letras de Ribeirão Preto, Universidade de São Paulo, Ribeirão Preto, 2013.

Complex systems which present competitive interactions are ubiquitous in nature. Obtaining adequate descriptions of the thermodynamic properties of these systems is a major challenge to understand many chemical and physical processes. Analytical solutions in terms of Statistiscal Mechanics are extremely hard to obtain for these systems. Thus, in most cases numerical simulations become the only possible approach. In this Thesis we evaluate the performance of two categories of generalized Monte Carlo algorithms employed to determine the nature of phase transitions in two complex systems: the two-dimensional (2D) dipolar Ising model and a minimal model to describe proteins. In the first category, which represents serial algorithms, we include the multicanonical (MUCA) and entropic sampling (ES) algorithms, which are known as flat histogram algorithms. In the second category, which concerns parallelizable algorithms, we include the Metropolis algorithm associated with replica exchange method (REM). For both categories we introduce methodological contributions aiming the increase of efficiency in obtaining the canonical and microcanonical properties of the models. In case of flat histogram algorithms, we characterized protocols based on round trip counting to optimize the determination of the sampling weights, and therefore increasing the efficiency in obtaining the density of states. Regarding the use of canonical simulations implemented with REM, we introduce ST-WHAM-MUCA as a new method to evaluate the microcanonical entropy, associating the inverse of the statistical temperature obtained from ST-WHAM with the recursions equations of MUCA algorithm. From canoni- 
xii

cal simulations for both models, we show that the microcanonical thermostatistics obtained via ST-WHAM is equivalent to that obtained by MUCA algorithm, even for a region where a first-order phase transition takes place and a non concavity is observed in the microcanonical entropy. In addition to the studies about the methodology employed in implementation of the algorithms, we present the contributions we make to understand the criticality in the models. In particular, we determined the critical aspects of the 2D dipolar Ising model for two different scenarios. For Scenario I, where only one transition is between the stripe and tetragonal phases is observed, we use MUCA algorithm associated with the analysis of the complex zeros from the canonical partition function. In this case, it was possible to determine the continuous character of the stripe-tetragonal phase transition, excluding the existente of a tricritical point, as suggested in the literature for the $h=1$ region in the phase diagram. For Scenario II, which describe a region that presents two phase transitions due to the appearance of a nematic phase between the stripe and tetragonal phases, we show that the MUCA algorithm present problems even for small lattices. Using the canonical Metropolis algorithm with REM, we run simulations for a lattice with size $L=72$. From ST-WHAM analysis of these simulations, we obtained estimates for the microcanonical inverse temperature, which suggests that both phase transitions, stripe-nematic and nematic-tetragonal, are first order, excluding the possibility of a Kosterlitz-Thouless (KT) transition. We also performed simulations using the canonical Metropolis algorithm associated with the REM to study the criticality in proteins described by a minimal model. In this study we characterized the microcanonical thermostatistics of the folding transitions of four polypeptide chains with known propensity to form aggregates. Our results suggest that the absence of a free-energy barrier favors the presence of partial unfolded conformations, which could facilitate the aggregation of the proteins. Finally, we introduce the hydrophobic radius of gyration as an order parameter for the folding transition. In addition to provide consistent results with the microcanonical description, this quantity can be used even if there is no information about the native state. 


\section{LISTA DE FIGURAS}

2.1 Curvas da temperatura $T(\varepsilon)$ em função da energia específica $\varepsilon$ obtidas no ensemble gaussiado estendido (EGE) para o modelo $\mathrm{BC}$ e vários valores de $\gamma$ na região de inequivalência de ensembles $(\Delta / J=$ 0,462407). Figura retirada da Ref. [68]. . . . . . . . . . . . 17

2.2 Comportamento microcanônico para do modelo BC na região de inequivalência de ensembles $(\Delta / J=0.462407)$. (a) Temperatura microcanônica em função da energia específica $\varepsilon$. A linha horizontal corresponde à temperatura de transição canônica (construção de Maxwell). (b) Entropia microcanônica deslocada (ou shifted microcanonical entropy) $\tilde{s}(\varepsilon)$. Tal deslocamento ou subtração é feito para melhorar a visualização da não concavidade na entropia em relação a função linear que une $s\left(\varepsilon_{a}\right)$ à $s\left(\varepsilon_{b}\right)$. (c) Calor específico $c(\varepsilon)$. Apresenta dois polos localizados nos zeros do determinante $d(\varepsilon, m)$, onde $m$ representa os valores da magnetização por spin que maximizam a entropia na energia $\varepsilon$. Tais polos podem ser observados como consequência do comportamento de $T(\varepsilon)$ em (a), nos pontos $d$ e $e$, sendo que $c(\varepsilon)$ torna-se negativo entre esses valores. (d) Susceptibilidade específica $\chi(\varepsilon)$ em função de $\varepsilon$, a qual também torna-se negativa entre os zeros de $d(\varepsilon, m)$. (e) Comportamento do determinante $d(\varepsilon, m)$ como função de $\varepsilon$. A linha vertical pontilhada sinaliza os zeros de $d(\varepsilon, m)$. Figura retirada da Ref. [68] (Anexo II), onde mais detalhes podem ser encontrados. 
2.3 Trajetória no espaço das energias para as configurações amostradas (linha vermelha). As linhas horizontais representam o número de varreduras nos quais o caminhante atinge alguma das energias extremas. Regiões cinzas e brancas representam caminhantes com rótulos "+" e "-", respectivamente. As energias foram mapeadas no índice inteiro $m$, sendo que $m^{*}=410$ corresponde à energia inicial de referência $E^{*}$, e $m_{+}=487$ e $m_{-}=332$ correspondem às energias extremas máxima $E_{+}$e mínina $E_{-}$, respectivamente. . . . . . . . . . . . . 25

2.4 Esquema de troca entre réplicas alternando entre as réplicas com índices ímpares e suas vizinhas $(2 \alpha-1,2 \alpha)$ e réplicas pares e suas vizinhas $(2 \alpha, 2 \alpha+1)$. Swaps aqui corresponde ao número de tentativas de trocas entre réplicas. . . . . . . . . . . . . . . . . . . . . . 27

2.5 Comparação entre simulações MUCA e Metropolis para a obtenção da termoestatística microcanônica para o modelo de Ising dipolar 2D na região onde o acoplamento é $\delta=2$ utilizando uma rede de tamanho $L=32$. (a) histogramas $H_{\alpha}(E)$ obtidos via simulações independentes de Metropolis em temperaturas $T_{\alpha}$. (b) estimativas do inverso da temperatura microcanônica $\beta(E)$ obtidas via ST-WHAM (linha sólida) e MUCA (linha tracejada). (c) entropias microcanônicas deslocadas obtidas pela solução ST-WHAM-MUCA (linha sólida) e puramente multicanônica (linha tracejada) em função da energia por spin $E / N$. Figura retirada da Ref. [70]. . . . . . . . . . . . . . . . . . . 33 
3.1 Diagrama de fase para o modelo de Ising dipolar 2D: (o) dados da referência [120] e $(\downarrow)$ correspondem aos resultados apresentados na subseção 3.3.2 (vide referência [74] ou Anexo VII). As linhas verticais pontilhadas representam os limites das fases onde o estado fundamental é caracterizado por configurações antiferromagnéticas (AF) e de faixas com largura $h=1$ e $h=2$. A linha contínua corresponde a transição de segunda ordem esperada, exceto para o pequeno intervalo $\delta$ em $(0,4152: 0,4403)$, e a linha tracejada $(---)$ representa transições de primeira ordem de acordo com as Refs. [120] e [126]. Figura retirada da Ref. [74].

3.2 Configurações típicas para o modelo de Ising dipolar 2D para o Cenário I para a região $h=1$ : fase de faixas (à esquerda) e fase tetragonal (à direita). Ao centro incluimos uma configuração de transição, dessa maneira a figura observada da esquerda para a direita representa configurações típicas para um aumento na temperatura do sistema. Figura adaptada da Ref. [74]. . . . . . . . . . . . . . . . . . . . 39

3.3 Configurações típicas para o modelo de Ising dipolar 2D para o cenário II para a região $h=2$ : fase de faixas (extrema esquerda), fase nemática (centro) e fase tetragonal (extrema direita). Incluimos também configurações típicas para estados nas duas transições. Dessa maneira a figura da esquerda para a direita representa configurações típicas para um aumento na temperatura do sistema. Figura adaptada da referência [80]

3.4 Comparação entre os algoritmos MUCA e ES para a obtenção da densidade de estados do modelo de Ising dipolar 2D para $L=48$, $\delta=1,7$ utilizando os quatro protocolos descritos na seção $2.3 .3 \mathrm{e}$ uma discretização na energia $\epsilon=1$. (a) e (c): energia mínima por volume $E_{\min } / N$ em função do número de varreduras $N_{\text {var }}$; (b) e (d): número de varreduras médio $\left\langle N_{\text {var }}\right\rangle$ em função do módulo da energia mínima por volume $E_{\min } / N$. 
3.5 Curvas calóricas $b(E)$ em função da energia mínima por volume $E / N$ após o sistema completar o procedimento de recorrência. Resultados para $L=48, \delta=1,7$ e $\varepsilon=1$, comparando os algoritmos MUCA e ES para os quatro protocolos. Cores distintas representam realizações distintas. . . . . . . . . . . . . . . . . . . . . 45

3.6 Diferença de energia livre $\Delta F\left(\beta_{c}, E\right)$ em função da energia mínima por volume $E / N$ na região do intruso convexo na entropia microcanônica após o sistema ter completado o procedimento de recorrência. Resultados para $L=48, \delta=1,7$ e $\varepsilon=1$, comparando os algoritmos MUCA e ES para os quatro protocolos. Cores distintas representam realizações distintas. . . . . . . . . . . . . . . . . . . . . 47

3.7 Regressões lineares utilizando a relação de escala de tamanho finito (FSS) 3.3 para a obtenção do expoente $d \nu$ para alguns valores do acoplamento $\delta$. Os pontos correspondem à parte imaginária dos zeros complexos da função de partição no plano da temperatura em função de tamanho linear da rede $L$. Figura retirada da Ref. [74]. . . . . . . 50

3.8 Comportamento de $H_{m u}^{n-1}(E)$ e $b^{n}(E)$ para $L=32, \epsilon=2$ e $n_{s}=5 \times 10^{4}$ entradas no histograma em dois estágios diferentes do procedimento de recorrência: $n=100$ nas figuras (a) e (b); $n=400$ nas figuras (c) e (d). Figura retirada da Ref. [75] para o modelo de Ising dipolar 2D. 54

3.9 Comportamento de $H_{m u}^{n-1}(E)$ e $b^{n}(E)$ para $L=48, \epsilon=1$ e $n_{s}=5 \times 10^{4}$ entradas no histograma em três estágios diferentes do procedimento de recorrência: $n=150$ nas figuras (a) e (b); $n=300$ nas figuras (c) e (d); $n=550$ nas figuras (c) e (d). Figura retirada da Ref. [75] para o modelo de Ising dipolar 2D. . . . . . . . . . . . . . . . 56

3.10 Convergência do parâmetro multicanônico $b(E)$ para $L=48$ e $n_{s}=$ $2 \times 10^{4}$ entradas no histograma para diferentes tamanhos de bin $\epsilon$. A Figura (a) mostra resultados para $n=800$ passos de recorrência, e (b) para $n=999$. Figura retirada da Ref. [75] . . . . . . . . . . . 59 
3.11 Termoestatística microcanônica para o modelo de Ising dipolar 2D para acoplamento $\delta=2$ para uma rede de tamanho $L=72$. Região do cenário II $(h=2)$. (a) Histogramas $H_{\alpha}$ obtidos via simulação REM para as 12 réplicas utilizando o conjunto de temperaturas definido em 3.10); (b) curva calórica $b(E)$ obtida via ST-WHAM em função da energia por volume $E / N \ldots \ldots \ldots$. . . . . . . . . . . . . . 61

3.12 Comparação da termoestatística microcanônica para o modelo de Ising dipolar 2D para acoplamento $\delta=2$ para uma rede de tamanho $L=72$ para duas simulações REM. (a) Histogramas $H_{\alpha}$ obtidos via simulação REM para as 6 réplicas utilizando o conjunto de temperaturas definido em 3.11); (b) curvas calóricas $b(E)$ obtidas via ST-WHAM em função da energia por volume $E / N$. A linha preta contínua representa a curva obtida a partir dos dados da simulação REM utilizando 12 temperaturas, enquanto que a linha vermelha tracejada indica a simulação feita com 6 temperaturas. . . . . . . . . . . 62

4.1 Conformações ilustrativas para as sequências AB representando as cadeias (a) A $\beta 40$, (b) A $\beta 42$, (c) Src SH3, e (d) hPrP na região de transição de enovelamento. Esferas escuras (vermelhas) indicam monômeros hidrofóbicos. (Estas figuras foram feitas com ajuda do software $\operatorname{VMD}[180]) \ldots \ldots \ldots$

4.2 Temperaturas utilizadas nas simulações com troca entre réplicas na produção de dados para os quatro heterpolímeros estudados. . . . . . 71

4.3 (a) Estimativas para o inverso da temperatura microcanônica $\beta(\varepsilon)=$ $1 / T(\varepsilon)$, e (b) calor específico microcanônico $C_{v}(\varepsilon)=-\beta^{2} /(\partial \beta / \partial \varepsilon)$ para o heteropolímero $\mathrm{A} \beta 40$. Dentro da Fig. (a) apresentamos as mudanças na energia livre construídas a partir da entropia $S(\varepsilon)$ para

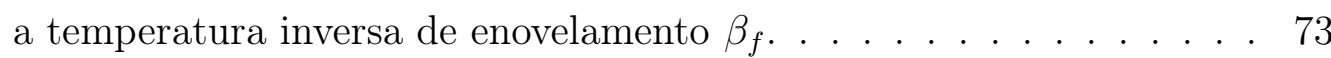


xviii

4.4 (a) Estimativas para o inverso da temperatura microcanônica $\beta(\varepsilon)$, e (b) calor específico microcanônico $C_{v}(\varepsilon)$ para o heteropolímero $\mathrm{A} \beta 42$. Dentro da Fig (a) apresentamos as mudanças na energia livre construídas a partir da entropia $S(\varepsilon)$ para a temperatura inversa de enovelamento $\beta_{f} \ldots \ldots \ldots \ldots \ldots \ldots$. . . . . . . . . . . . . . . . . .

4.5 (a) Estimativas para o inverso da temperatura microcanônica $\beta(\varepsilon)$, e (b) calor específico microcanônico $C_{v}(\varepsilon)$ para o heteropolímero Src SH3. Dentro da Fig (a) apresentamos as mudanças na energia livre construídas a partir da entropia $S(\varepsilon)$ para a temperatura inversa de enovelamento $\beta_{f} \ldots \ldots \ldots \ldots \ldots$. . . . . . . . . . . . . . . . . .

4.6 (a) Estimativas para o inverso da temperatura microcanônica $\beta(\varepsilon)$, e (b) calor específico microcanônico $C_{v}(\varepsilon)$ para o heteropolímero hPrP. $\quad 77$

4.7 Comportamento do raio de giração hidrofóbico $r_{h}$ (a) e a sua derivada $<d r_{h} / d T>$ (b) em função da temperatura. . . . . . . . . . . . 78

A.1 Curvas calóricas obtidas via ST-WHAM para o modelo XY bidimensional na região de transição KT para dois tamanhos de rede $L=48$ e $L=128 \ldots \ldots \ldots 110$

B.1 Comparação entre simulações de Metropolis independentes e utilizando o método de troca entre réplicas para o modelo AB. Energia média por monômero em função da temperatura para a sequência Fibonacci (ABBABBABABBAB) com 13 monômeros. . . . . . . . . . . . . 112

B.2 Curva calórica microcanônica para o sistema de duas sequências de Fibonacci com 13 aminoácidos cada obtida a partir de simulações de Metropolis com troca entre réplicas aliadas ao ST-WHAM. As linhas pontilhas representam as temperaturas inversas utilizadas na simulações. . . . . . . . . . . . . . . . . . . . . 113 


\section{LISTA DE TABELAS}

3.1 Estimativa (sobre 4 realizações) do número de varreduras total para obtenção da densidade de estados do modelo de Ising dipolar 2D realizando passos de recorrência até o sistema atingir a energia do estado fundamental. Resultados para $L=48, \delta=1,7$ e $\varepsilon=1$. . . . 44

3.2 Estimativas (sobre 4 realizações) para a temperatura $T_{c}$ de transição de fase faixas-tetragonal logo após completar o procedimento de recorrência para os algoritmos MUCA e ES associados aos diferentes protocolos. Resultados para $L=48, \delta=1,7$ e $\varepsilon=1$. . . . . . . . 46

3.3 Temperaturas de transição e expoentes críticos para vários valores de $\delta$ obtidos pelos zeros complexos da função de partição, calor específico $C_{v}$ e susceptibilidade do parâmetro de ordem $\chi\left(O_{h v}\right)$. Dados retirados da Ref. [74] para o modelo de Ising dipolar 2D. . . . . . . . . . . . . 52

3.4 Estimativa do número de varreduras total $N_{\text {var }}$ (acumulado) para obtenção da densidade de estados até a energia mínimaatingida $E_{\min } / N$. O valor de $\Delta N_{\text {var }}$ fornece o número de varreduras contabilizado entre o sistema ter alcançado $E_{\min } / N$ e nós termos encerrado (arbitrariamente) a simulação, também chamado tempo de estagnação. Os valores marcados com * correspondem aos valores do estado fundamental. Simulações feitas para $\delta=2, \varepsilon=1$ e diferentes tamanhos de rede $L$ utilizando o protocolo (iv) para ambos algoritmos: ES e MUCA. 58

4.1 Códigos PDB, número de aminoácidos $N$ e mapeamento da sequência primária na sequência $\mathrm{AB}$ via escala Roseman [178] para os quatro heteropolímeros estudados. . . . . . . . . . . . . . . . . . 68 
4.2 Resultados comparativos para os diferentes modelos de heterpolímeros. Temperaturas de enovelamento $T_{f}$ obtidas via construção de Maxweel. Temperaturas de enovelamento $T_{r}$ obtidas via raio de giração hidrofóbicos. Barreiras de energia livre $\Delta F$ e calor latente por monômero $\ell$. Índice de propensidade de agregação $Z_{\text {agg }}$. . . . . . . . 80 


\section{SUMÁRIO}

Lista de Figuras xiii

Lista de Tabelas $\quad$ xix

1 Introdução $\quad 3$

2 Algoritmos de Monte Carlo generalizados 11

2.1 Introdução . . . . . . . . . . . . . . . . . . . . . . 11

2.2 Relação com a Teoria dos Ensembles . . . . . . . . . . . . . . . . 12

2.3 Algoritmos de amostragem uniforme . . . . . . . . . . . . . 20

2.3.1 Algoritmo multicanônico . . . . . . . . . . . . . . . . . . 21

2.3.2 Algoritmo entrópico . . . . . . . . . . . . . . . . 23

2.3.3 Protocolos de obtenção dos pesos . . . . . . . . . . . . 23

2.4 Método de troca entre réplicas . . . . . . . . . . . . . . 26

2.4 .1 Definição . . . . . . . . . . . . . . 26

2.4.2 Protocolo de obtenção do conjunto de temperaturas . . . . . . 27

2.5 Análise via temperatura estatística . . . . . . . . . . . . . 28

2.5.1 ST-WHAM . . . . . . . . . . . . . . . . . . 29

2.5.2 ST-WHAM-MUCA . . . . . . . . . . . . . . 30

2.5.3 Comparação entre ST-WHAM e MUCA . . . . . . . . . . . 30

3 Simulações numéricas do modelo de Ising dipolar 35

3.1 Descrição do modelo . . . . . . . . . . . . . . . . . . . . 35

3.2 Revisão bibliográfica . . . . . . . . . . . . . . . . . . . 36

3.3 Cenário I: Transição de fase faixas-tetragonal . . . . . . . . . . . . . . 41

3.3.1 Obtenção da densidade de estados . . . . . . . . . . . . . . . . 42 


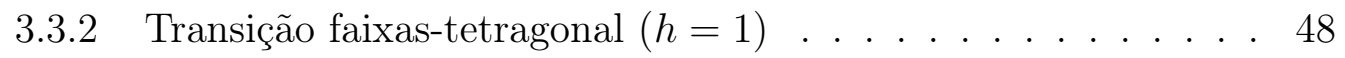

3.4 Cenário II: Transições de fase faixas-nemática e nemática-tetragonal . 53

3.4.1 Metaestabilidade e aprisionamento . . . . . . . . . . 53

3.4 .2 Termoestatística microcanônica . . . . . . . . . . . . . . . 59

4 Simulações numéricas de proteínas descritas por um modelo mínimo

4.1 Introdução . . . . . . . . . . . . . . . . . . . . . 65

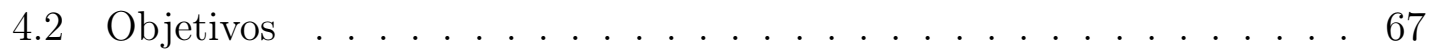

4.3 Descrição do modelo . . . . . . . . . . . . . . . . . . . . . . . . . 69

4.4 Resultados . . . . . . . . . . . . . . . . . . 71

4.4.1 Conjunto de temperaturas . . . . . . . . . . . . . . 71

4.4 .2 Termoestatística microcanônica . . . . . . . . . . . . . . 72

4.4.3 Raio de giração hidrofóbico . . . . . . . . . . . . . . . . 77

4.5 Discussões e conclusões . . . . . . . . . . . . . . . . . . . . . . 79

5 Conclusões $\quad 83$

$\begin{array}{lr}\text { Referências Bibliográficas } & 89\end{array}$

A Curva calórica para o modelo XY bidimensional 109

B Validação da implementação do modelo AB 111

$\begin{array}{ll}\text { Anexos: artigos } & 115\end{array}$ 


\section{CApÍtulo}

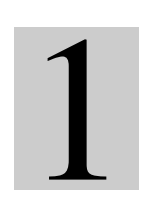

\section{INTRODUÇÃO}

Para compreender aspectos fundamentais dos processos físicos e químicos, faz-se necessário na grande maioria das vezes analisar o seu comportamento em termos de alterações nas suas variáveis termodinâmicas tais como temperatura, pressão, campo magnético externo, voltagem aplicada, etc. Processos de suma importância em campos tão diversos como, por exemplo, o desenho racional de fármacos e a fabricação de dispositivos de armazenamento de informação, não podem ser previstos ou planejados de forma confiável sem o conhecimento do comportamento termodinâmico dos sistemas envolvidos.

Na Física, a área que reune os formalismos que tratam da obtenção das propriedades termodinâmicas dos sistemas é chamada de Mecânica Estatística [1, 2, 3, 4, 5]. Para a maioria dos sistemas não podemos desprezar as interações entre os seus componentes, o que dificulta enormemente a obtenção de tais propriedades via métodos puramente analíticos. Assim, a caracterização da termodinâmica dos sistemas através de simulações numéricas com base em princípios da Mecânica Estatística constitui na maioria dos casos a única abordagem possível e vem se tornando uma importante metodologia nas últimas décadas. A perspectiva é que os desenvolvimentos metodológicos, em conjunto com o aumento contínuo da capacidade computacional, irão contribuir para transformar a obtenção das propriedades termodinâmicas via simulações computacionais em ferramentas de modelagem robustas e bem caracterizadas, ampliando o seu campo de aplicações [6]. Com isso, as simulações ajudariam não só no entendimento qualitativo de processos mas também na predição quantitativa de propriedades e fenômenos termodinâmicos que envolvem a ocorrência de 
novas fases em sistemas físicos reais. A caracterização das fases existentes em um dado material pode ser de enorme importância para diversas aplicações tecnológicas (veja, por exemplo, a Ref. [7]).

Dentre os métodos computacionais mais conhecidos para obtenção de propriedades termodinâmicas de modelos em Mecânica Estatística estão os chamados algoritmos de Monte Carlo (MC) [8, 9]. O primeiro algoritmo de MC para esse fim foi desenvolvido no início da década de cinquenta por Metropolis e colaboradores [10]. A característica fundamental dos algoritmos de MC é amostrar aleatoriamente configurações do sistema com relevância estatística, que é uma técnica também conhecida como amostragem por importância (ou importance sampling) [11, 12]. Para o caso particular do algoritmo de Metropolis, isso significa que as configurações de um sistema com energia $E$ serão amostradas de acordo com o peso de Boltzmann, resultando na distribuição característica do ensemble canônico $\Omega(E) e^{-\beta E}$, definida por uma temperatura constante ${ }^{1} T=1 / k_{B} \beta$ e pela densidade de estados $\Omega(E)$. A utilidade de um algoritmo como o de Metropolis é evidente, já que a partir da energia microscópica, ou hamiltoniano(a) do sistema, é possível obter quantidades tais como, por exemplo, energia média e calor específico desse sistema em função da sua temperatura.

Por causa da enorme gama de aplicações [12], o algoritmo de Metropolis praticamente virou sinônimo de algoritmo de MC. Contudo, várias outras maneiras de construir algoritmos de MC para amostrar aleatoriamente configurações podem ser elaboradas. De fato, principalmente após o surgimento dos métodos de repesagem de histogramas $[13,14,15,16,17,18,19]$, vários algoritmos, entre eles o algoritmo de amostragem de guarda-chuva ou umbrella samping (US) [20], foram propostos. Isso porque os métodos de repesagem permitem que a distribuição canônica seja recuperada a partir de histogramas obtidos por simulações que utilizam outros pesos de amostragem, desde que haja um número suficiente de configurações amostradas. Tais métodos melhoraram significativamente a eficiência das simulações de MC $[21,22]$.

Atualmente, sabemos que simulações de MC canônicas, da maneira como Metropolis e colaboradores originalmente propuseram, não são eficientes para o estudo de

\footnotetext{
${ }^{1}$ Por simplicidade, adotamos unidades onde a constante de Boltzmann $k_{B}$ é igual a 1.
} 
sistemas complexos tais como vidros de spin e biopolímeros [23]. Esses são sistemas que podem apresentar interações competitivas, desordem, frustração e, como consequência, exibir perfis de energia livre rugosos. Nesse caso, as simulações canônicas são severamente prejudicadas pelo problema de múltiplos mínimos na energia. À baixas temperaturas, as simulações tendem a ficar aprisionadas em estados metaestáveis (próximos à mínimos locais na energia), os quais são separados por altas barreiras de energia livre. Isso resulta em uma evolução bastante lenta na dinâmica da caminhada aleatória e em uma alta correlação entre as configurações amostradas ${ }^{2}$, sendo muito difícil obter distribuições canônicas para essas temperaturas.

Nas últimas décadas, vários algoritmos de MC foram desenvolvidos para tentar solucionar o problema de como obter uma amostragem eficiente mesmo na presença de múltiplos mínimos na energia. A elaboração desses algoritmos foi feita, principalmente, utilizando pesos baseados em ensembles generalizados ${ }^{3}$, onde as configurações são amostradas utilizando um peso artificial não-Boltzmanniano ${ }^{4}$ (para revisões veja $[27,28,29,30])$.

A princípio, o uso dos algoritmos de MC generalizados tinha como finalidade fazer com que o sistema realizasse caminhadas aleatórias no espaço da energia sem ficar preso em mínimos de energia locais, atravessando assim as barreiras de energia livre para visitar uma região mais ampla do espaço de configurações do que o algoritmo de Metropolis. As vantagens dessa estratégia seriam que, além das simulações muitas vezes conseguirem alcançar a energia mínima global do sistema, estimativas das médias térmicas canônicas das suas propriedades termodinâmicas poderiam ser recuperadas utilizando técnicas de repesagem de histogramas em um intervalo maior de temperaturas. Mas, nos últimos anos, percebeu-se que esses algoritmos generalizados também poderiam ser utilizados para obter estimativas da entropia microcanônica do sistema, facilitando assim a sua caracterização pela termoestatística microcanônica. Principalmente quando o sistema apresenta transições de fase de primeira ordem e existem estados metaestáveis, as propriedades termodinâmicas

\footnotetext{
${ }^{2}$ Esse problema é conhecido como decaimento lento crítico (ou critical slowing down) [24, 25].

${ }^{3}$ Por isso são conhecidos como algoritmos de MC generalizados.

${ }^{4}$ Recentemente publicamos um trabalho sobre a caráter prático do uso de ensembles generalizados para a obtenção das propriedades termodinâmicas de um sistema magnético de spins de Ising não aditivo com interações de longo alcance [26].
} 
desse sistema são melhores descritas com ajuda do ensemble microcanônico [31, 32]. De fato, muitos sistemas apresentam propriedades de equilíbrio no ensemble microcanônico as quais não possuem equivalentes no ensemble canônico [33, 34, 35]. Isso é consequência da existência de uma região não côncava na entropia, a qual produz estados de equilíbrio dependentes da energia no ensemble microcanônico que não podem ser associados a nenhum estado de equilíbrio dependente da temperatura no ensemble canônico. Esses estados excluídos são estados fora do equilíbrio no ensemble canônico, e geralmente correspondem à estados metaestáveis ou instáveis nesse ensemble [36].

Baseado no tipo de procedimento utilizado pelos algoritmos de MC generalizados na execução dos cálculos numéricos para amostrar as configurações, podemos classificá-los em duas classes: algoritmos que são essencialmente seriais (ou sequênciais) e algoritmos paralelizáveis.

Dentre os algoritmos seriais incluimos os chamados algoritmos de amostragem uniforme, os quais são utilizados para amostrar configurações uniformemente sobre todo o espaço de energias. Em particular, temos os algoritmos multicanônico (MUCA) [37, 38] (para revisões veja as Refs. [25, 39]) e entrópico ${ }^{5}$ (ES) [43]. Ambos têm sido aplicados intensivamente no estudo de sistemas de spin [44, 45, 46, 47, 48, 49], e em proteínas [23, 50, 51]. Outros exemplos que fazem uso de implementações seriais são os algoritmos MUCA-CFT (classical fluctuations theory) [52] e o algoritmo multigaussiano modificado (MEGE ou multiple Gaussian modified ensemble) [53]. Uma característica comum à todos esses algoritmos é que os pesos utilizados por eles para amostrar as configurações são desconhecidos a priori. Dessa maneira, para todos eles, é necessário realizar uma etapa de obtenção dos pesos, a qual é obrigatoriamente serial. Uma das vantagens dos algoritmos MUCA e ES está no fato de que a entropia microcanônica pode ser obtida diretamente da etapa de obtenção dos pesos.

Além desses exemplos, não podemos deixar de incluir algoritmos seriais tais como os de passeio aleatório, cujo representante principal é o algoritmo de Wang-Landau (WL) $[54,55]$, e os algoritmos baseados na teoria de matrizes de transição [56],

\footnotetext{
${ }^{5}$ Como veremos, o algoritmo entrópico, também conhecido como algoritmo de amostragem entrópica ou entropic sampling, é um algoritmo de amostragem uniforme conceitualmente muito semelhante ao MUCA [40, 41, 42].
} 
dentre os quais temos o algoritmo broad-histogram [57].

Com o intuito de diminuir a correlação entre as caminhadas aleatórias produzidas pelas simulações de MC mas evitando a etapa serial de obtenção dos pesos, foram desenvolvidas implementações paralelas de algoritmos que utilizam pesos conhecidos. Em geral, dizemos que esses algoritmos usam o método de troca entre réplicas, ou replica exchange method (REM), também conhecido como parallel tempering (PT) [58, 59], que é um método intimamente relacionado com o algoritmo simulated tempering (ST) [60]. Simulações que utilizam o REM exploram caminhadas aleatórias realizadas por réplicas do sistema em diferentes temperaturas, tentando realizar trocas entre as suas configurações periodicamente.

Como alternativa, também existem algoritmos baseados em procedimentos mistos, isto é, os quais realizam simulações paralelas utilizando pesos obtidos serialmente para diversas regiões do espaço de energias. Como exemplos temos os algoritmos REMUCA e MUCAREM [61, 62, 63], o algoritmo MEGE na sua versão paralela [64] e um algoritmo baseado na estatística de Tsallis [65]. Vale notar que tais algoritmos mistos estão dentro de uma generalização (gREM) proposta recentemente por Kim e colaboradores [66, 67].

\section{Objetivos da Tese}

Nesta Tese, estamos interessados em avaliar o desempenho das duas classes de algoritmos de MC generalizados apresentadas anteriormente no estudo da criticalidade em sistemas complexos. Como representantes da primeira classe incluimos os algoritmos multicanônico (MUCA) e de amostragem entrópica (ES), que além do fato de serem algoritmo seriais, são conhecidos como algoritmos de amostragem uniforme. Na segunda classe, que diz respeito aos algoritmos paralelizáveis, incluimos o algoritmo canônico de Metropolis associado ao método de troca entre réplicas (REM). Em particular, analisamos diversos aspectos da implementação desses algoritmos para a obtenção das propriedades termoestatísticas descritas pelos ensembles canônico e microcanônico de dois sistemas complexos: o modelo bidimensional de Ising dipolar e proteínas descritas por um modelo mínimo. 


\section{Organização e contribuições da Tese}

Como a Tese possui um caráter extenso por causa da diversidade de fenomenologias apresentadas pelos modelos estudados e de métodos de simulação, sumarizamos a seguir os aspectos que nortearam a organização da Tese, indicando as principais contribuições realizadas.

No Capítulo 2 apresentamos uma breve introdução sobre os algoritmos de MC e as suas possíveis generalizações. Relacionamos os aspectos envolvidos na elaboração desses algoritmos com a Teoria dos Ensembles em Mecânica Estatística. Além de discorrer sobre as metodologias tradicionais dos algoritmos utilizados, introduzimos novos protocolos para a determinação de pesos de amostragem nos algoritmos MUCA e ES.

Foram também incluídas no Capítulo 2 as contribuições correspondentes à três artigos publicados. Os dois primeiros ${ }^{6}[68,69]$ são relacionados ao estudo que realizamos sobre um modelo de Blume-Capel (BC) de alcance infinito, o qual apresenta uma região onde ocorre uma transição de fase e, mesmo no limite termodinâmico, não há equivalência entre as descrições nos ensembles canônico e microcanônico. A partir da solução analítica no ensemble gaussiano extendido (EGE), que é conhecido como um ensemble interpolador entre os dois ensembles, mostramos como a estabilidade de estados instáveis no ensemble canônico pode ser recuperada variando um parâmetro associado ao tamanho do reservatório térmico. O outro trabalho ${ }^{7}$ [70] corresponde à introdução do ST-WHAM-MUCA como um novo método para obter a entropia microcanônica, o qual foi desenvolvido com base no método de análise via temperatura estatística [71] (ST-WHAM) associado às equações de recorrência do algoritmo MUCA. Neste trabalho também mostramos que a termoestatística microcanônica obtida via ST-WHAM é equivalente àquela obtida pelo algoritmo MUCA, mesmo para uma região onde ocorre uma transição de fase de primeira ordem e que apresenta uma região não côncava na entropia microcanônica.

No Capítulo 3 são apresentados os resultados para as simulações do modelo de Ising dipolar bidimensional (2D). É conhecido na literatura que esse modelo apresenta um diagrama de fases bastante complexo [72]. Contudo, com o intuito de

\footnotetext{
${ }^{6}$ Os artigos $[68,69]$ encontram-se nos Anexos II e III, respectivamente.

${ }^{7} \mathrm{O}$ artigo [70] encontra-se no Anexo V.
} 
facilitar a compreensão dos estudos realizados aqui, realizamos uma distinção entre dois cenários, fazendo alusão aos trabalhos de Abanov e colaboradores [73]. Cenário I: o qual caracteriza regiões onde uma única transição de fase ocorre separando a fase ordenada, caracterizada por configurações de faixas, da fase desordenada, também conhecida como tetragonal; e Cenário II: o qual corresponde à regiões no diagrama de fases caracterizadas por duas transições de fase, com uma fase, conhecida como nemática, surgindo entre as fases de faixas e a fase tetragonal. Primeiramente realizamos um estudo metodológico comparando os diversos protocolos propostos para obtenção dos pesos de amostragem nos algoritmos MUCA com ES. A partir desse estudo caracterizamos o protocolo mais adequado para estudar a transição de faixastetragonal (Cenário I). Utilizando o algoritmo MUCA aliado à metodologia de obtenção dos zeros complexos da função de partição canônica, foi possível determinar a natureza contínua dessas transições de fase na região do diagrama de fases onde o estado fundamental para o modelo de Ising dipolar 2D é caracterizada por faixas de $\operatorname{largura}^{8} h=1$, excluindo um possível ponto trícritico, como sugerido na literatura. Nesse capítulo também descrevemos nossos esforços para obter pesos multicanônicos para a região do Cenário II. Identificamos a presença de uma forte barreira de energia livre nessa região e discutimos as dificuldades apresentadas pelo algoritmo MUCA nesse caso mesmo para redes pequenas ${ }^{9}$. Ainda no Capítulo 3, avaliamos o desempenho de simulações canônicas que utilizam o REM aliado à análise via STWHAM para caracterizar a termoestatística microcanônica do Cenário II utilizando uma rede maior. Nossos resultados sugerem que ambas transições, faixas-nemática e nemática-tetragonal, sejam de primeira ordem, excluindo a possibilidade de uma transição de Kosterlitz-Thouless (KT), como sugerido na literatura para essa região.

No Capítulo 4 apresentamos o estudo relacionado à criticalidade de um modelo mínimo que descreve proteínas. Em particular, empregamos simulações canônicas utilizando o REM associadas à análise via ST-WHAM para caracterizar a termoestatística microcanônica da transição de enovelamento em heteropolímeros inspirados biologicamente em cadeias polipeptídicas com conhecida propensidade à formação de agregados. Com base em resultados para propensidade de agregação dessas cadeias,

\footnotetext{
${ }^{8}$ Esse estudo foi publicado no artigo [74] que encontra-se no Anexo VII.

${ }^{9}$ Esses resultados foram incluídos no trabalho publicado listado na Ref. [75], o qual também é apresentado no Anexo IV.
} 
discorremos sobre a relação entre a presença de estados parcialmente desenovelados causados pela ausência de barreiras de energia livre e o favorecimento na formação de agregados. Outro ponto importante no Capítulo 4 é a introdução do que chamamos de raio de giração hidrofóbico $r_{h}$ como parâmetro de ordem em simulações de enovelamento de proteínas. Esta quantidade é definida em termos do raio de giração usual mas considerando apenas os monômeros hidrofóbicos, O interessante é que, além do raio $r_{h}$ não depender de informações sobre o estado nativo das proteínas, os resultados fornecidos por ele para temperaturas de transição concordam com aqueles obtidos via termoestatística microcanônica.

No Capítulo 5 são apresentadas conclusões gerais relacionando todos os resultados obtidos na Tese, indicando perspectivas para o uso dos algoritmos de MC generalizados em estudos sobre transições de fase em sistemas complexos.

Por fim, indicamos que o Apêndice A trata de um estudo feito para o modelo $\mathrm{XY}$, tendo em vista a comparação com os resultados do modelo de Ising dipolar no Capítulo 3. Já o Apêndice B inclui simulações para validar o modelo de proteínas utilizado no Capítulo 4. Todos os artigos publicados pelo autor e relacionados aos resultados apresentados nesta Tese foram incluidos na íntegra na seção "Anexos" ao final da Tese. 


\section{CAPÍTUlo}

\section{Algoritmos De Monte Carlo GENERALIZADOS}

\subsection{Introdução}

Métodos de MC são bastante gerais e podem ser empregados em inúmeras áreas do conhecimento. Aqui, estamos interessados em aplicações desses métodos em problemas de destaque em Física da Matérica Condensada e em Biofísica. Nesse caso, a questão central é como tais métodos nos ajudam a obter as propriedades termodinâmicas dos sistemas físicos através de uma amostragem estatística da sua mecânica microscópica [8, 9]. Nosso principal interesse é analisar como esses métodos podem ser úteis na caracterização de transições de fase em sistemas complexos.

De maneira geral, cada algoritmo é definido de acordo com um peso de amostragem $w(E)$, onde $E$ é a energia ${ }^{1}$ do microestado definido por um conjunto específico de coordenadas generalizadas $\left\{\sigma_{i}\right\}$, com $i=1, \ldots, N$, para $N$ graus de liberdade. Considerando o sistema em um microestado com energia $E$, o algoritmo determina se uma nova configuração com energia $E^{\prime}$ será aceita considerando a probabilidade de transição dada por

$$
p\left(E \rightarrow E^{\prime}\right)=\min \left[1, \frac{w\left(E^{\prime}\right)}{w(E)}\right] .
$$

As alterações na configuração do sistema fazem com que ele realize uma caminhada aleatória no espaço de fase, a qual pode ser projetada em uma trajetória no espaço das energias. Assumindo que essa caminhada seja ergódica ${ }^{2}$, o histograma

\footnotetext{
${ }^{1}$ A rigor podemos pensar na energia $E$ como um auto-valor da(o) hamiltoniana $(\mathrm{o}) \mathcal{H}\left(\left\{\sigma_{i}\right\}\right)$.

${ }^{2}$ Ergodicidade: condição na qual todos os microestados podem ser acessados a partir de todos os outros em um número de passos de Monte Carlo finito.
} 


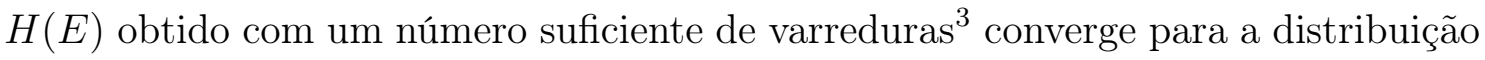

$$
H(E) \propto \Omega(E) w(E),
$$

onde $\Omega(E)$ é a densidade de estados do sistema. A expressão acima é válida para qualquer peso de amostragem que dependa da energia. Detalhes sobre a convergência representada pela Eq. 2.2 podem ser encontrados no trabalho de Nadler e Hansmann [76], onde eles utilizam uma abordagem via processos estocásticos. Nesse estudo eles também fazem uma análise indicando os pontos em comum entre os algoritmos de MC generalizados e os algoritmos que utilizam o método de troca entre réplicas.

Vale notar que, considerando a relação 2.2, podemos pensar nos algoritmos de MC como uma ferramenta para obter a descrição microscópica dos sistemas em termos da Teoria dos Ensembles da Mecânica Estatística. Essa relação é descrita a seguir.

\subsection{Relação com a Teoria dos Ensembles}

A escolha mais comum para o peso $w(E)$ advém do trabalho seminal feito por Metropolis e colaboradores [10] em 1953. Eles definiram $w(E)$ como o peso de Boltzmann $^{4} e^{-\beta E}$. Nesse caso, é possível observar ${ }^{5}$ que o histograma $H(E)$ possui um formato aproximado de uma distribuição gaussiana $\Omega(E) e^{-\beta E}$ e está diretamente relacionado à distribuição de probabilidade no ensemble canônico:

$$
p(E, \beta)=\frac{\Omega(E) e^{-\beta E}}{\mathcal{Z}(\beta)},
$$

sendo

$$
\mathcal{Z}(\beta)=\sum_{E^{\prime}} \Omega\left(E^{\prime}\right) e^{-\beta E^{\prime}}
$$

a função de partição canônica do sistema. O algoritmo de Metropolis introduziu o conceito de amostragem por importância, onde as configurações mais relevantes do sistema na temperatura $T$ são amostradas. A partir dessa distribuição é possível $[8,9]$ obter estimativas canônicas para diversas quantidades termodinâmicas, tais

\footnotetext{
${ }^{3}$ Definimos varredura, passo de Monte Carlo ou sweep, como $N$ tentativas de alterar a configuração do sistema utilizando a probabilidade de transição definida pela Eq. 2.1.

${ }^{4}$ Lembrando que $\beta$ é igual ao inverso da temperatura $T$ do reservatório térmico canônico.

${ }^{5}$ Para casos onde $\beta$ está longe da temperatura de transição de fase.
} 
como: energia interna, calor específico, magnetização, susceptibilidade magnética, etc, em função da temperatura.

Desde o trabalho seminal de Metropolis, diversas outras maneiras de escolher o peso $w(E)$ foram propostas, principalmente após os trabalhos de repesagem de histogramas $[13,14,15,16,18,19]$. Dentre os métodos de repesagem mais utilizados está o método de Ferrenberg-Swendsen [77]. Dado um número suficientemente grande de configurações amostradas para um intervalo de energias utilizando um peso qualquer $w(E)$, eles mostraram que é possível obter estimativas canônicas para uma quantidade física $A$ através da repesagem de dados [77] ,

$$
\overline{A(\beta)}=\sum_{k=1}^{n_{\text {meas }}} A_{k} p\left(\beta, E_{k}\right),
$$

onde

$$
p\left(\beta, E_{k}\right)=\frac{\left[w\left(E_{k}\right)\right]^{-1} \exp \left(-\beta E_{k}\right)}{\sum_{i=1}^{n_{\text {meas }}}\left[w\left(E_{i}\right)\right]^{-1} \exp \left(-\beta E_{i}\right)}
$$

e $n_{\text {meas }}$ é o número de varreduras na série ou caminhada aleatória. Também é possível combinar histogramas obtidos a partir de várias simulações canônicas, dentro os quais listamos o WHAM $[21,22,78]$, ou weighted histogram analysis method, bastante difundido na literatura, e o método de patching de histogramas ${ }^{6}$ [81, 82], o qual estabelece pesos aos histogramas de acordo com sua variância estatística.

Tais métodos de repesagem melhoraram significativamente a eficiência das simulações de MC. No entanto, há um problema ${ }^{7}$ que é inerente às caminhadas aleatórias geradas pelos algoritmos de MC: sempre existe correlação entre as configurações amostradas, o que resulta em um viés na quantidade $\overline{A(\beta)}$. Tais correlações podem ter origem na escolha dos pesos, mas, nesse caso, muitas vezes é possível minimizar o problema do viés utilizando técnicas de análise como jackknife [85, 86]. Além disso, a intensidade das correlações também é consequência das características intrínsecas de cada sistema. Próximo à uma transição de fase, por exemplo, o sistema pode ficar preso em uma das fases e não conseguir amostrar corretamente a outra fase,

\footnotetext{
${ }^{6}$ Esse método foi utilizado em algumas estimativas canônicas dessa Tese e é descrito em detalhes nas Refs. [79, 80].

${ }^{7}$ Nem sempre a existência de correlação é um problema. Propriedades críticas dos sistemas podem ser estudadas através do cálculo dos tempos de auto-correlação das séries produzidas [83] e também via dinâmica de tempos curtos [84].
} 
principalmente quando temos transições de fase de primeira ordem. Essa situação é conhecida por decaimento lento crítico (ou critical slowing down) [24, 25].

Nas últimas décadas os métodos de MC aplicados na amostragem de configurações tiveram melhoras significativas, principalmente com o desenvolvimento de algoritmos generalizados $[25,27,28,29,30,43]$. Esses algoritmos foram desenvolvidos para aumentar o número de caminhadas entre diferentes regiões no espaço das energias, permitindo uma amostragem de estados mais eficiente, diminuindo o decaimento lento crítico. Com isso, é possível obter uma produção de dados com qualidade superior (com uma correlação menor) utilizando a mesma estatística dos métodos convencionais.

Além da questão da otimização na amostragem, percebeu-se que os algoritmos de MC generalizados poderiam ser utilizados na obtenção da termoestatística microcanônica dos sistemas. Entendemos por termoestatística microcanônica aquela descrita pela entropia microcanônica $S(E)$, a qual é definida a partir da densidade de estados do sistema $[1,2,4,5,31]$, ou seja:

$$
S(E) \equiv k_{B} \ln \Omega(E)
$$

A partir dessa definição é possível obter tanto uma expressão para o inverso da temperatura microcanônica

$$
b(E)=\frac{1}{T(E)}=\frac{d S}{d E}
$$

quanto uma expressão para o capacidade térmica microcanônica [31],

$$
C(E)=\frac{d E}{d T}=-\left(\frac{d S}{d E}\right)^{2} /\left(\frac{d^{2} S}{d E^{2}}\right) .
$$

É bem conhecido que o ensemble canônico pode ser obtido como uma aproximação do ensemble microcanônico. Especificamente, podemos obter a distribuição canônica (Eq. 2.3) considerando a expansão em série da entropia em torno de uma energia média até o termo de primeira ordem e associando a derivada primeira da entropia à temperatura do reservatório térmico [87]. Dessa maneira, pode-se considerar que o ensemble microcanônico tem um caráter mais fundamental que o ensemble canônico. A entropia microcanônica fornece informações sobre as características geométricas fundamentais intrínsecas do sistema. Assim, de maneira geral, a partir 
do conhecimento da densidade de estados $\Omega(E)$ é possível acoplar diversos tipos de reservatórios para obter descrições mais convenientes ${ }^{8}$.

Para o caso limite onde a vizinhança do sistema pode ser considerada um reservatório térmico infinito (muito maior que o sistema), a formulação canônica é uma aproximação válida e possivelmente a mais adequada do ponto de vista do cálculo das propriedades termodinâmicas do sistema. Contudo, existem situações para as quais a descrição que assume um reservatório térmico infinito pode não ser a mais adequada, em particular, para

(i) sistemas mesoscópicos, onde as flutuações nas quantidades termodinâmicas não podem ser desprezadas (nesse caso incluimos os sistemas finitos que são utilizados quase sempre nas simulações computacionais);

(ii) sistemas com interações de longo alcance ${ }^{9}$. Para tais sistemas mesmo uma formulação microcanônica seria temerária, já que é complicado definir um contorno para isolar o sistema do resto do universo.

No contexto das simulações de MC, Challa e Hetherington [91] introduziram heuristicamente a ideia de utilizar pesos de amostragem baseados em um ensemble gaussiano, o qual seria obtido mantendo o termo de segunda ordem na expansão da entropia. Como resultado, estados metaestáveis próximos à transições de primeira ordem se tornariam estáveis, diminuindo assim o decaimento lento crítico.

Em uma abordagem mais rigorosa, é possível mostrar que o termo de segunda ordem na expansão da entropia está associado à razão entre o tamanho do sistema e o tamanho do reservatório térmico [88, 92]. De maneira geral, pode-se construir um ensemble gaussiano estendido (EGE) cuja distribuição de probabilidade é dada por

$$
p_{\gamma}(E, \alpha)=\frac{\Omega(E) e^{-\alpha E-\gamma(E-U)^{2}}}{\mathcal{Z}_{\gamma}(\alpha, U)},
$$

onde $\mathcal{Z}_{\gamma}(\alpha, U)$ é uma constante de normalização que representa uma função de partição generalizada, o parâmetro $\alpha$ representa uma temperatura generalizada,

\footnotetext{
${ }^{8}$ Podemos, por exemplo, utilizar a densidade de estados $\Omega(E)$ para obter as propriedades termodinâmicas do sistema no ensemble gaussiano estendido (EGE) [88]. Assim como possível inserir a densidade de estado na função logarítmo generalizada $\ln _{q}$ para obter a termoestatística de Tsallis, como feito para o modelo de Ising ferromagnético na Ref. [89].

${ }^{9}$ Definimos interações de longo alcance quando $0 \leq \alpha / d \leq 1$, sendo $d$ é a dimensão do sistema e $\alpha$ é o expoente da interação $1 / r^{\alpha}$. Veja Ref. [90] para mais detalhes.
} 
enquanto o parâmetro $\gamma$ pode ser associado à razão entre os tamanhos do reservatório térmico e do sistema. O valor da energia média $U$ é definido de maneira autoconsistente dependendo da escolha dos parâmetros $\alpha$ e $\gamma$.

Do ponto de vista teórico, a utilização do EGE pode ser bastante interessante, já que, dependendo da escolha do parâmetro $\gamma$, é possível interpolar entre as distribuições nos ensembles canônico $(\gamma=0)$ e microcanônico $(\gamma \rightarrow \infty)$. Para ilustrar esses conceitos sumarizo a seguir os resultados obtidos em uma colaboração recente [69, 68], onde encontramos uma solução semi-analítica no EGE para o modelo de Blume-Capel (BC) com interações de alcance infinito ${ }^{10}$. Consideramos o modelo BC , uma vez que Barré e colaboradores [33] já haviam obtido suas soluções analíticas e seu diagrama de fases tanto no ensemble microcanônico quanto no ensemble canônico. Além disso, esses mesmos autores monstraram que, mesmo no limite termodinâmico, tais soluções fornecem resultados que não são equivalentes em uma região do diagrama de fases onde a linha de transição de fase ainda é de primeira ordem de acordo com o ensemble canônico (Veja Figs. 1 e 3 da Ref. [33] para mais detalhes). Tal inequivalência aparece como consequência da presença de uma região não côncava na entropia microcanônica [93, 94, 35]. A Fig. 2.1 mostra as curvas da temperatura $T(\varepsilon)$ em função da energia específica $\varepsilon$ obtidas pelo EGE para o modelo BC nessa região onde não há a equivalência entre os ensembles. Observamos que, para $\gamma=0$ (limite canônico), há uma descontinuidade na temperatura ao redor de uma região da energia onde não existem estados estáveis. Conforme o parâmetro $\gamma$ aumenta, a solução no EGE faz com que a estabilidade desses estados seja recuperada. No limite onde não há reservatório térmico $(\gamma \rightarrow \infty)$, a temperatura no EGE torna-se idêntica à temperatura microcanônica (vide Fig. 2.2(a)) e todos os estados tornam-se estáveis nessa região.

A inequivalência entre os ensembles ocorre para regiões que apresentam os chamados intrusos convexos na entropia microcanônica $S(E)$ [93, 94, 35]. A presença de regiões não côncavas na entropia microcanônica parece ser uma característica comum das transições de fase de primeira ordem [33, 93, 95, 96, 97, 98]. Nesse caso, propriedades termodinâmicas tais como descontinuidade na temperatura e calor es-

\footnotetext{
${ }^{10}$ Detalhes sobre o modelo tal como seu hamiltoniano podem ser encontrados nos artigos apresentados nos Anexos II e III.
} 


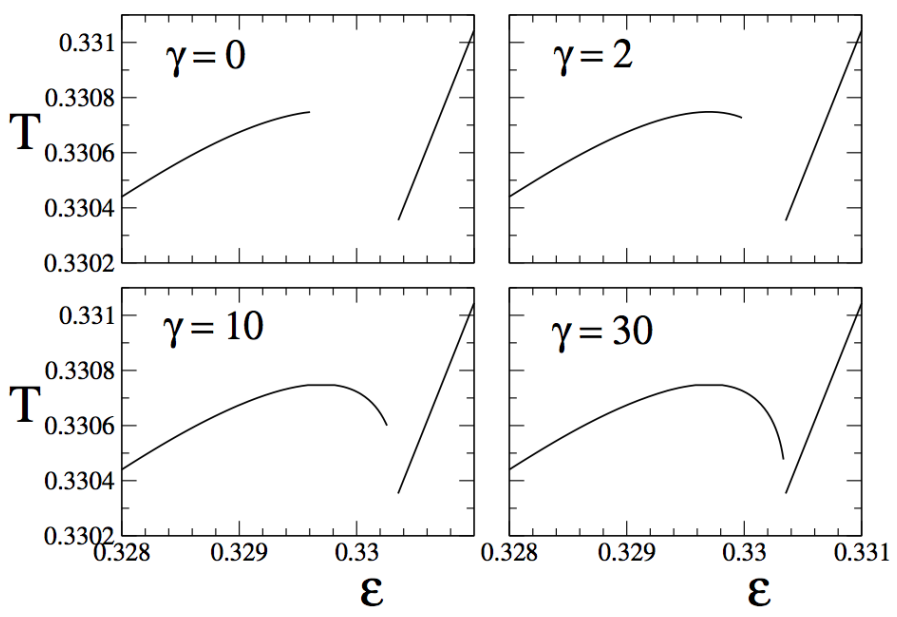

Figura 2.1: Curvas da temperatura $T(\varepsilon)$ em função da energia específica $\varepsilon$ obtidas no ensemble gaussiado estendido (EGE) para o modelo BC e vários valores de $\gamma$ na região de inequivalência de ensembles $(\Delta / J=0,462407)$. Figura retirada da Ref. [68].

pecífico microcanônico negativo podem ser observadas [31]. Dessa maneira, a análise da termoestatística microcanônica é vista como uma ferramenta interessante para obter informações sobre a natureza das transições de fase.

Como a não concavidade presente na entropia microcanônica muitas vezes não possui resolução suficiente para ser observada na escala usual em que os gráficos simples de $S(E)$ são apresentados, é conveniente calcular a entropia microcanônica deslocada (ou shifted microcanonical entropy),

$$
\Delta S(E)=S(E)-(A+B E) .
$$

Assim, $\Delta S(E)$ é a diferença entre a entropia microcanônica $S(E)$ e a função linear que liga $S\left(E_{a}\right)$ à $S\left(E_{b}\right)$, sendo $E_{a}$ e $E_{b}$ tais que $\Delta S\left(E_{a}\right)=\Delta S\left(E_{b}\right)=0$. Na Fig. 2.2(b) apresentamos o gráfico da entropia microcanônica deslocada $\tilde{s}=\Delta S / N$ em função da energia específica $\varepsilon=E / N$ para o modelo $\mathrm{BC}$ na região onde ocorre a transição de primeira ordem no ensemble canônico. Na região entre as energias $\varepsilon_{a} \mathrm{e}$ $\varepsilon_{b}$, há inequivalência entre os ensembles por causa do comportamento não concavo em $S(\varepsilon)$. Note que determinar $E_{a}$ e $E_{b}$, considerando $\Delta S\left(E_{a}\right)=\Delta S\left(E_{b}\right)=0$, é o mesmo que fazer uma construção de Maxwell, similar à linha tracejada mostrada para $T(\varepsilon)$ na Figura 2.2(a), na curva calórica $b(E)$ por $E$. Tal construção de Maxwell permite identificar o inverso da temperatura canônica $\beta_{c}$ como a temperatura na qual 


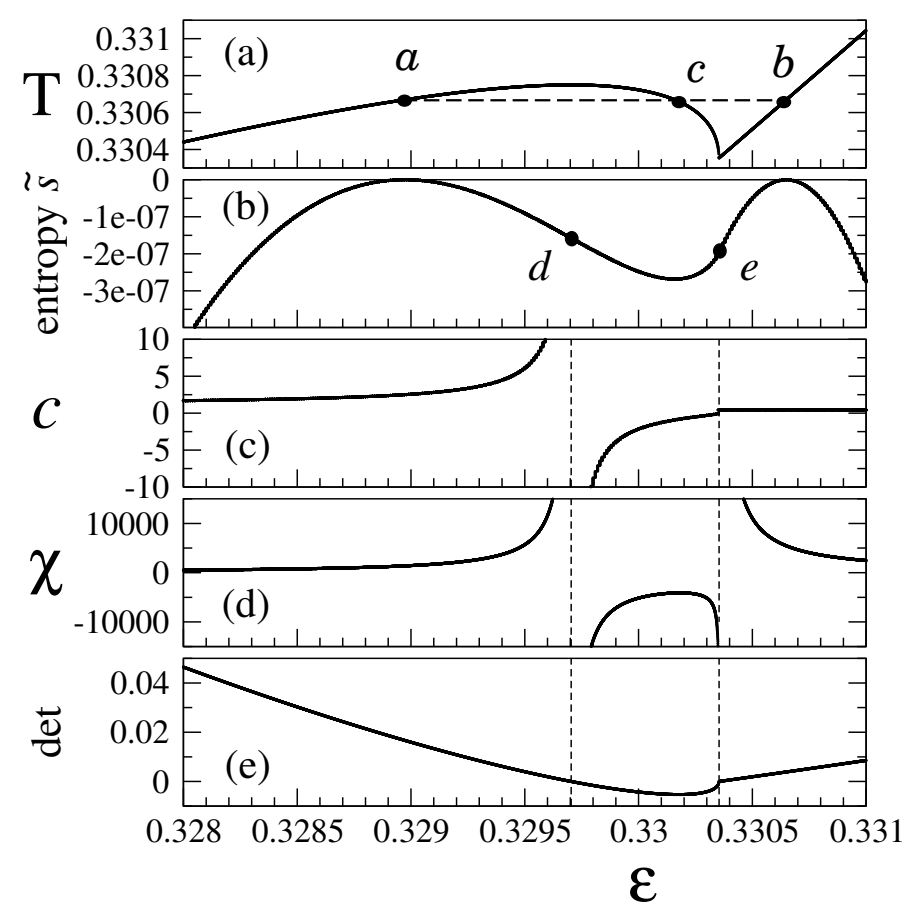

Figura 2.2: Comportamento microcanônico para do modelo BC na região de inequivalência de ensembles $(\Delta / J=0.462407)$. (a) Temperatura microcanônica em função da energia específica $\varepsilon$. A linha horizontal corresponde à temperatura de transição canônica (construção de Maxwell). (b) Entropia microcanônica deslocada (ou shifted microcanonical entropy) $\tilde{s}(\varepsilon)$. Tal deslocamento ou subtração é feito para melhorar a visualização da não concavidade na entropia em relação a função linear que une $s\left(\varepsilon_{a}\right)$ à $s\left(\varepsilon_{b}\right)$. (c) Calor específico $c(\varepsilon)$. Apresenta dois polos localizados nos zeros do determinante $d(\varepsilon, m)$, onde $m$ representa os valores da magnetização por spin que maximizam a entropia na energia $\varepsilon$. Tais polos podem ser observados como consequência do comportamento de $T(\varepsilon)$ em (a), nos pontos $d$ e $e$, sendo que $c(\varepsilon)$ torna-se negativo entre esses valores. (d) Susceptibilidade específica $\chi(\varepsilon)$ em função de $\varepsilon$, a qual também torna-se negativa entre os zeros de $d(\varepsilon, m)$. (e) Comportamento do determinante $d(\varepsilon, m)$ como função de $\varepsilon$. A linha vertical pontilhada sinaliza os zeros de $d(\varepsilon, m)$. Figura retirada da Ref. [68] (Anexo II), onde mais detalhes podem ser encontrados.

ocorre a transição de fase de primeira ordem, e estando relacionada com a mudança na entropia,

$$
\beta_{c}=\frac{S\left(E_{b}\right)-S\left(E_{a}\right)}{E_{b}-E_{a}},
$$

a qual pode ser identificada como o coeficiente linear $B$ da reta definida na Eq. 2.11. A diferença entre as energias $E_{a}$ e $E_{b}$ definem uma descontinuidade ou o calor 
latente da transição,

$$
L=E_{b}-E_{a} .
$$

Considerando a capacidade calorífica microcanônica definida pela Eq. 2.9, podemos escrever o calor específico $c(E)=C(E) / N$ em termos do inverso da temperatura microcanônica $b(E)=1 / T(E)$ como

$$
c(E)=-b^{2}(E) / N\left(\frac{d b(E)}{d E}\right) .
$$

Note que para energias onde $d b(E) / d E=0$, ou equivalentemente $d T(E) / d E=0$, o calor específico $c(E)$ diverge. Se a derivada $d b(E) / d E$ é positiva, ou equivalentemente $d T(E) / d E<0$, o resultado é que teremos um calor específico microcanônico negativo. Isso é ilustrado para o caso do modelo BC na Fig. 2.2(c), onde $c(\varepsilon)$ é negativo na região entre as energias $\varepsilon_{a}$ e $\varepsilon_{b}$, onde $d T(E) / d E<0$. Assim, a ocorrência de calores específicos negativos é consequência da não concavidade na entropia microcanônica $S(E)$ [31]. É interessante notar que é justamente nas regiões onde existe a presença de $c(E)<0$ que os algoritmos canônicos mais sofrem com o decaimento lento crítico.

$\mathrm{Na}$ natureza, no entanto, é impossível isolar completamente um sistema como requer a descrição microcanônica. Ao incluirmos um instrumento de medida (por exemplo, um termômetro) estaríamos alterando essa condição. Assim, é preciso certo cuidado ao interpretar resultados provenientes puramente de uma análise microcanônica. Discussões detalhadas podem ser encontradas nos trabalhos de Velazquez e Curilef [99, 100]. Considerando um enemble gaussiano, eles derivaram uma expressão para a capacidade térmica efetiva do sistema acoplado a um reservatório finito que sempre será positiva, desde que a relação entre as flutuações na energia $\Delta E \mathrm{e}$ na temperatura efetiva do reservatório $\Delta \beta_{w}$, dada por

$$
\Delta E \Delta \beta_{w} \geq k_{B}
$$

seja obedecida [101]. Vale ressaltar a elegância desse resultado, que é uma expressão análoga a relação de incerteza de Heisenberg na Mecânica Quântica [102]. Curiosamente, outros trabalhos de Velazquez e Curilef também têm encontrado aplicações na otimização de simulações de MC [103, 104]. 
Embora os trabalhos de Challa e Heterington sejam do final da década de 80, percebemos que há um ressurgimento de algoritmos baseados em ensembles gaussianos na última década $[52,53,64,66,67]$. Uma das vantagens da utilização de pesos gaussianos nesses algoritmos, assim como nos trabalhos de Velazquez e Curilef, seria que a estabilidade dos estados em regiões onde $c(E)<0$ seria recuperada, assim como mostrado por nós para a solução no EGE do modelo BC (veja Fig. 2.1). Ressaltamos que esse tipo de abordagem está relacionada com o estudo de sistemas pequenos, onde o reservatório térmico não é infinito, além disso, é possível encontrar na literatura estudos recentes que tentam explorar a equivalência entre tais abordagens generalizadas e a estatística de Tsallis [88, 92, 66, 67].

Na literatura também há um grande esforço na busca por modelos cujas soluções analíticas no ensemble microcanônico possam ser obtidas [97, 105]. Contudo, principalmente no caso de sistemas complexos, que envolvem interações competitivas, frustração e desordem em diferentes escalas, é quase impossível obter tais soluções analíticas. Assim, há uma atenção especial na obtenção de algoritmos capazes de descrever a termoestatística microcanônica desses sistemas.

Veremos a seguir como alguns algoritmos de MC generalizados podem ser utilizados tanto para obter a descrição microcanônica, em termos da entropia microcanônica $S(E)$, quanto canônica, em termos da energia média, calor específico, etc. Em particular, apresentaremos detalhes de algoritmos MC generalizados das duas classes caracterizadas na Introdução. A primeira classe, a qual corresponde aos algoritmos seriais, é representada por dois algoritmos de amostragem uniforme: o algoritmo multicanônico (MUCA) e o algoritmo entrópico (ES). Na outra classe, definida por algoritmos paralelizáveis, incluimos o algoritmo canônico de Metropolis associado ao método de troca entre réplicas (replica exchange method ou REM).

\subsection{Algoritmos de amostragem uniforme}

Visando minimizar os efeitos do decaimento lento crítico, certos algoritmos foram desenvolvidos para amostrar configurações com base na definição da entropia microcanônica (Eq. 2.7), definindo seus pesos como

$$
w_{1 / \Omega}(E)=e^{-S(E)} \simeq 1 / \Omega(E) .
$$


Considerando pesos desse tipo teremos que histograma $H(E)$, proporcional à $\Omega(E) w_{1 / \Omega}(E)$, será aproximadamente constante. Ou seja, todas as energias serão, a princípio, amostradas com a mesma probabilidade. É por isso que algoritmos que utilizam tais pesos são conhecidos como algoritmos de amostragem uniforme.

Uma das grandes vantagens dos algoritmos de amostragem uniforme é que eles obtém a densidade de estados diretamente da etapa de obtenção dos pesos. Uma vez determinada a densidade de estados podemos realizar toda uma análise microcanônica do sistema, além disso podemos recuperar qualquer interação com a vizinhança escolhendo outro ensemble. Por exemplo, combinando a produção de dados desses algoritmos de amostragem uniforme com o procedimento de repesagem (por exemplo, da Eq. 2.5), podemos obter estimativas para as quantidades físicas canônicas em qualquer temperatura $T$. Isso contrasta com o algoritmo de Metropolis, onde a repesagem é limitada a um intervalo bastante restrito ao redor da temperatura fixa no peso de Boltzmann.

Note que, em geral, a implementação desses algoritmos requer que as energias sejam discretizadas. Embora a discretização seja natural no modelo de Ising, este procedimento requer um certo cuidado em modelos com energias contínuas. Neste trabalho definimos energias $E_{m}=E_{0}+m \epsilon$, onde cada energia está associada a um número inteiro $m=0, \cdots, M_{E}$, com $M_{E}$ definido de acordo com o valor de $\epsilon$ e o intervalo de energias a ser amostrado. Todas as energias no intervalo $\left[E_{m}, E_{m+1}[\right.$ estão no $m$-ésimo intervalo e contribuem para o histograma $H\left(E_{m}\right)$. A constante $E_{0}$ é definida como uma energia de referência próxima mas, por conveniência, abaixo da energia do estado fundamental ou da energia mínima encontrada.

\subsubsection{Algoritmo multicanônico}

Proposto por Berg e Neuhaus em 1991 [37, 38], o algoritmo multicanônico ${ }^{11}$ (MUCA) é um algoritmo baseado em uma parametrização por partes da entropia microcanônica, a qual é reescrita como $S(E)=b(E) E-a(E)$, onde $a(E)$ e $b(E)$ são os chamados parâmetros multicanônicos. Dessa maneira os pesos multicanônicos são dados por $w_{m u}(E)=\exp [-b(E) E+a(E)]$, com os parâmetros $a(E)$ e $b(E)$ interpretados, respectivamente, como uma energia livre multicanônica e o inverso

\footnotetext{
${ }^{11}$ Para uma descrição detalhada do algoritmo e referências sobre suas aplicações veja [25, 106].
} 
da temperatura microcanônica ${ }^{12}$.

Como os pesos $w_{m u}(E)$ são desconhecidos a priori, precisamos de um procedimento para obtê-los. Descrevemos aqui um procedimento de recorrência baseado essencialmente na Ref. [106]. O n-ésimo passo de recorrência é realizado após a obtenção do histograma $H_{m u}^{n-1}(E)$, o qual é obtido a partir de $n_{s}$ varreduras, de acordo com a probabilidade de aceitação $(2.1)$ e os pesos $w_{m u}^{n-1}(E)$. Cada passo de recorrência consiste na atualização os parâmetros multicanônicos,

$$
\begin{aligned}
a^{n}\left(E_{m-1}\right) & =a^{n}\left(E_{m}\right)+\left[b^{n}\left(E_{m-1}\right)-b^{n}\left(E_{m}\right)\right] E_{m}, \\
b^{n}\left(E_{m}\right) & =b^{n-1}\left(E_{m}\right)+\left[\ln \hat{H}_{m u}^{n-1}\left(E_{m+1}\right)-\ln \hat{H}_{m u}^{n-1}\left(E_{m}\right)\right] / \epsilon,
\end{aligned}
$$

para todo $E_{m}$, com $\hat{H}_{m u}^{n}\left(E_{m}\right)=\max \left[h_{0}, H_{m u}^{n}\left(E_{m}\right)\right]$, onde $0<h_{0}<1$. Sendo as condições iniciais dadas por $a^{0}\left(E_{m}\right)=0$ e um valor pequeno ${ }^{13}$ para $b^{0}\left(E_{m}\right)$ para todo $m$. Notamos que para restringir o espaço de amostragem somente para valores positivos de $b(E)$ (temperaturas positivas), atualizamos os parâmetros $a(E)$ e $b(E)$ apenas para energias mais baixas que uma energia $E_{\text {med }}$, calculada como o valor da mediana do histograma do primeiro passo de recorrência, como descrito na Ref. [106].

Ressaltamos que, assim como sugerido nas Refs. [25, 106], a relação 2.18 foi implementada em nossas simulações utilizando o peso normalizado

$$
\hat{g}_{0}^{n}\left(E_{m}\right)=\frac{g_{0}^{n}\left(E_{m}\right)}{g^{n}\left(E_{m}\right)+g_{0}^{n}\left(E_{m}\right)}
$$

para obter $b^{n+1}\left(E_{m}\right)$, com os pesos $g^{n}\left(E_{m}\right)$ determinados pela relação de recorrência $g^{n}\left(E_{m}\right)=g^{n-1}\left(E_{m}\right)+g_{0}^{n-1}\left(E_{m}\right)$, considerando $g^{0}\left(E_{m}\right)=0$ e os pesos $g_{0}^{n}\left(E_{m}\right)$ determinados a partir dos histogramas através da relação

$$
g_{0}^{n}\left(E_{m}\right)=\frac{\hat{H}_{\mathrm{mu}}^{n}\left(E_{m+1}\right) \hat{H}_{\mathrm{mu}}^{n}\left(E_{m}\right)}{\hat{H}_{\mathrm{mu}}^{n}\left(E_{m+1}\right)+\hat{H}_{\mathrm{mu}}^{n}\left(E_{m}\right)} .
$$

Dessa maneira, a relação de recorrência para $b\left(E_{m}\right)$ é reescrita utilizando $\hat{g}_{0}^{n}\left(E_{m}\right)$ como

$$
b^{n+1}\left(E_{m}\right)=b^{n}\left(E_{m}\right)+\hat{g}_{0}^{n}\left(E_{m}\right)\left[\ln \hat{H}_{\mathrm{mu}}^{n}\left(E_{m+1}\right)-\ln \hat{H}_{\mathrm{mu}}^{n}\left(E_{m}\right)\right] / \epsilon .
$$

\footnotetext{
${ }^{12} \mathrm{O}$ parâmetro multicanônico $b(E)$ é utilizado inclusive como estimativa para o inverso da temperatura microcanônica definida pela Eq. 2.8.

${ }^{13}$ Usualmente escolhemos $b^{0}(E)=0,02$, condizente com o regime de altas temperaturas.
} 


\subsubsection{Algoritmo entrópico}

Uma das variantes do algoritmo multicanônico é o algoritmo entrópico (ES) ou de amostragem entrópica (entropic sampling), o qual foi proposto em 1993 [43]. Conceitualmente, o ES é bastante semelhante ao MUCA [40, 41, 42], mas, na prática, sua implementação é mais simples. Considerando o peso $w_{\mathrm{ES}}(E)=e^{-S(E)}$, os passos de recorrência são definidos por:

$$
S^{n}(E)= \begin{cases}S^{n-1}(E)+\ln \left[H^{n-1}(E)\right] & , \\ S^{n-1}(E) & \text { se } H(E) \neq 0\end{cases}
$$

As condições iniciais são definidas por uma reta $S(E)=\beta_{0} E$, ou seja, o primeiro passo de recorrência é como uma simulação de Metropolis tradicional na temperatura $T_{0}=1 / \beta_{0}$.

Com o intuito de restringir a amostragem de configurações a temperaturas positivas, conforme realizado no algoritmo MUCA, nós atualizamos os valores de $S(E)$ apenas para energias menores que $E_{\text {med }}$. Para energias $E>E_{\text {med }}$ atualizamos $S^{n}(E)$ como $S^{n-1}(E)+\ln \left[H^{n-1}\left(E_{\text {med }}\right)\right]$.

\subsubsection{Protocolos de obtenção dos pesos}

Para ambos algoritmos de amostragem uniforme, conforme o procedimento de recorrência atualiza os pesos da amostragem, o método coleta configurações com energias mais baixas, gerando um processo construtivo dos pesos e, por consequência, da densidade de estados. Usualmente, o que se faz é escolher um número de varreduras $n_{s}$ fixo para cada passo de recorrência. O problema é como escolher $n_{s}$ de modo a otimizar o processo de obtenção dos pesos. Pensando nisso, nós propomos um método de otimização, não mais escolhendo um valor fixo de $n_{s}$, mas escolhendo valores dinamicamente, conforme o sistema amostra o espaço de energias. Tal procedimento foi elaborado explorando o conceito de viagens de ida e volta (RT) (ou roundtrips), o qual é descrito a seguir.

Considere a trajetória formada por configurações de um sistema projetada no espaço das energias. Essa trajetória pode ser considerada como um processo análogo a uma caminhada aleatória. Escolhemos uma dada energia $E^{*}$ para o caminhante 
iniciar sua viagem. Para contar as viagens de ida e volta adicionamos um rótulo "+" ou "-" ao caminhante, o qual indica qual das duas energias extremas, $E_{+}$ou $E_{-}$, ele visitou mais recentemente. As energias extremas atuam como fronteiras "refletoras" ou "absorventes" para o caminhante rotulado, ou seja, se o rótulo é "+", uma visita a $E_{+}$não muda o rótulo, então essa é uma fronteira "refletora". No entanto, uma visita a energia $E_{-}$altera o rótulo, assim o caminhante "+" é "absorvido" nesta fronteira. Definimos uma viagem de ida e volta (RT) como o processo do caminhante partir de uma dada energia de referência $E^{*}$ e retornar a esta energia após ter alterado duas vezes seu rótulo. Por exemplo, na Figura 2.3 mostramos uma trajetória tal como uma caminhada aleatória (linha vermelha). As energias estão mapeadas no índice inteiro $m$. As regiões em cinza representam o caminhante com rótulo "+" e as regiões brancas com rótulo "-". Neste exemplo o caminhante inicia sua viagem em $m^{*}=410$. Após aproximadamente $0,4 \times 10^{5}$ varreduras (primeira linha vertical), o caminhante alcança a energia mínima $E_{-}$e seu rótulo é alterado para “"”, o qual é mantido até ele alcançar a energia $E_{+}$, próximo a $2,8 \times 10^{5}$ varreduras (segunda linha vertical). Então, depois de $5,0 \times 10^{5}$ varreduras contadas do início da caminhada, o caminhante retorna para $m^{*}=410$, completando uma viagem de ida e volta.

Para investigar a otimização na obtenção dos pesos de amostragem via contagem de viagens de ida e volta, definimos quatro protocolos diferentes de atualização, aplicáveis à ambos algoritmos:

i) A atualização dos pesos é feita sempre após $n_{s}$ varreduras, caracterizando o método usual.

ii) A atualização dos pesos é feita após $n_{s}$ varreduras ou após a contagem de 3 viagens de ida e volta, o que ocorrer primeiro, exceto para os casos onde o sistema não realiza nenhuma viagem de ida e volta. Neste último caso, o histograma $H(E)$ não é zerado e as energias de referência $E^{*}$ e mínima $E_{-}$são mantidas.

iii) A atualização dos pesos é feita após a contagem de 3 viagens de ida e volta, ou após um múltiplo do número de varreduras médio definido por

$$
\left\langle N_{\mathrm{var}}\right\rangle(n)=\frac{1}{n-1} \sum_{k=1}^{n-1} n_{s}(k),
$$




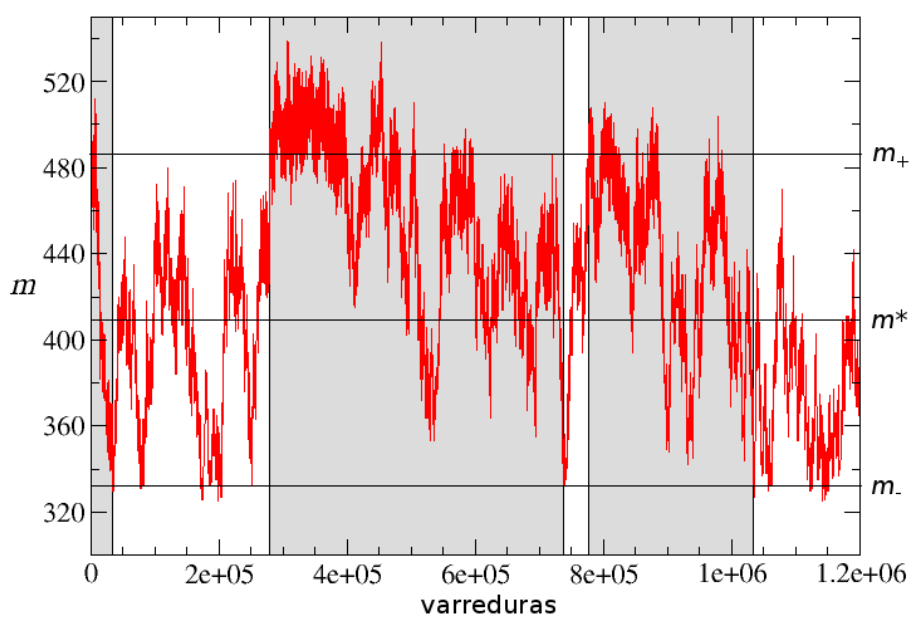

Figura 2.3: Trajetória no espaço das energias para as configurações amostradas (linha vermelha). As linhas horizontais representam o número de varreduras nos quais o caminhante atinge alguma das energias extremas. Regiões cinzas e brancas representam caminhantes com rótulos "+" e "-", respectivamente. As energias foram mapeadas no índice inteiro $m$, sendo que $m^{*}=410$ corresponde à energia inicial de referência $E^{*}$, e $m_{+}=487$ e $m_{-}=332$ correspondem às energias extremas máxima $E_{+}$e mínina $E_{-}$, respectivamente.

o que ocorrer primeiro, mesmo que o sistema não realize nenhuma viagem de ida e volta. Consideramos o máximo de varreduras igual a $3\left\langle N_{\text {var }}\right\rangle$.

iv) A atualização dos pesos é feita após a contagem de 3 viagens de ida e volta ou após $3\left\langle N_{\text {var }}\right\rangle$, exceto para os casos onde o sistema não realiza nenhuma viagem de ida e volta. Neste último caso, o histograma $H(E)$ não é zerado e as energias de referência $E^{*}$ e mínima $E_{-}$são mantidas.

Ressaltamos que, exceto para os casos (ii) e (iv) onde o sistema não realiza nenhuma viagem de ida e volta, todos os protocolos estabelecem que o histograma $H(E)$ deve ser zerado e as energias de referência $E^{*}$ e mínima $E_{-}$são redefinidas dinamicamente pela energia da última configuração e a menor energia amostrada no passo de recorrência anterior, respectivamente. A energia $E_{+}$é definida pela mediana do primeiro histograma obtido no procedimento de recorrência utilizando pesos $w^{0}(E)$ e permanece fixa até o final, quando o procedimento de recorrência encontra $E_{-}$ correspondente à energia do estado fundamental do sistema. 
Usualmente, a etapa de obtenção dos pesos é finalizada após $N_{r}$ passos de recorrência, estabelecidos a posteriori, quando os histogramas apresentam certa convergência para uma distribuição uniforme [25]. No entanto, para evitar qualquer subjetividade na avaliação da convergência dos histogramas, consideramos aqui que essa etapa pára quando o sistema alcança o estado fundamental.

\subsection{Método de troca entre réplicas}

O outro método muito utilizado nas simulações de MC para tentar minimizar os efeitos do decaimento lento crítico consiste em tentar fazer permutações entre diversas réplicas do sistema, as quais, por sua vez, realizaram caminhadas aleatórias no espaço das energias independentes e em paralelo. Tal procedimento é conhecido como método de troca entre réplicas (REM, do inglês replica exchange method) ou também parallel tempering (PT). Como discutido no Capítulo 1, o método de trocas entre réplicas é geral e pode ser aplicado em simulações de MC paralelas que utilizam quaisquer tipos de pesos [66]. No entanto, aqui estaremos interessados em aplicá-lo às simulações que utilizam pesos canônicos, tal como foi proposto originalmente por Hukushima e Nemoto [59].

\subsubsection{Definição}

Considere $M$ réplicas do sistema, cada uma à uma dada temperatura $T_{\alpha}$, com $\alpha=1, \ldots, M$. Cada réplica evolui como uma simulação canônica de MC independente numa caminhada aleatória com $n_{s}$ varreduras, conforme descrito pela Eq. 2.1, utilizando pesos de Metropolis definidos como $w_{\alpha}(E)=e^{-\beta_{\alpha} E}$, onde $\beta_{\alpha}=\left[T_{\alpha}\right]^{-1}$ é o inverso da temperatura da $\alpha$-ésima réplica. Então, a cada $n_{s}$ varreduras, tentativas para trocar réplicas vizinhas são feitas com a probabilidade de aceitação dada por

$$
p\left(\alpha, E \rightarrow E^{\prime} ; \alpha^{\prime}, E^{\prime} \rightarrow E\right)=\min \left[1, e^{\Delta}\right],
$$

onde $\Delta=\left(\beta_{\alpha^{\prime}}-\beta_{\alpha}\right)\left(E^{\prime}-E\right)$, sendo $E$ a energia da réplica à uma temperatura $T_{\alpha}$, e $E^{\prime}$ a energia da outra réplica, que está com uma temperatura $T_{\alpha^{\prime}}$. Cada tentativa de troca corresponde a um swap, assim, a estatística total produzida será $n_{s} \times n_{\text {swaps }}$ por réplica. 
Diversos protocolos para realizar as trocas entre réplicas são possíveis. Aqui adotamos trocas entre réplicas que estão em temperatuars vizinhas, alternando entre as réplicas com índices ímpares e suas vizinhas $(2 \alpha-1,2 \alpha)$, e réplicas pares e suas vizinhas $(2 \alpha, 2 \alpha+1)$, assim como descrito na Ref. [107]. A Fig. 2.4 ilustra esse esquema para $M=8$ réplicas. Por exemplo, as trocas entre as réplicas 2 e 3, 4 e 5, 6 e 7 só podem acontecer quando o número de swaps passa de ímpar para par. Outro ponto interessante que podemos notar nessa figura é que a réplica (linha roxa) que inicialmente estava em uma temperatura extrema $T_{8}$ foi para a outra temperatura extrema $T_{1}$ após 15 tentativas de trocas.

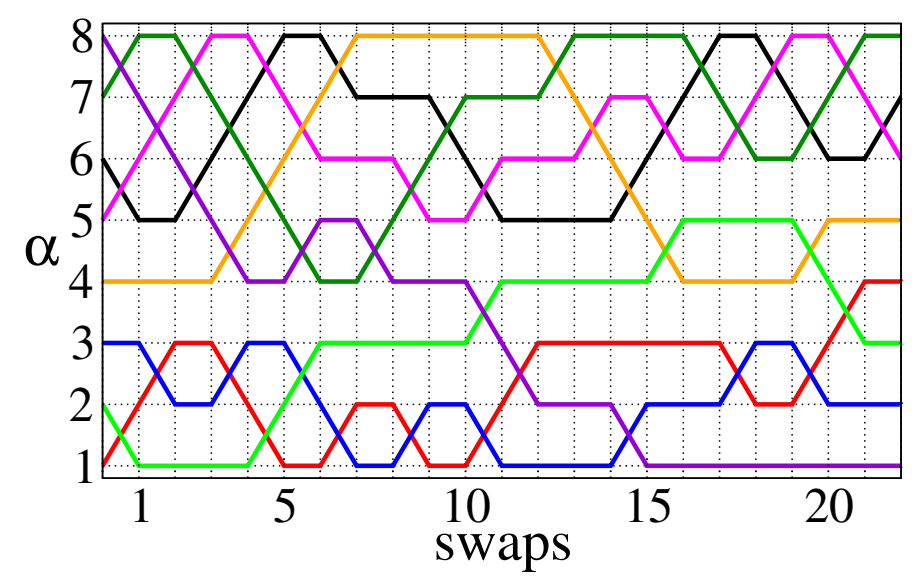

Figura 2.4: Esquema de troca entre réplicas alternando entre as réplicas com índices ímpares e suas vizinhas $(2 \alpha-1,2 \alpha)$ e réplicas pares e suas vizinhas $(2 \alpha, 2 \alpha+1)$. Swaps aqui corresponde ao número de tentativas de trocas entre réplicas.

\subsubsection{Protocolo de obtenção do conjunto de temperaturas}

Embora o método de troca entre réplicas seja considerado bastante simples, a dificuldade está na determinação do conjunto de temperaturas que, por sua vez, define o conjunto de pesos a serem utilizados. Invariavelmente todos os protocolos requerem informações prévias sobre o sistema ${ }^{14}$. Um bom chute inicial parece ser uma progressão aritmética para o inverso da temperatura:

$$
\beta_{\alpha}=\beta_{M}+(M-\alpha) \delta \beta
$$

\footnotetext{
${ }^{14}$ Por exemplo, valores para as temperaturas mínima $T_{\min }$ e máxima $T_{\max }$ a serem utilizadas nas simulações.
} 
sendo nesse caso necessário definir a temperatura mais alta $T_{M}=\beta_{M}^{-1}$ e o intervalo de discretização $\delta \beta$. Uma comparação entre diversos esquemas de determinação do conjunto de temperaturas pode ser encontrada na Ref. [108].

Tendo em vista que todos os protocolos precisam de informações prévias sobre o sistema, as quais são obtidas por simulações exploratórias, nós introduzimos aqui uma maneira ad hoc para encontrar o conjunto de temperatura de acordo com o seguinte protocolo: dada uma temperatura inversa inicial $\beta_{\alpha}$, a próxima temperatura inversa $\beta_{\alpha+1}$ é determinada por simulações teste que utilizam apenas duas réplicas do sistema. Primeiro realizamos $n_{\text {swaps }} \times n_{s}$ varreduras para equilibrar ambas as réplicas na mesma temperatura de referência $T_{\alpha}=1 / \beta_{\alpha}$. Depois disso, a temperatura inversa de uma das réplicas é aumentada por uma pequena variação $\delta \beta$, então $n_{\text {swaps }} \times n_{s}$ varreduras são realizadas novamente, mas agora tentando realizar trocas entre as réplicas a cada $n_{s}$ varreduras. Se a fração de trocas aceitas $f_{a c}$ é aproximadamente igual a probabilidade $p_{a c}$, essa nova temperatura inversa $\beta_{\alpha+1}$ é aceita como uma temperatura inversa de referência. Senão, a temperatura inversa é aumentada de $\delta \beta$ novamente. Esse procedimento permite determinar todas as temperaturas de maneira recorrente. Foi demonstrado que probabilidades $p_{a c}$ da ordem de $23 \%$ a $40 \%$ fornecem um número conveniente de viagens de ida e volta entre temperaturas extremas $[109,108]$. Usualmente fazemos várias realizações desse protocolo para ter uma estimativa melhor de $f_{a c}$ e assim estabeler o conjunto de temperatura $\left\{T_{\alpha}\right\}$.

\subsection{Análise via temperatura estatística}

Como vimos nas subseções anteriores, os algoritmos de amostragem uniforme fornecem uma maneira natural para obter a entropia microcanônica $S(E)$. Nessa seção apresentaremos o conceito de temperatura estatística, o qual utiliza a estatística produzida por simulações de MC para obter histogramas, os quais são, por sua vez, utilizados para estimar o inverso da temperatura microcanônica $b(E)$. Como veremos, diferentemente dos algoritmos de amostragem uniforme tradicionais, o método de análise da temperatura estatística pode ser utilizado para explorar a combinação de várias simulações, sendo particularmente interessante quando associado ao método de troca entre réplicas. 


\subsubsection{ST-WHAM}

Apresentamos nessa subseção o método proposto recentemente por Kim e calaboradores [71] conhecido como ST-WHAM ou statistical temperature weighted histogram analysis method. Esse método foi desenvolvido com base nas equações do método WHAM [21, 22], as quais são bastante gerais e podem ser utilizadas para combinar dados gerados a partir de um número arbitrário $M$ de simulações $\mathrm{MC}$, independentes ou realizadas em paralelo com auxílio do REM. A vantagem é que o ST-WHAM não precisa de um procedimento iterativo para calcular a função de partição como no caso do WHAM.

Para derivar a estimativa do inverso da temperatura microcanônica, ou temperatura estatística, $\tilde{b}(E)$, o método assume a seguinte forma para a densidade de estados,

$$
\tilde{\Omega}(E)=\sum_{\alpha=1}^{M} \tilde{f}_{\alpha}(E) \Omega_{\alpha}(E),
$$

com a condição de normalização $\sum_{\alpha=1} \tilde{f}_{\alpha}(E)=1$. As densidades de estado $\Omega_{\alpha}(E)$ são obtidas a partir dos histogramas $H_{\alpha}(E)$ amostrados por pesos $w_{\alpha}(E)$ para cada uma das $M$ simulações, considerando a Eq. 2.2. Utilizando tais estimativas para $\Omega_{\alpha}(E)$, é possível mostrar (vide [71]) que o inverso da temperatura estatística pode ser estimado pela seguinte expressão:

$$
\begin{aligned}
\tilde{b}(E) & =\frac{\partial \ln \Omega(E)}{\partial E} \\
& \simeq \sum_{\alpha=1} f_{\alpha}^{*}\left(\beta_{\alpha}^{H}+\beta_{\alpha}^{w}\right),
\end{aligned}
$$

onde

$$
\begin{aligned}
& \beta_{\alpha}^{H}=\frac{\partial \ln H_{\alpha}}{\partial E}, \\
& \beta_{\alpha}^{w}=-\frac{\partial \ln w_{\alpha}}{\partial E}
\end{aligned}
$$

e

$$
f_{\alpha}^{*}=\frac{H_{\alpha}}{\sum_{\alpha^{\prime}} H_{\alpha^{\prime}}}
$$

No caso de simulações canônicas que utilizam $w_{\alpha}(E)=e^{-E / T_{\alpha}}$, por exemplo, a Eq. 2.30 se reduz à temperatura canônica $\beta_{\alpha}^{w}=1 / T_{\alpha}$. 
A vantagem de utilizar a Eq. 2.28 do ST-WHAM é que, diferentemente de algoritmos como o de amostragem entrópica (ES) ou mesmo de Wang-Landau (WL), os quais obtém estimativas para a entropia $S(E)$, a quantidade microcanônica obtida $\tilde{b}(E)$ é uma variável intensiva. Isso pode ser utilizado, por exemplo, em eventuais extrapolações da densidade de estados para sistemas a partir de simulações com redes menores.

Vale notar ainda que o sinal $\simeq$ na Eq. 2.28 aparece porque um termo remanescente das equações originais do WHAM, relacionado ao cálculo iterativa da função de partição, foi desprezado. Como discutido na Ref. [71], isso só pode ser feito quando o número de configurações amostradas (em cada histograma) $N_{\alpha}$ é muito maior que 1.

\subsubsection{ST-WHAM-MUCA}

A princípio, a estimativa para a entropia microcanônica pode ser obtida pela integração numérica de $\tilde{b}(E)$, ou seja,

$$
\tilde{S}(E)=\int \sum_{\alpha=1}^{M} f_{\alpha}^{*}\left(\beta_{\alpha}^{H}+\beta_{\alpha}^{W}\right) d E,
$$

contudo, o uso dessa expressão pode levar à uma estimativa bastante imprecisa. Como sugeriram Kim e colaboradores [71], uma estimativa melhor para a entropia microcanônica $\tilde{S}(E)$ poderia ser obtida pela integração analítica de $1 / T(E)$. Nós, por outro lado, propomos estimar $\tilde{S}(E)$ utilizando as relações de recorrência do MUCA (Eqs. 2.17 e 2.18). Denominamos esse procedimento como ST-WHAMMUCA [70] e consiste em utilizar a estimativa do ST-WHAM para o inverso da temperatura estatística como temperatura microcanônica e incluí-la na seguinte expressão

$$
\tilde{a}\left(E_{m-1}\right)=\tilde{a}\left(E_{m}\right)+\left[\tilde{b}\left(E_{m-1}\right)-\tilde{b}\left(E_{m}\right)\right] E_{m}
$$

e depois utilizar a expressão $\tilde{S}\left(E_{m}\right)=\tilde{b}\left(E_{m}\right) E_{m}-\tilde{a}\left(E_{m}\right)$ para obter a entropia.

\subsubsection{Comparação entre ST-WHAM e MUCA}

Como vimos na seção 2.2, a análise microcanônica contrasta com a análise usual obtida pelas simulações no ensemble canônico, principalmente quando a fenomenologia do sistema apresenta transições de fase de primeira ordem. Nesses casos, 
também é interessante definir a diferença de energia livre $\Delta F(E)$ em função da energia para a temperatura $T_{c}=1 / \beta_{c}$ utilizando a entropia deslocada definida pela Eq. 2.11. Fazemos isso considerando a seguinte relação

$$
\beta_{c}\left[F(E)-F_{a}\right]=\beta_{c} E-S(E),
$$

onde $\beta_{c} F_{a}=\beta_{c} E_{a}-S\left(E_{a}\right)$ é a energia livre de referência e está associada ao coeficiente linear $A$ da reta definida na Eq. 2.11. Dessa maneira, a diferença de energia livre $\Delta F(E)=\left[F(E)-F_{a}\right]$ relaciona-se com a entropia deslocada como

$$
\Delta F(E)=-\frac{1}{\beta_{c}} \Delta S(E) .
$$

É interessante notar que os potenciais termodinâmicos entropia $S(E)$ e energia livre $F(\beta)$ estão relacionadas por uma transformada de Legendre-Fenchel (LF): $F(\beta)=\mathcal{L}[S(E)]$. Tal relação é válida sempre, independente do formato de $S(E)$, mesmo na região não côncava no seu domínio. A transformada LF sempre produz uma função côncava. Por outro lado, se uma função não é côncava no seu domínio, então ela não pode ser obtida de uma transformada LF de outra função [35]. Então, se $S(E)$ possui um intruso convexo, ela não pode ser calculada a partir de energias livres naquele domínio, como consequência as descrições termodinâmicas são não equivalentes.

Todavia, a diferença de energia livre expressa pela Eq. 2.35 é uma quantidade que depende da energia $E$. Assim, a rigor, $\Delta F(E)$ não corresponde à energia livre $F(\beta)$ obtida pela transformada de LF como discutido anteriormente. Por outro lado, é bem conhecido que as equações envolvidas no WHAM fornecem essencialmente energias livres $F(\beta)$. Isso motivou nosso estudo [70] para comparar os resultados da termoestatística microcanônica fornecidos tanto pelo algoritmo multicanônico quanto pelo método ST-WHAM associado às simulações canônicas.

Realizamos tal comparação utilizando resultados para o modelo de Ising dipolar 2D, sobre o qual já havíamos feito um estudo utilizando simulações de Metropolis independentes combinadas com a análise de múltiplos histogramas [80]. A partir do cálculo dos tempos de auto-correlação, mostramos que o efeito de decaimento lento crítico é bastante severo para a região do diagrama de fases caracterizada pelo acoplamento $\delta=2$. Apesar dos resultados não apresentarem evidências conclusivas 
à respeito da natureza das transições observadas, nossa análise sugere a presença de uma forte barreira de energia livre na região de transição para esse acoplamento.

Os dados utilizados para a análise via ST-WHAM correspondem aos histogramas $H_{\alpha}(\mathrm{E})$ obtidos em temperaturas $T_{\alpha}$ via algoritmo de Metropolis para cinco simulações independentes, cada uma contendo $3,4 \times 10^{7}$ configurações amostradas (vide Fig. 2.5(a)). Para a obtenção dos pesos multicanônicos utilizamos o protocolo (i) como descrito na subseção 2.3.3, realizando $N_{r}=10^{3}$ passos de recorrência com $n_{s}=5 \times 10^{4}$ varreduras em cada passo. Para ambas análises utilizou-se a discretização na energia $\epsilon=1$. Para comparar os resultados obtidos via MUCA (Eq. 2.18) e ST-WHAM (Eq. 2.28), primeiro consideramos as estimativas para inverso da temperatua microcanônica para uma rede de tamanho $L=32$, as quais são apresentadas na Fig. 2.5(b). O comportamento ruidoso na curva calórica $\beta(E)$ para energias $E / N \lesssim-1.18$ ocorre pois os histogramas, tanto nas simulações de Metropolis quanto MUCA, não amostraram configurações suficientes para essa região. As estimativas para a entropia microcanônica foram feitas a partir das estimativas para o inverso da temperatura microcanônica utilizando o procedimento que chamados de ST-WHAM-MUCA, como descrito na subseção 2.5.2. Na Figura 2.5(c) incluimos a estimativa da entropia deslocada $\Delta S(E)$ (Eq. 2.11) utilizando as entropias obtidas pelos dois algoritmos. Como podemos ver, as duas estimativas fornecem resultados equivalentes mesmo na região onde a transição de fase onde a entropia microcanônica apresenta uma região convexa. Para essa região, a curva calórica $\beta(E)=1 / T(E)$ por $E / N$ exibe o comportamento característico para transições de primeira ordem, que é o formato de $\mathrm{S}$ correspondente ao chamado loop do tipo van der Waals, ou ainda $S$-loop ou S-bend. 

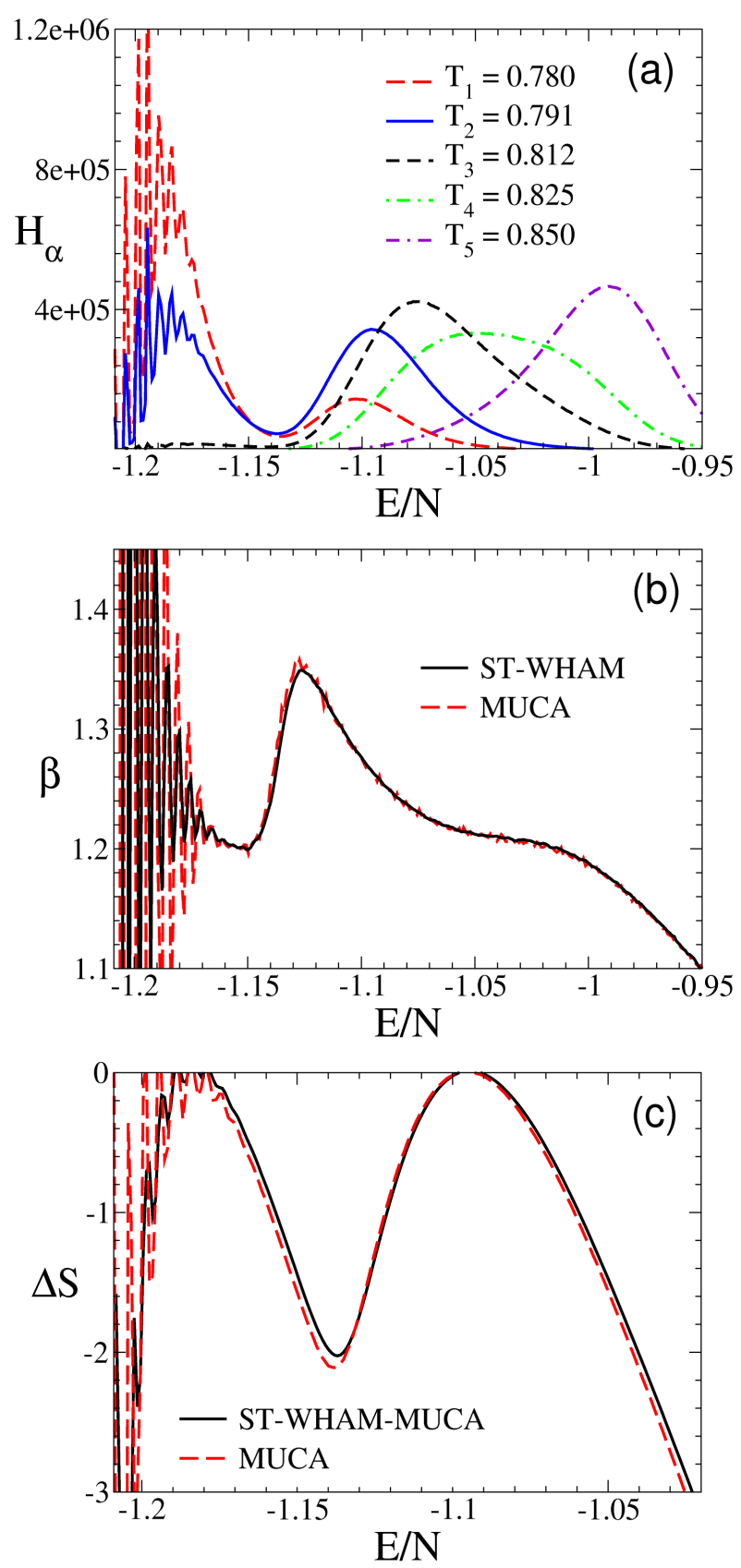

Figura 2.5: Comparação entre simulações MUCA e Metropolis para a obtenção da termoestatística microcanônica para o modelo de Ising dipolar 2D na região onde o acoplamento é $\delta=2$ utilizando uma rede de tamanho $L=32$. (a) histogramas $H_{\alpha}(E)$ obtidos via simulações independentes de Metropolis em temperaturas $T_{\alpha}$. (b) estimativas do inverso da temperatura microcanônica $\beta(E)$ obtidas via ST-WHAM (linha sólida) e MUCA (linha tracejada). (c) entropias microcanônicas deslocadas obtidas pela solução ST-WHAM-MUCA (linha sólida) e puramente multicanônica (linha tracejada) em função da energia por spin $E / N$. Figura retirada da Ref. [70]. 


\section{CAPÍTULO}

\section{SIMULAÇÕES NUMÉRICAS DO MODELO DE ISING DIPOLAR}

\subsection{Descrição do modelo}

Apresentamos nessa seção uma breve descrição do modelo de Ising dipolar bidimensional (2D) [110, 111], o qual tem sido utilizado para descrever propriedades de filmes magnéticos ultrafinos [112]. Além da interação de troca ferromagnética entre os spins primeiros vizinhos, usual no modelo de Ising, esse modelo leva em consideracão a contribuição da interação entre os momentos de dipolo magnético dos spins ${ }^{1}$. A hamiltoniana para uma rede quadrada com $N=L^{2}$ sítios ocupados por spins de Ising $\sigma_{i}= \pm 1$ é definida por

$$
\mathcal{H}=-\delta \sum_{<i, j>} \sigma_{i} \sigma_{j}+\sum_{i<j} \frac{\sigma_{i} \sigma_{j}}{r_{i j}^{3}}
$$

onde $\delta=J / g$ é a razão entre a interação ferromagnética de troca $(J>0)$ e a intensidade da interação dipolar antiferromagnética $(g>0)$; e $r_{i j}$ é a distância, em unidades de rede, entre pares de spins distintos ${ }^{2}$ nos sítios $i$ e $j$. Note que, enquanto a interação de troca ferromagnética favorece o alinhamento entre spins vizinhos, a interação entre os seus momentos de dipolo magnético favorece estados antiferro-

\footnotetext{
${ }^{1}$ Estudos experimentais sugerem que a contribuição da interação entre os momentos de dipolo magnético dos spins, que é essencialmente anisotrópica nesse caso, aumenta a medida que a espessura do filme diminui $[113,114,115,116]$.

${ }^{2}$ Aqui nós adotamos a mesma convenção de soma da referência [117]. Detalhes sobre a diferença entre as convenções utilizadas na literatura e suas implicações na leitura do diagrama de fases, além de uma revisão detalhada sobre a descrição e propriedades do modelo de Ising dipolar, podem ser encontrados na referência [79].
} 
magnéticos. Assim, a presença da competição entre as duas interações dá origem ao fenômeno de frustração, característico em muitos sistemas ditos complexos.

Um aspecto importante na implementação do modelo é a utilização da técnica do somatório de Ewald, a qual incorpora condições periódicas de contorno infinitas ${ }^{3}$. Sem utilizá-la, o custo computacional para a convergência do segundo termo na Eq. 3.1 (interação entre dipolos) seria proibitivo. Nas Refs [75] (diponível no Anexo IV) e [79], incluimos uma tabela com o tempo de CPU estimado para uma varredura de MC, o qual escala com $L^{3,6}$. Apesar de razoável, tal custo computacional pode limitar o tamanho das redes utilizadas para alguns estudos, principalmente aqueles que envolvem valores grandes para o acoplamento $\delta$.

\subsection{Revisão bibliográfica}

Podemos encontrar na literatura diversas abordagens teóricas para representar a fenomenologia do modelo de Ising dipolar 2D. Tais abordagens vão desde modelos que apresentam soluções analíticas utilizando aproximações como da teoria de ondas de spin até aproximações de campo médio $[118,73,110,110,119,120,121,122$, 123, 124, 72, 125]. Embora tais aproximações analíticas não sejam estritamente equivalentes ao modelo discreto (Eq. 3.1), elas fornecem importantes conclusões tais como o fato de que a magnetização espontânea deve ser zero para qualquer temperatura e de que, para $T=0$, as configurações do estado fundamental podem apresentar padrões de domínios magnéticos classificados em tabuleiros de xadrez (ou checkerboards) regulares ou irregulares, ou faixas com diferentes larguras.

Os padrões de tabuleiros correspondem à formação de domínios magnéticos representados por retângulos de spins para cima (simbolizado pela cor preta) e spins para baixo (simbolizados pela cor branca) ${ }^{4}$. Cada um desses retângulos contendo sítios com spins do mesmo tipo são denotados por $<m, n>$, onde $m$ e $n$ representam unidades de rede [120]. Tabuleiros regulares e irregulares são definidos por $m=n$ e $m \neq n$, respectivamente. Os padrões de faixas correspondem a formação de domínios magnéticos ilustrados por retângulos de tamanho ${ }^{5}<m, n>$ mas com

\footnotetext{
${ }^{3}$ Para mais detalhes veja a referência [79] e as referências mencionadas.

${ }^{4}$ Algumas dessas configurações são mostradas nas Figs. 3.2 e 3.3 a seguir.

${ }^{5}$ Nesse caso utilizamos apenas a notação $h$ (onde $m=h$ ) para denotar a largura das faixas.
} 
$n \rightarrow \infty$.

Esforços têm sido feitos na direção de uma prova rigorosa paraa formação espontânea dessas configurações no estado fundamental $(T=0)$ [121, 122]. Contudo, a formação de tais padrões em diferentes regiões do diagrama de fase $(\delta, T)$ têm sido confirmada principalmente por simulações de MC. Na Fig. 3.1 mostramos o diagrama de fase obtido por simulações de MC [74] para $\delta$ em $(0: 1,9)$, onde ocorrem os padrões descritos para o estado fundamental. Para o caso particular onde $\delta=0$, que representa um modelo com a interação apenas entre os momentos de dipolo magnético, temos a transição de fase contínua com expoentes críticos de acordo com a classe de universalidade do modelo de Ising 2D [126, 127]. Para $0<\delta<0.4152$, o modelo apresenta estados fundamentais antiferromagnéticos (AF) caracterizados por configurações de spin do tipo tabuleiro com $<1,1>$. Estimativas para o calor específico indicam uma transição contínua associada com a mudança entre a fase AF e a fase com quebra de simetria orientacional, também chamada de fase tetragonal [120]. Configurações irregulares de tabuleiros $\langle 1, n\rangle$ aparecem somente no inter-

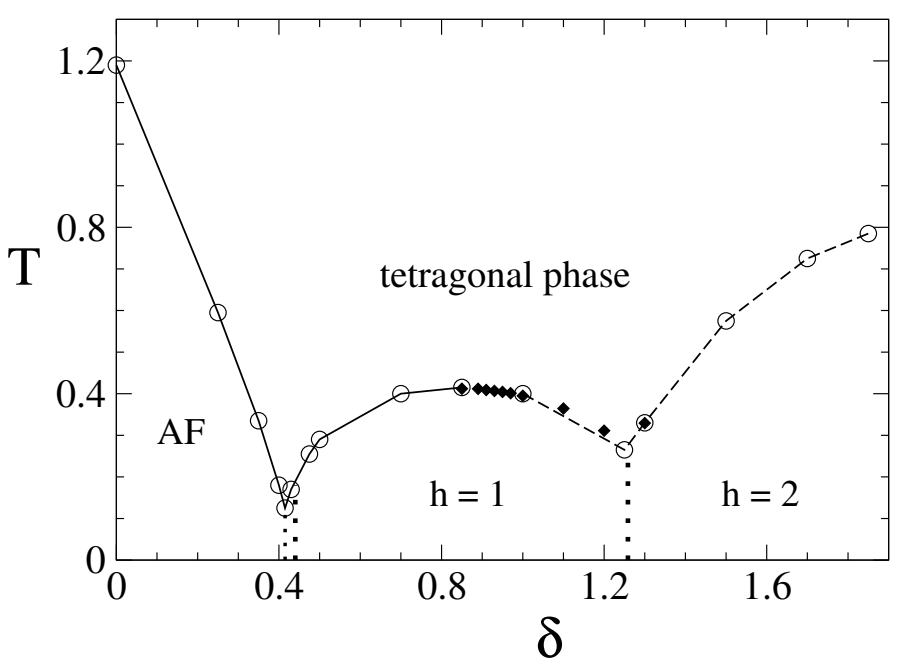

Figura 3.1: Diagrama de fase para o modelo de Ising dipolar 2D: (o) dados da referência [120] e ( $)$ correspondem aos resultados apresentados na subseção 3.3.2 (vide referência [74] ou Anexo VII). As linhas verticais pontilhadas representam os limites das fases onde o estado fundamental é caracterizado por configurações antiferromagnéticas (AF) e de faixas com largura $h=1$ e $h=2$. A linha contínua corresponde a transição de segunda ordem esperada, exceto para o pequeno intervalo $\delta$ em $(0,4152: 0,4403)$, e a linha tracejada $(---)$ representa transições de primeira ordem de acordo com as Refs. [120] e [126]. Figura retirada da Ref. [74]. 
valo $0.4152<\delta<0.4403$. Nesse intervalo, resultados sugerem que a transição para a fase tetragonal seja de primeira ordem [120]. Para valores de $\delta$ maiores, o estado fundamental é caracterizado por domínios magnéticos do tipo faixas alternadas de spins, cuja largura $h$ aumenta com o aumento de $\delta$ [110, 122]. Configurações de faixas com largura $h=1$ e $h=2$ ocorrem para $0.4403<\delta<1.2585$ e $1.2585<\delta<2.1724$, respectivamente.

Além das fases tetragonal e do tipo faixas, uma nova fase foi identificada no diagrama $(\delta, T)$ para $\delta=2$, a chamada fase nemática ${ }^{6}$ (em analogia com a terminologia empregada para cristais líquidos). Nessa nova fase os spins ainda permanecem com algum ordenamento orientacional remanescente da fase ordenada, contudo a simetria translacional da rede é perdida. Tal fase nemática foi primeiramente identificada por Cannas e colaboradores [128] via simulações de MC, em uma região do diagrama de fases próxima à linha de transição que separa as fases $h=2$ e $h=3$, entre as fases de faixas $(h=2)$ e tetragonal. Nesse caso, duas transições de fase ocorrem: faixas-nemática e nemática-tetragonal. Píghin e Cannas [72] mostraram posteriormente que tal fase nemática também aparece em intervalos estreitos da temperatura para outros valores do acoplamento $\delta$, e próximos às transições entre estados de faixas, i.e. $\langle h=2\rangle \leftrightarrow\langle h=3\rangle$. A presença da fase nemática também é sugerida pelos resultados de Rastelli e colaboradores [120]. Nós também verificamos a existência dessa nova fase para o acoplamento $\delta=2$ em um trabalho publicado em 2010 [80].

Como vimos, a inclusão da interação entre os momentos de dipolo magnético altera completamente o comportamento do modelo de Ising $2 \mathrm{D}$ ferromagnético. A presença da competição entre as interações leva a um diagrama de fases bastante complexo. Contudo, por simplicidade, apresentaremos nossos resultados separando a discussão considerando apenas dois cenários para as transições de fase ${ }^{7}$. O Cenário I corresponde a apenas uma transição entre as fases do tipo faixas com largura $h \mathrm{e}$ a fase tetragonal. As configurações características para esse cenário são ilustradas na Fig. 3.2 para o caso onde o estado fundamental é caracterizado por faixas de largura $h=1$. Além das configurações da fase do tipo faixas (à esquerda) e da

\footnotetext{
${ }^{6}$ A fase nemática é mostrada no centro da Fig. 3.3.

${ }^{7} \mathrm{~A}$ discriminação em dois cenários possíveis faz alusão ao trabalho para um modelo contínuo estudado por Abanov e colaboradores [73].
} 

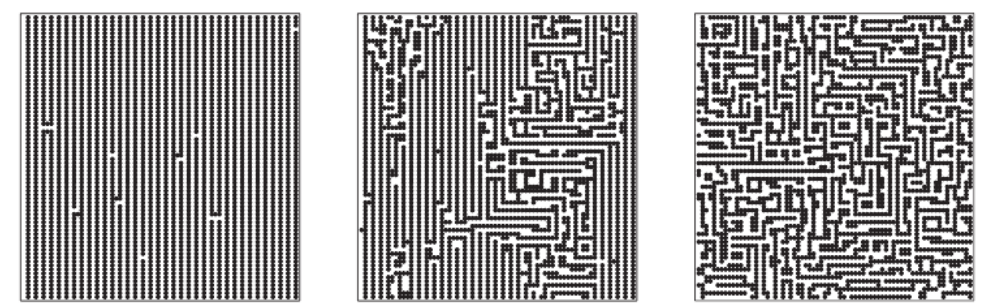

Figura 3.2: Configurações típicas para o modelo de Ising dipolar 2D para o Cenário I para a região $h=1$ : fase de faixas (à esquerda) e fase tetragonal (à direita). Ao centro incluimos uma configuração de transição, dessa maneira a figura observada da esquerda para a direita representa configurações típicas para um aumento na temperatura do sistema. Figura adaptada da Ref. [74].

fase tetragonal (à direita), incluimos uma configuração do ensemble de estados de transição (ao centro). O Cenário II é caracterizado por regiões onde duas transições de fase são observadas: uma transição onde o sistema passa da fase de faixas para a fase nemática e a outra transição onde o sistema sai da fase nemática e vai para a fase tetragonal. Na Fig. 3.3 apresentamos o comportamento do sistema para esse cenário na região onde o estado fundamental é caracterizado por faixas de largura $h=2$. Ilustramos o comportamento observado referente à um aumento na temperatura do sistema, sendo a fase de faixas apresentada à extrema esquerda e a fase tetragonal à extrema direita, com a fase nemática aparecendo entre as duas (bem no centro). Incluimos também configurações que representam estados nas duas transições entre as três fases observadas para esse cenário.

Embora existam estudos para diversos pontos do diagrama de fases $(T, \delta)$, a de-
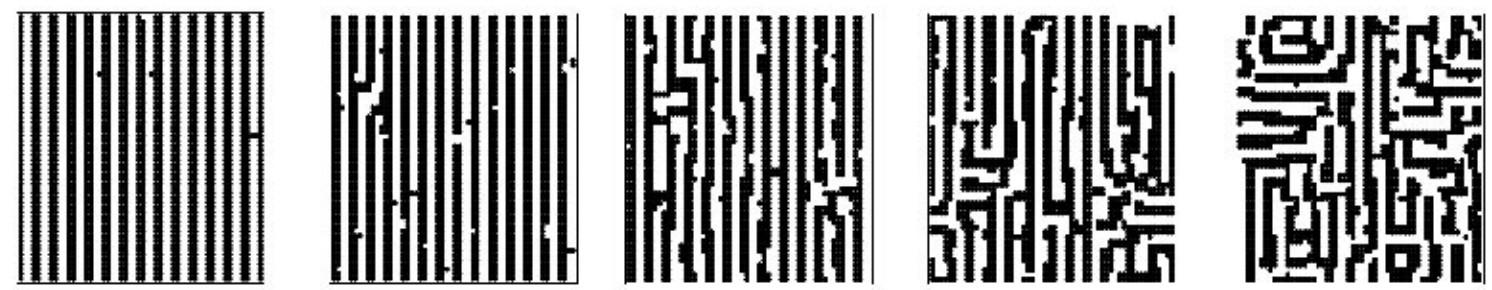

Figura 3.3: Configurações típicas para o modelo de Ising dipolar 2D para o cenário II para a região $h=2$ : fase de faixas (extrema esquerda), fase nemática (centro) e fase tetragonal (extrema direita). Incluimos também configurações típicas para estados nas duas transições. Dessa maneira a figura da esquerda para a direita representa configurações típicas para um aumento na temperatura do sistema. Figura adaptada da referência [80]. 
terminação precisa da natureza das transições de fase ainda se faz necessária, mesmo para valores pequenos de $h$. De fato, resultados controversos têm sido reportados na literatura. Em particular, algumas simulações de MC para a região de $\delta$ entre 0,2 e 2 exibem uma linha de transição contínua $[129,130]$ entre as fases ordenada e tetragonal (Cenário I). Por outro lado, outros autores indicam que a linha de transição deve ser de primeira ordem para $\delta$ onde o estado fundamental é caracterizado por faixas de largura igual $h=1$ [120]. Em um outro trabalho [126], esses mesmos autores mostram que para $\delta=0,85$ a transição é contínua, com expoentes ${ }^{8}$ $d \nu=2,0 \pm 0,1, \alpha=0,09 \pm 0,07$ e $\gamma=1,75 \pm 0,05$ na temperatura crítica $T_{c}=0,41$. Para o acoplamento $\delta=1$, a transição parece ser de primeira ordem para $T_{c}=0,40$ na referência [120], e considerada apenas como primeira ordem fraca em $T_{c}=0,404$ pelos autores da referência [128]. Dessa maneira, considerando os resultados acima, pode-se inferir a existência de duas linhas de transição, uma contínua e outra de primeira ordem, separadas por um ponto tricrítico para $\delta$ em algum ponto entre 0,85 e $1[72]$.

Em relação ao Cenário II, as evidências apresentadas até o momento também não permitem que conclusões definitivas sejam apresentadas. Em particular, para o acoplamento $\delta=2$, Cannas e colaboradores [128] apresentaram, através de um estudo de escala de tamanho finito (FSS), resultados para a transição de fase faixasnemática os quais sugerem que ela seja uma transição de fase de primeira ordem. Entretanto, ressalvas são feitas por causa de uma saturação incomum no máximo do calor específico, o que sugeriria um mecanismo do tipo Kosterlitz-Thouless (KT) [131, 132]. Em um trabalho subsequente [72], Píghin e Cannas nem sequer incluem a natureza da transição faixas-nemática no seu diagrama de fases obtido via simulações de MC. Com respeito à transição de fase nemática-tetragonal, Cannas e colaboradores [128] argumentam que a mudança descontínua do parâmetro de ordem sugere uma transição de fase de primeira ordem. Mas, nas palavras deles, são resultados inconclusivos, justificados pela presença de fortes efeitos de tamanho finito. No trabalho de Rastelli e colaboradores [120], os resultados para a transição faixas-nemática indicada pelo pico no calor específico mal pode ser observado.

\footnotetext{
${ }^{8}$ Aqui os expoentes $\nu, \alpha$ e $\gamma$ correspondem aos expoentes do comprimento de correlação, calor específico e susceptibilidade, respectivamente.
} 
Em nosso trabalho da Ref. [80] (Anexo I), evidenciamos a presença de estados metaestáveis com tempo de vida muito longos próximos à transição faixas-nemática através da análise do tempo de auto-correlação integrado para o acoplamento $\delta=$ 2. Obtivemos valores enormes para o expoente crítico dinâmico ${ }^{9} z: 6,2$ (faixasnemática) e 4,6 (nemática-tetragonal). Nossos resultados corroboram o fato de que, para o Cenário II definido na região de acoplamento $\delta=2$, a fenomenologia do modelo de Ising dipolar 2D somente pode ser observada quando tamanhos grandes de rede $(L>32)$ são considerados. Mostramos que as funções resposta canônicas tais como o calor específico e a susceptibilidade do parâmetro de ordem possuem fortes efeitos de tamanho finito, frustrando qualquer obtenção convincente dos expoentes críticos por simples análise de escala de tamanho finito. Como consequência, nossos dados para esse trabalho, infelizmente, fornecem resultados controversos para ambas transições. Nossa análise de histogramas múltiplos [80] mostra uma natureza de primeira ordem forte para a transição de fase faixas-nemática. No entanto, nossa análise de escala de tamanho finito sugere uma transição contínua. Para a transição de fase nemática-tetragonal uma natureza de primeira ordem é sugerida pela análise de histogramas múltiplos, porém a análise de escala de tamanho finito não descarta a possibilidade de ser uma transição de fase contínua.

É interessante notar que todos os trabalhos mencionados anteriormente que utilizam simulações de MC para obter as propriedades termodinâmicas do modelo de Ising dipolar 2D foram efetuadas com o algoritmo usual de Metropolis.

\subsection{Cenário I: Transição de fase faixas-tetragonal}

O Cenário I, o qual corresponde a uma única transição de fase (faixas-tetragonal), pode ser observado para diversos valores do acoplamento $\delta$ (vide diagrama de fases na Fig. 3.1). Apresentamos nessa subseção dois estudos realizados os quais estão associados à ocorrência desse tipo de transição no diagrama de fases. Primeiramente avaliamos os protocolos de determinação dos pesos dos algoritmos de amostragem uniforme apresentados na subseção 2.3.3, comparando-os tanto com o algoritmo entrópico (ES) quanto com o algoritmo multicanônico (MUCA). A partir da deter-

\footnotetext{
${ }^{9}$ Esse expoente reflete o quanto as séries produzidas estão correlacionadas. Para mais detalhes veja [83].
} 
minação do melhor protocolo, realizamos um estudo para carecterizar a transição na região onde o estado fundamental é descrito por faixas de largura $h=1$ e avaliar a existência e localização do possível ponto tricrítico nessa região ${ }^{10}$.

\subsubsection{Obtenção da densidade de estados}

Apresentamos nessa subseção uma comparação entre os algoritmos MUCA e ES para obtenção dos pesos de amostragem utilizando os diferentes protocolos descritos na subseção 2.3.3. Todos os resultados apresentados aqui foram realizados para a rede de tamanho $L=48$, acoplamento $\delta=1,7, \epsilon=1$ e $E_{0} / N=-0,92$. Esse valor de acoplamento encontra-se na região onde o estado fundamental do sistema é descrito pela fase do tipo faixas com largura $h=2$. Escolhemos esse valor de $\delta$ em particular pois encontramos dois trabalhos na literatura que já haviam explorado a determinação da natureza da transição faixas-tetragonal nessa região, ambos realizados utilizando o algoritmo de Metropolis usual. O primeiro trabalho é de 2006, onde Rastelli e colaboradores [126] realizaram simulações para tamanhos de rede até $L=64$ e, através de uma análise de escala de tamanho finito (FSS), mostraram que a única transição de fase observada corresponde a uma transição de primeira ordem entre as fases de faixas $(h=2)$ e tetragonal (cenário I). Em 2007, Píghin e Cannas [72] verificaram esse resultado para uma rede de tamanho $L=48$ utilizando a técnica de integração termodinâmica.

Conforme o procedimento de recorrência evolui, a caminhada aleatória tende a alcançar regiões com energias mais baixas e os pesos (ou a densidade de estados) vão sendo obtidos. Na Fig. 3.4 apresentamos os gráficos da energia mínima por volume $E_{\min } / N$ em função do número de varreduras $N_{\text {var }}$ e também do número de varreduras médio $\left\langle N_{\text {var }}\right\rangle$ em função de $E_{\min } / N$ (em módulo) para o procedimento de recorrência completo. Cada cor representa quatro realizações independentes de um dos protocolos. Os gráficos (a) e (c) da Fig. 3.4 mostram que, de uma maneira geral, o algoritmo ES chega mais rapidamente à energia do estado fundamental do que o algoritmo MUCA. Os gráficos (b) e (d) mostram que, para ambos os algoritmos, os protocolos (ii), (iii) e (iv), ou seja, aqueles que consideram as viagens de ida e volta, apresentaram um desempenho melhor que o protocolo (i), o qual

\footnotetext{
${ }^{10}$ Esse trabalho foi publicado e corresponde à referência [74], e incluido no Anexo VII.
} 

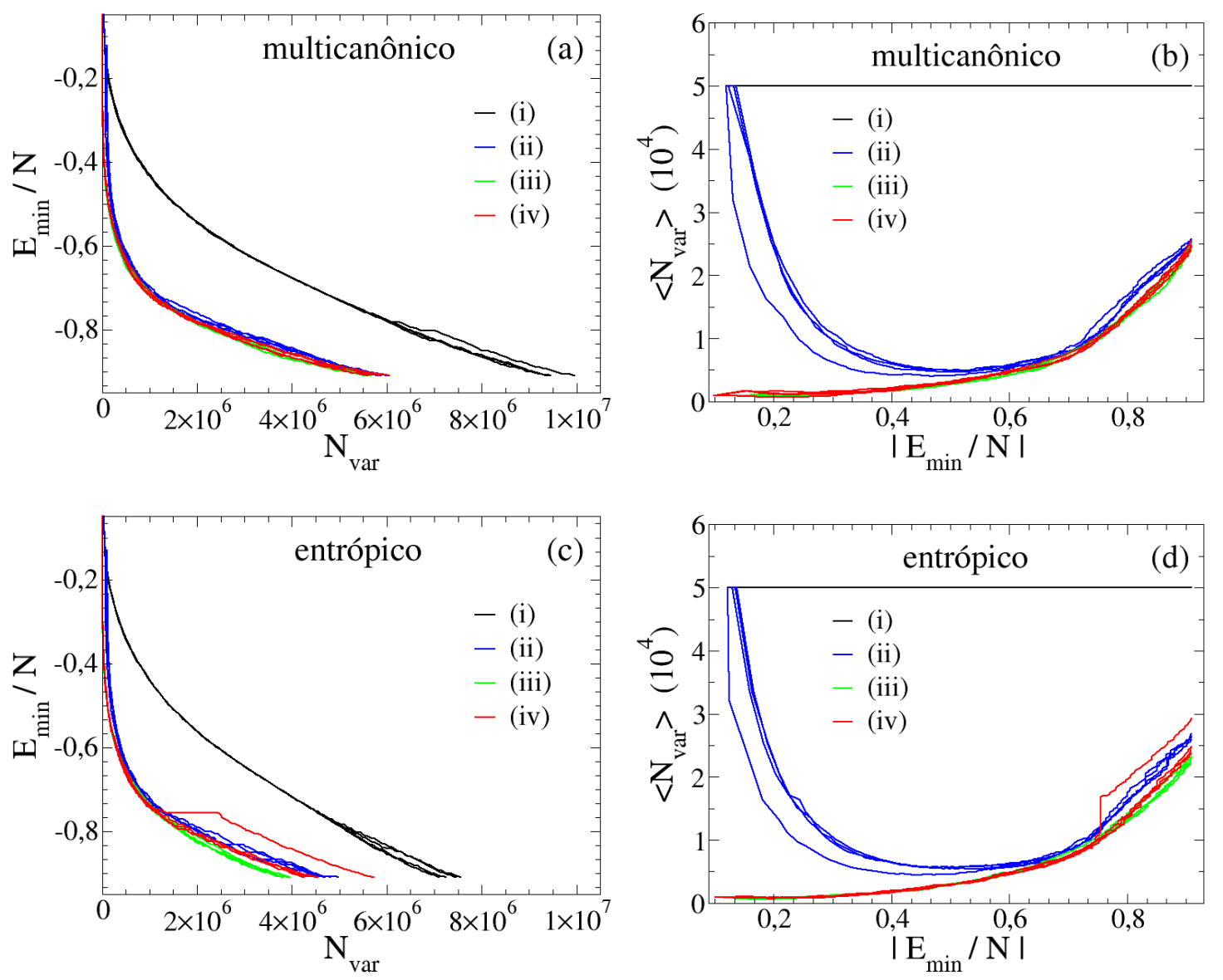

Figura 3.4: Comparação entre os algoritmos MUCA e ES para a obtenção da densidade de estados do modelo de Ising dipolar 2D para $L=48, \delta=1,7$ utilizando os quatro protocolos descritos na seção 2.3 .3 e uma discretização na energia $\epsilon=1$. (a) e (c): energia mínima por volume $E_{\min } / N$ em função do número de varreduras $N_{\text {var }}$; (b) e (d): número de varreduras médio $\left\langle N_{\text {var }}\right\rangle$ em função do módulo da energia mínima por volume $E_{\min } / N$.

estabelece um número fixo de varreduras $\left(n_{s}=5 \times 10^{4}\right)$. Na Tabela 3.1 mostramos a estimativa do número total de varreduras utilizado para os dois algoritmos e cada um dos protocolos. O melhor resultado, considerando somente o procedimento que fornece o menor número de varreduras total, é obtido pelo algoritmo ES utilizando o protocolo (iii). Contudo, é preciso checar a qualidade dos pesos obtidos. Na Fig. 3.5 mostramos resultados para a curva calórica ${ }^{11} b(E)$ em função de $E / N$ após o protocolos terem alcançado a energia do estado fundamental, ou seja, após o

\footnotetext{
${ }^{11}$ No caso do algoritmo ES, a curva $b(E)$ correspondente é obtida a partir de $d S(E) / d E$ utilizando a fórmula da diferença centrada com estêncil de quatro pontos.
} 


\begin{tabular}{ccc}
\hline \hline Protocolo & MUCA & ES \\
\hline (i) & $9,5(3) \times 10^{6}$ & $7,3(2) \times 10^{6}$ \\
$($ ii $)$ & $5,9(1) \times 10^{6}$ & $4,8(1) \times 10^{6}$ \\
$($ iii $)$ & $5,6(1) \times 10^{6}$ & $3,9(1) \times 10^{6}$ \\
(iv) & $5,8(2) \times 10^{6}$ & $4,8(7) \times 10^{6}$ \\
\hline \hline
\end{tabular}

Tabela 3.1: Estimativa (sobre 4 realizações) do número de varreduras total para obtenção da densidade de estados do modelo de Ising dipolar 2D realizando passos de recorrência até o sistema atingir a energia do estado fundamental. Resultados para $L=48, \delta=1,7$ e $\varepsilon=1$.

procedimento de recorrência ser completado. Notamos que as curvas de $b(E)$ obtidas pelo algoritmo MUCA, gráficos (a), (c), (e) e (g) da Fig. 3.5, são muito melhores definidas quando comparadas com as curvas obtidas pelo algoritmo ES, gráficos (b), (d), (f) e (h) da Fig. 3.5. Além disso, as curvas resultantes do algoritmo ES associadas aos protocolos (i) e (iii), os quais atualizam os pesos e zeram os histogramas para todos os passos de recorrência, são notavelmente mais ruidosas que as demais.

Como discutimos na subseção 2.5.3, o formato de S em curvas calóricas é característico de transições de fase de primeira ordem. Com isso, os resultados apresentados na Fig. 3.5 confirmariam a natureza de primeira ordem para a transição de fase faixas-tetragonal para essa região do diagrama de fase, como sugerido nas referências [126, 72].

Uma análise mais robusta pode ser feita observando que a entropia possui uma região onde um intruso convexo aparece. Essa região é determinada pelas energias $E_{a}$ e $E_{b}$ obtidas a partir da construção de Maxwell ${ }^{12}$ na curva calórica $b(E)$ da entropia $S(E)$ correspondente. Escolhendo valores fixos $E_{a} / N=-0,8171$ e $E_{b} / N=$ $-0,6838$, obtemos valores da temperatura de transição $T_{c}=1 / \beta_{c}$ para os algoritmos ES e MUCA e os quatro protocolos utilizando a Eq. 2.12. Note que, como as entropias $S(E)$ são diferentes para cada algoritmo e protocolo, os valores estimados para a temperatura $T_{c}$ serão ligeiramente diferentes para cada um dos algoritmos e

\footnotetext{
${ }^{12}$ Escolhendo uma curva calórica não tão ruidosa da Fig.. 3.5 é possível fazer uma construção de Maxwell grosseira para estimar os valores das energias $E_{a}$ e $E_{b}$.
} 


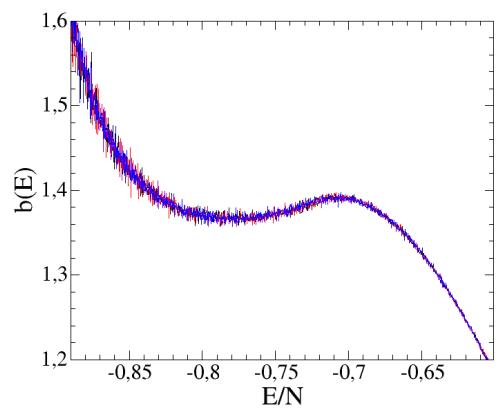

(a) MUCA (i)

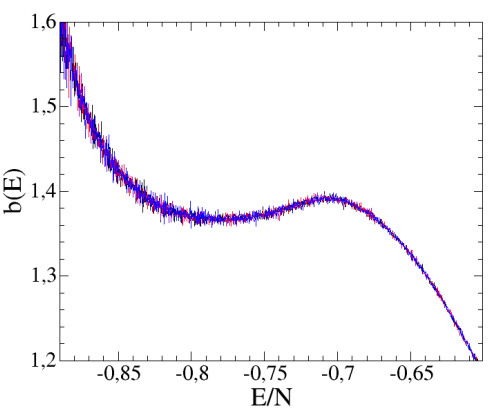

(c) MUCA (ii)

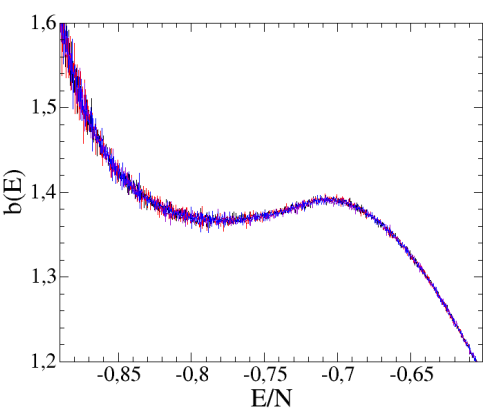

(e) MUCA (iii)

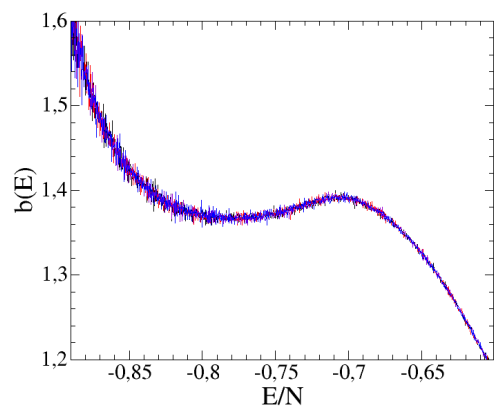

(g) MUCA (iv)

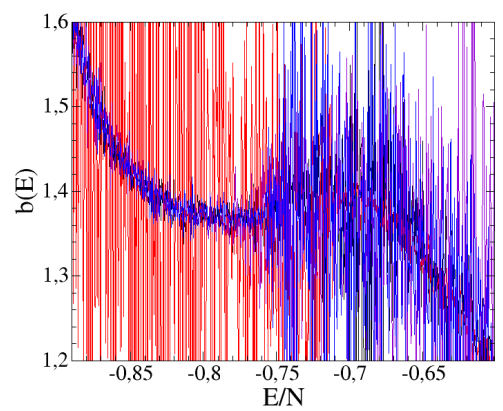

(b) ES (i)

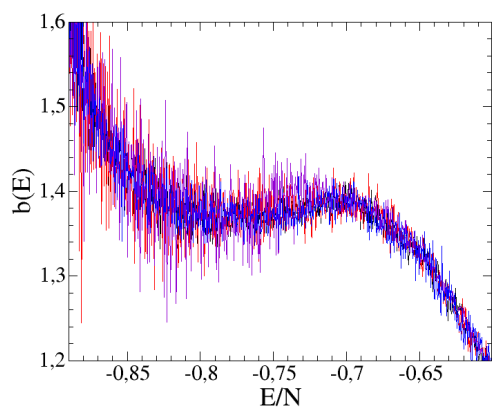

(d) ES (ii)

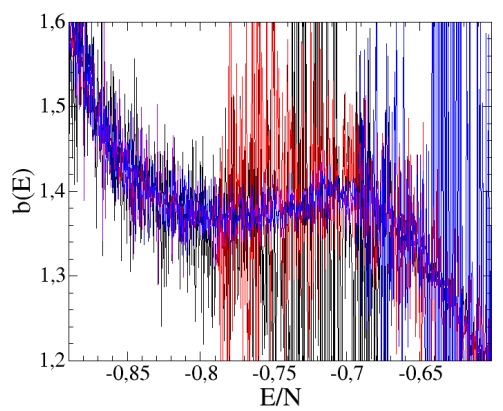

(f) ES (iii)

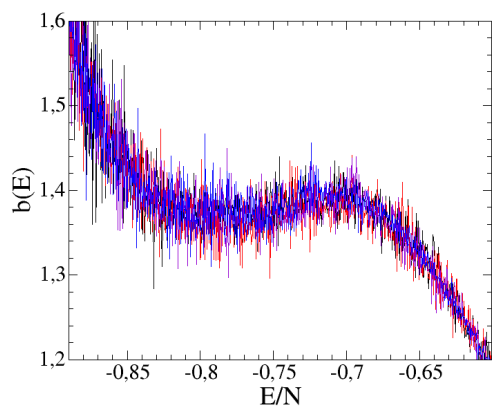

(h) ES (iv)

Figura 3.5: Curvas calóricas $b(E)$ em função da energia mínima por volume $E / N$ após o sistema completar o procedimento de recorrência. Resultados para $L=48$, $\delta=1,7$ e $\varepsilon=1$, comparando os algoritmos MUCA e ES para os quatro protocolos. Cores distintas representam realizações distintas. 


\begin{tabular}{ccccc}
\hline \hline & (i) & (ii) & (iii) & (iv) \\
\hline MUCA & $0,7262(1)$ & $0,7261(2)$ & $0,7262(3)$ & $0,7262(3)$ \\
ES & $0,729(4)$ & $0,725(1)$ & $0,73(2)$ & $0,725(2)$ \\
\hline \hline
\end{tabular}

Tabela 3.2: Estimativas (sobre 4 realizações) para a temperatura $T_{c}$ de transição de fase faixas-tetragonal logo após completar o procedimento de recorrência para os algoritmos MUCA e ES associados aos diferentes protocolos. Resultados para $L=48, \delta=1,7$ e $\varepsilon=1$.

protocolos, como mostrado na Tabela 3.2. Todos os valores obtidos estão próximos ${ }^{13}$ às estimativas apresentadas nas referências [126, 72].

Podemos também avaliar os gráficos da funcão $\Delta F(E)$ obtida pela relação 2.35. Como vimos, essa função pode ser associada à diferença de energia livre do sistema em relação à energia $F\left(E_{a}\right)$, ambas definidas na temperatura de transição $T_{c}$. Apresentamos na Fig. 3.6 as curvas $\Delta F(E)$ obtidas para cada um dos algoritmos e protocolos após o procedimento de recorrência completo. Observamos que todas as curvas obtidas pelo algoritmo MUCA, gráficos (a), (c), (e) e (g) da Fig. 3.6, já possuem uma estrutura de dois vales. Para o algoritmo ES, apenas as curvas obtidas pelos protocolos (ii) e (iv), gráficos (d) e (h) da Fig. 3.6,possuem uma estrutura parecida com essa, ainda que ruidosa. As curvas dos gráficos (b) e (f) da Fig. 3.6, associadas às curvas ruidosas da Fig. 3.5, possuem uma forma bastante diferente da estrutura esperada de dois vales. Possivelmente os resultados ruins obtidos para o algoritmo ES sejam em razão dos protocolos (i) e (iii) reiniciarem o histograma para todo passo de recorrência. Principalmente quando a estatística entre um passo e outro não é muito grande, uma atualização considerando as entradas do histograma diretamente, como é feito no algoritmo ES, pode prejudicar a estimativa de $S(E)$. Isso não afeta muito o algoritmo MUCA, já que este leva em consideração relações entre histogramas vizinhos (vide Eq. 2.18) para obter a estimativa de $b(E)$.

É interessante notar que a existência de dois vales de mesma profundidade nas energias $E_{a}$ e $E_{b}$ reflete o fato de que a diferença de energia livre entre esses estados é nula e que há coexistência de duas fases para essa temperatura. Além disso, a

\footnotetext{
${ }^{13}$ Embora seja tentador dizer que os valores de $T_{c}$ obtidos aqui sejam muito precisos, vale lembrar que os erros apresentados na Tabela 3.2 estão subestimados, pois não levam em consideração o erro na escolha das energias $E_{a}$ e $E_{b}$.
} 


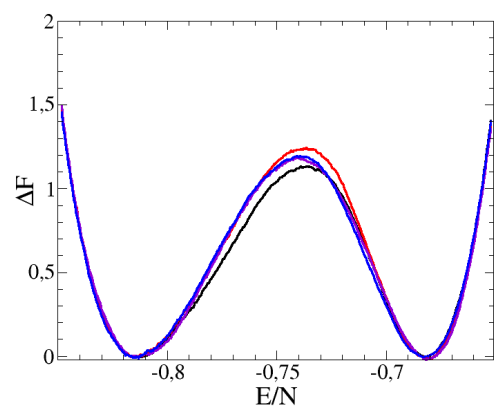

(a) MUCA (i)

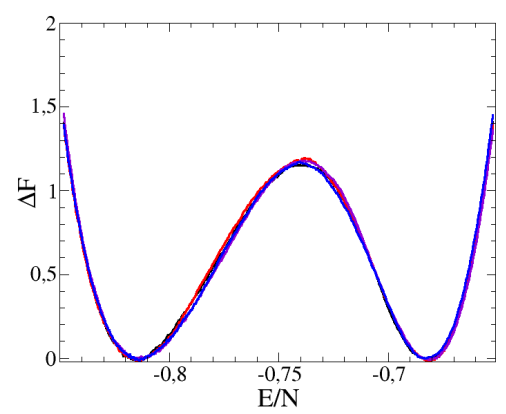

(c) MUCA (ii)

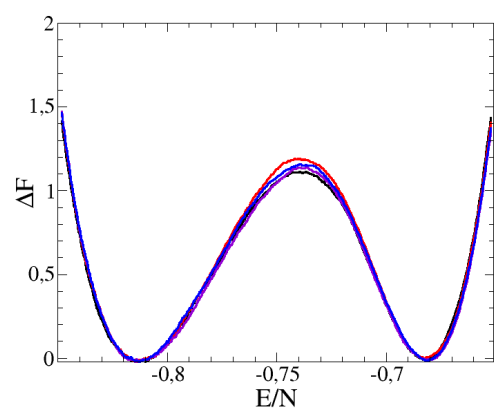

(e) MUCA (iii)

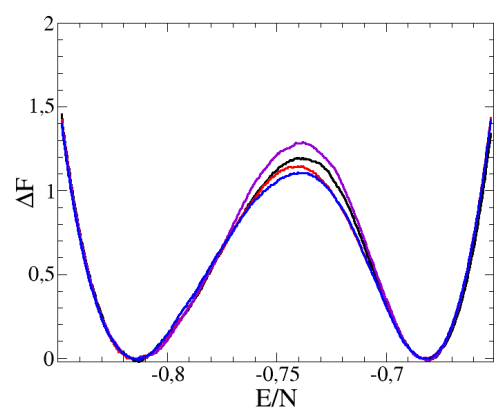

(g) MUCA (iv)

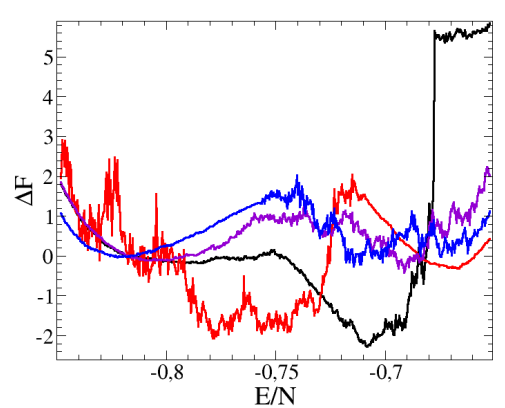

(b) ES (i)

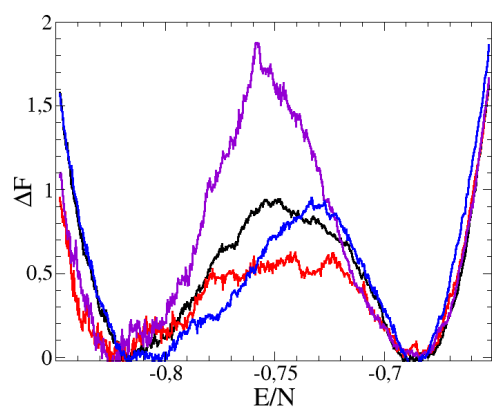

(d) ES (ii)

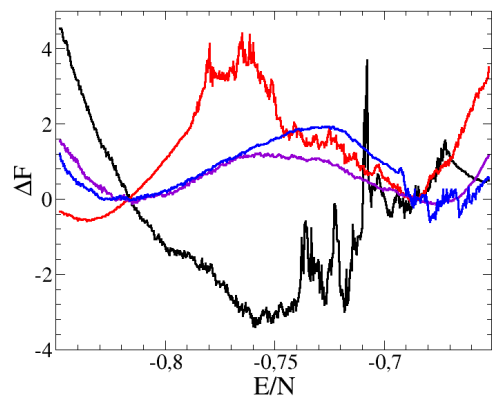

(f) $\mathrm{ES}$ (iii)

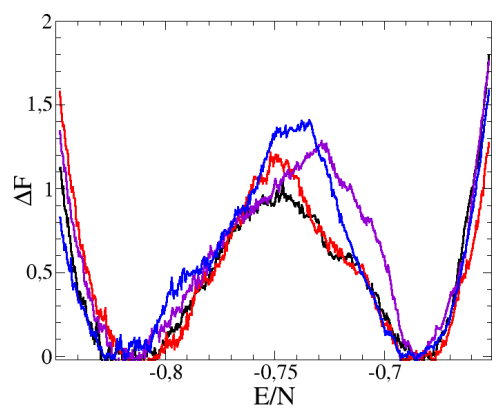

(h) ES (iv)

Figura 3.6: Diferença de energia livre $\Delta F\left(\beta_{c}, E\right)$ em função da energia mínima por volume $E / N$ na região do intruso convexo na entropia microcanônica após o sistema ter completado o procedimento de recorrência. Resultados para $L=48, \delta=1,7$ e $\varepsilon=1$, comparando os algoritmos MUCA e ES para os quatro protocolos. Cores distintas representam realizações distintas. 
altura do pico central pode ser considerada como uma barreira de energia livre. A determinação precisa da altura desse pico em função do tamanho da rede permite que uma análise de tamanho finito seja efetuada, ajudando a determinar a natureza da transição de fase [133, 134, 135].

\subsubsection{Transição faixas-tetragonal $(h=1)$}

Como vimos, existem evidências na literatura indicando a existência de um ponto tricrítico no diagrama de fases do modelo de Ising dipolar para $\delta \sim 0,9$, onde a largura das faixas é $h=1$. Em particular, apresentamos nessa seção o estudo feito em colaboração [74] para determinar a existência e localização desse ponto tricrítico $^{14}$. Simulações de MC foram efetuadas para determinar a natureza das transições de fase para valores do acoplamento $\delta$ indo de 0,85 até 1,30.

Com base nos resultados obtidos na seção anterior, consideramos o algoritmo multicanônico utilizando o protocolo (iii), o qual utiliza a ideia de viagens de ida e volta para otimizar a obtenção dos pesos. Ao final de cada determinação do pesos, consideramos ainda uma última atualização feita a partir de uma série contendo 20 viagens de ida e volta. Foram realizadas simulações para redes de tamanho até $L=72$. Nossas análises finais foram baseadas em estatísticas produzidas ${ }^{15}$ com essas estimativas finais para os pesos de amostragem MUCA.

A análise principal para a determinação da natureza das transições foi baseada nos zeros complexos da função de partição no plano da temperatura [137, 138]. Tal análise têm sido aplicada com sucesso a diversos modelos, tais como modelos de spin [139, 81, 140], teorias de calibre na rede [141, 82] e modelos de proteínas [142, 143].

A partir da produção de dados utilizando os pesos multicanônicos, podemos utilizar os histogramas para estimar a densidade de estados utilizando a relação 2.2 , ou seja, $\Omega(E)=H_{m u}(E) w_{m u}^{-1}(E)$, a partir da qual podemos construir a função de partição

$$
Z(\beta)=\sum_{E} \Omega(E) u^{E}
$$

\footnotetext{
${ }^{14}$ Diversos detalhes sobre esse estudo também podem ser encontrados na dissertação de mestrado listada na Ref. [136].

${ }^{15}$ A produção de dados varia de acordo com o tamanho de rede e o acoplamento utilizado, mais detalhes podem ser encontrados na Ref. [74], a qual é apresentada no Anexo VII.
} 
onde $u=e^{-\beta}$. A raízes complexas do polinômio em $u,\{\operatorname{Re}(u), \operatorname{Im}(u)\}$, descrevem o comportamento crítico do sistema, e são conhecidas como zeros de Fisher [137, 138].

É importante notar que a Eq. 3.2 torna-se um polinômio quando discretizamos a energia em intervalos de largura $\epsilon$. Para redes de tamanho $L \leq 32$, a equação polinominal pode ser resolvida utilizando o MATHEMATICA, contudo, para redes maiores o grau do polinômio aumenta signicativamente, o que faz com que o método de escaneamento [144] seja o único meio de obter tais raízes complexas.

Utilizando as partes real e imaginária dos zeros complexos da função de partição, realizamos uma análise via relações de escala de tamanho finito [145, 139] para determinar o expoente $d \nu$ e a temperatura termodinâmica de transição $T_{c}$.

Para estimar o expoente $d \nu$ consideramos os zeros complexos organizando-os em ordem crescente de acordo com sua parte imaginária. Desconsiderando termos de correções dependentes de $L$ para redes finitas, obtemos a seguinte relação para a distância entre o zero mais próximo do eixo real $u_{1}^{0}(L)$ (ou primeiro zero) e o zero no limite termodinâmico $u_{c}=e^{-\beta_{c}}$,

$$
-\ln \left|u_{1}^{0}(L)-u_{c}\right|=\frac{1}{\nu} \ln (L)+a .
$$

Como a temperatura crítica exata não é conhecida e a parte real de $u$ apresenta uma dependência pequena com $L$ quando comparada com a sua parte imaginária ${ }^{16}$, é usual substituir a distância $\left|u_{1}^{0}-u_{c}\right|$ apenas pela parte imaginária de $u_{1}^{0}$. Dessa maneira, obtemos o expoente $\nu$ a partir de uma regressão linear baseada na Eq. 3.3. Na Fig. 3.7 apresentamos as regressões lineares utilizando essa relação de escala de tamanho finito (FSS) para a obtenção do expoente $d \nu$ para alguns valores do acoplamento $\delta$.

A temperatura termodinâmica de transição pode ser obtida considerando a parte real dos zeros da função de partição, $\operatorname{Re}\left[\beta_{1}^{0}(L)\right]=-1 / 2 \ln \left\{\left[\operatorname{Re} u_{1}^{0}(L)\right]^{2}+\right.$ $\left.\left[\operatorname{Im} u_{1}^{0}(L)\right]^{2}\right\}$, utilizando a seguinte relação de FSS [146]:

$$
\operatorname{Re}\left[\beta_{1}^{0}(L)\right]=\beta_{c}^{0}+b L^{-1 / \nu} .
$$

Os resultados para a temperatura termodinâmica de transição $T_{c}^{0}=1 / \beta_{c}^{0}$ para vários valores de $\delta$ obtidos por essa relação estão mostrados na Tabela 3.3 Tais valores para

\footnotetext{
${ }^{16}$ Os valores para as raízes complexas no caso do modelo de Ising dipolar podem ser encontrados na Ref. [74] (Anexo VII).
} 


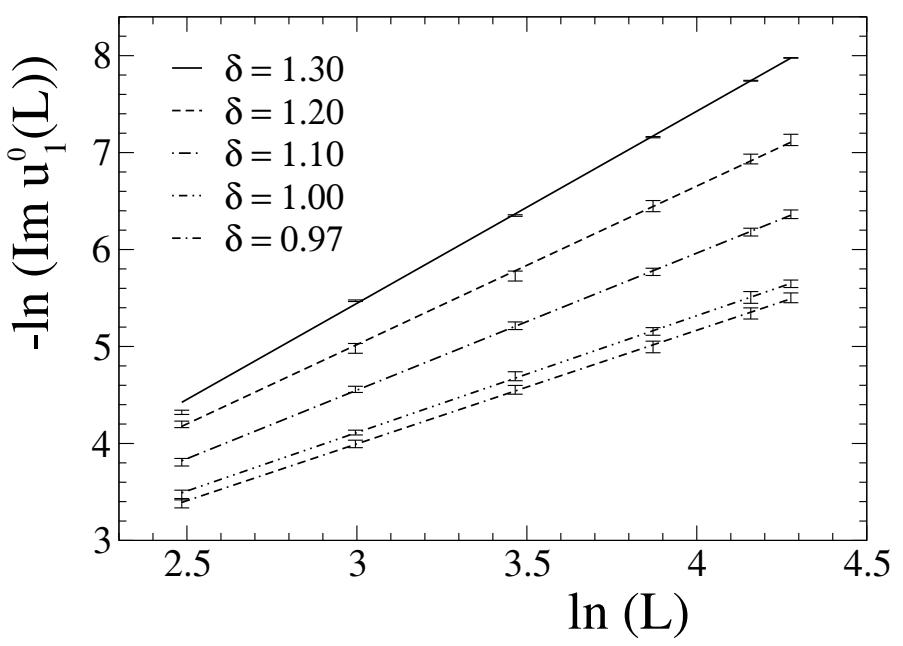

Figura 3.7: Regressões lineares utilizando a relação de escala de tamanho finito (FSS) 3.3 para a obtenção do expoente $d \nu$ para alguns valores do acoplamento $\delta$. Os pontos correspondem à parte imaginária dos zeros complexos da função de partição no plano da temperatura em função de tamanho linear da rede $L$. Figura retirada da Ref. [74].

$T_{c}^{0}$ também foram incluídos na Fig. 3.1 com o símbolo $(\bullet)$, onde também incluimos as temperaturas de transição apresentadas na Ref. [120] para $\delta$ entre 0,85 e 1,3. Notamos que esses valores são surpriendentemente bons quando comparados a $T_{c}^{0}$, considerando que eles foram obtidos com uma única rede de tamanho $L=48$. Na Tabela 3.3 também apresentamos os valores para os expoentes $d \nu$ (terceira coluna) obtidos pela relação 3.3. Podemos observar uma tendência para o valor $d \nu=1$ conforme aumentamos o valor de $\delta$. O valor $d \nu=1$ só é encontrado quando o sistema já está na fase $h=2$, para $\delta=1,3$.

É bem conhecido que, de acordo com a teoria de ponto fixo do grupo de renormalização para sistemas com $d$ dimensões numa geometria de bloco $L^{d}$, transições de fase de primeira ordem possuem um expoente crítico $d \nu=1[147,148]$. Dessa maneira, a análise dos valores para esse expoente crítico sugere clara consistência com uma linha de transição contínua para valores até $\delta=1,2$, excluindo o ponto tricrítico para a região $h=1$ do diagrama de fases. O caráter de primeira ordem para a transição faixas-tetragonal só é encontrado na simulação com $\delta=1,3$, na região onde o estado fundamental é representado por faixas de largura $h=2$. Isso sugere que a linha de transição contínua termine em $\delta=1,2585$ e torna-se de primeira 
ordem a partir desse ponto. É possível que as linhas da transição faixas-tetragonal estejam separadas por um ponto tricrítico para esse valor de $\delta$, levando em consideração que nesse ponto também ocorre a linha de separação entre as fases $h=1 \mathrm{e}$ $h=2$.

Para corroborar nossa análise de FSS via zeros da função de partição, também analisamos quantidades termodinâmicas como o calor específico,

$$
C_{v}(T)=\frac{1}{T^{2} N}\left(\left\langle E^{2}\right\rangle-\langle E\rangle^{2}\right),
$$

e a susceptibildade

$$
\chi\left(O_{h v}\right)=N\left(\left\langle O_{h v}^{2}\right\rangle-\left\langle O_{h v}\right\rangle^{2}\right)
$$

associada ao parâmetro de ordem orientacional [111]

$$
O_{h v}=\left|\frac{n_{v}-n_{h}}{n_{v}+n_{h}}\right|
$$

em um intervalo (contínuo) de temperaturas pela repesagem de dados, feita de acordo com a Eq. 2.5 associada a técnica de patching de histogramas. As quantidades $n_{h}$ e $n_{v}$ são o número de ligações horizontais e verticais entre spins vizinhos alinhados antiparalelamente, respectivamente. Esse parâmetro de ordem é +1 para configurações do tipo faixas como a do estado fundamental e zero para temperaturas altas quando a simetria orientacional é quebrada, como no caso da fase tetragonal.

Uma maneira comum de obter os expoentes críticos é através das seguintes relações de escala de tamanho finito para o máximo do calor específico

$$
\left.C_{v}\right|_{\max }\left(T_{c}(L), L\right) \propto L^{\alpha / \nu}
$$

e para o máximo da susceptibilidade,

$$
\chi_{\max }\left(T_{c}(L), L\right) \propto L^{\gamma / \nu}
$$

onde $T_{c}(L)$ é a temperatura crítica de tamanho finito. Identificamos $T_{c}^{C_{v}}$ and $T_{c}^{\chi}$ como as temperaturas onde ocorrem os máximos do calor específico $C_{v}(T, L)$ e da susceptibilidade $\chi(T, L)$, respectivamente. Determinamos as temperaturas $T_{c}^{C_{v}} \mathrm{e}$ $T_{c}^{\chi}$ a partir da Eq. 3.4 utilizando o expoente crítico $^{17} d \nu$ obtido pela relação de

\footnotetext{
${ }^{17}$ Onde $d$ corresponde a dimensão do sistema numa geometria de bloco com dimensões $L^{d}$.
} 


\begin{tabular}{ccccccc}
\hline \hline$\delta$ & $T_{c}^{0}$ & $d \nu$ & $T_{c}^{C_{v}}$ & $\alpha / \nu$ & $T_{c}^{\chi}$ & $\gamma / \nu$ \\
\hline 0,85 & $0,41189(53)$ & $1,837(76)$ & $0,41240(48)$ & $0,344(16)$ & $0,41200(51)$ & $1,519(19)$ \\
0,89 & $0,41168(53)$ & $1,807(70)$ & $0,41104(62)$ & $0,364(20)$ & $0,41100(48)$ & $1,531(27)$ \\
0,91 & $0,40887(50)$ & $1,817(68)$ & $0,40992(16)$ & $0,375(19)$ & $0,40964(17)$ & $1,538(22)$ \\
0,93 & $0,40681(19)$ & $1,779(61)$ & $0,40685(46)$ & $0,399(20)$ & $0,40682(45)$ & $1,561(24)$ \\
0,95 & $0,40435(17)$ & $1,741(53)$ & $0,40475(12)$ & $0,424(20)$ & $0,40475(18)$ & $1,552(24)$ \\
0,97 & $0,40108(40)$ & $1,706(46)$ & $0,40124(45)$ & $0,461(19)$ & $0,40130(31)$ & $1,575(20)$ \\
1,00 & $0,39499(37)$ & $1,659(37)$ & $0,39521(33)$ & $0,522(17)$ & $0,39527(29)$ & $1,590(23)$ \\
1,10 & $0,36429(29)$ & $1,415(25)$ & $0,36441(19)$ & $0,888(21)$ & $0,36456(15)$ & $1,736(21)$ \\
1,20 & $0,31102(32)$ & $1,223(21)$ & $0,31126(65)$ & $1,496(28)$ & $0,31073(40)$ & $1,987(29)$ \\
1,30 & $0,32929(72)$ & $1,0093(28)$ & $0,32892(15)$ & $2,0183(66)$ & $0,32885(14)$ & $2,3193(82)$ \\
\hline \hline
\end{tabular}

Tabela 3.3: Temperaturas de transição e expoentes críticos para vários valores de $\delta$ obtidos pelos zeros complexos da função de partição, calor específico $C_{v}$ e susceptibilidade do parâmetro de ordem $\chi\left(O_{h v}\right)$. Dados retirados da Ref. [74] para o modelo de Ising dipolar 2D.

hiperescala $\alpha=2-d \nu$. Admitindo o valor $d \nu=1$ para transição de fase de primeira ordem, teremos $\alpha=1$ e $\gamma=1$, ou seja, uma dependência das quantidades termodinâmicas $C_{v}$ e $\chi$ com o volume ${ }^{18} L^{d}$ será observada.

Incluimos os valores encontrados para as temperaturas termodinâmicas de transição e os respectivos expoentes críticos para os máximos de $C_{v}$ e $\chi$ na Tabela 3.3. Como vemos, todos os valores para a temperatura de transição obtidos pelas curvas de $C_{v}$ e $\chi$ estão em concordância com aqueles obtidos via zeros da função de partição. Assim como as conclusões feitas com base nas análise dos expoentes $d \nu$ obtidos via zeros complexos, o expoente $\alpha / \nu$ na quinta coluna claramente exclui qualquer possibilidade de ocorrência de uma transição de primeira ordem na região $h=1$, enquanto sugere fortemente essa possibilidade para $\delta=1,30$. O erro estatístico exclui o valor $\alpha / \nu=2$ para $\delta=1,30$, porém pode haver algum viés sistemático ${ }^{19}$ na análise [74]. Os resultados para a susceptibilidade são menos favoráveis para essa mesma conclusão, principalmente com relação às transições em $\delta=1,2$ e 1,3. Novamente os resultados podem precisar de correções nas relações de FSS, esperadas no caso de transições de primeira ordem.

\footnotetext{
${ }^{18}$ Esse fato tem sido suportado em diversos estudos de Monte Carlo [146, 140].

${ }^{19}$ Por exemplo, correções logarítimicas que não foram levadas em consideração.
} 


\subsection{Cenário II: Transições de fase faixas-nemática e nemática-tetragonal}

O Cenário II, o qual corresponde a presença de duas transições de fase (vide Fig. 3.3), pode ser observado num intervalo estreito na temperatura e para certos valores do acoplamento $\delta$ próximos às transições entre estados de faixas [72]. Em particular, incluimos nessa seção dois estudos visando a determinação da termoestatística microcanônica para o acoplamento $\delta=2$, que é uma região onde já havíamos explorado num trabalho utilizando simulações de Metropolis usuais [80]. Na primeira parte apresentamos nosso estudo ${ }^{20}$ envolvendo esforços para determinar a densidade de estados via algoritmo MUCA, enquanto na segunda parte mostramos os resultados obtidos a partir de simulações canônicas implementadas com o método de troca entre réplicas e associadas à análise ST-WHAM.

\subsubsection{Metaestabilidade e aprisionamento}

O estudo apresentado nessa subseção envolve nossas primeiras tentativas de conseguir uma amostragem eficiente para grandes tamanhos de rede no modelo de Ising dipolar 2D utilizando o algoritmo MUCA. Basicamente trata-se de um estudo para obtenção dos pesos de amostragem via relações de recorrência (vide subsecão 2.3.1) para a região onde largura das faixas do estado fundamental é $h=2$ e tendo o acoplamento $\delta=2$.

Todas as simulações apresentadas aqui foram efetuadas escolhendo ${ }^{21}$ a energia do estado fundamental $E_{0}=-1,22 L^{2}$ e $M_{E}=2 L^{2}$ para discretizar as energias de acordo como descrito na subsecão 2.3. Primeiro analisamos a convergência dos parâmetros multicanônicos utilizando o protocolo (i) para tamanhos de rede $L=32$, 48 e 56, utilizando estatísticas iguais $n_{s}=5 \times 10^{4}$ varreduras por passo de recorrência.

Primeiramente, apresentamos os resultados com respeito a obtenção dos parâmetros multicanônicos para $L=32$. A Fig. 3.8 mostra o histograma $H_{m u}^{n-1}(E)$ e o parâmetro multicanônico $b^{n}(E)$ para $L=32$ e $\epsilon=2$ em passos de recorrência diferentes. A Fig. 3.8(a) mostra que o histograma não contém medidas apreciáveis para energias $E / N \lesssim-1,13$, o que é bastante típico para passos de recorrência

\footnotetext{
${ }^{20}$ Esse trabalho foi publicado e corresponde à Ref. [75], disponível no Anexo IV.

${ }^{21}$ Lembramos que esse valor deve ser escolhido de acordo com o acoplamento $\delta$.
} 
até $n \sim 100$. Dessa maneira, a determinação de $b(E)$ apresenta um comportamento ruidoso para energias $E / N \lesssim-1,13$. Foi preciso atualizar os parâmetros multicanônicos até $n=400$ passos de recorrência para observar alguma melhora na estimativa de $b(E)$ ao redor dessa energia, assim como mostrado na Fig. 3.8(d). No entanto, mesmo com essa melhora, histogramas para os quais o sistema fica em apenas uma região do espaço das energias, tal como o mostrado na Fig. 3.8(c), são bastante recorrentes nos passos de recorrência posteriores a $n=400$.

Como podemos observar na Figura 3.8(d), a curva calórica $b(E)$ por $E / N$ para $L=32$ apresenta na região próxima à energia $E / N \sim-1,13$ um formato de $\mathrm{S}$. Conforme expresso pela Eq. 2.14, divergências no calor específico microcanônico são encontradas para $d b(E) / d E=0$. Nesse caso, duas divergências são observadas no
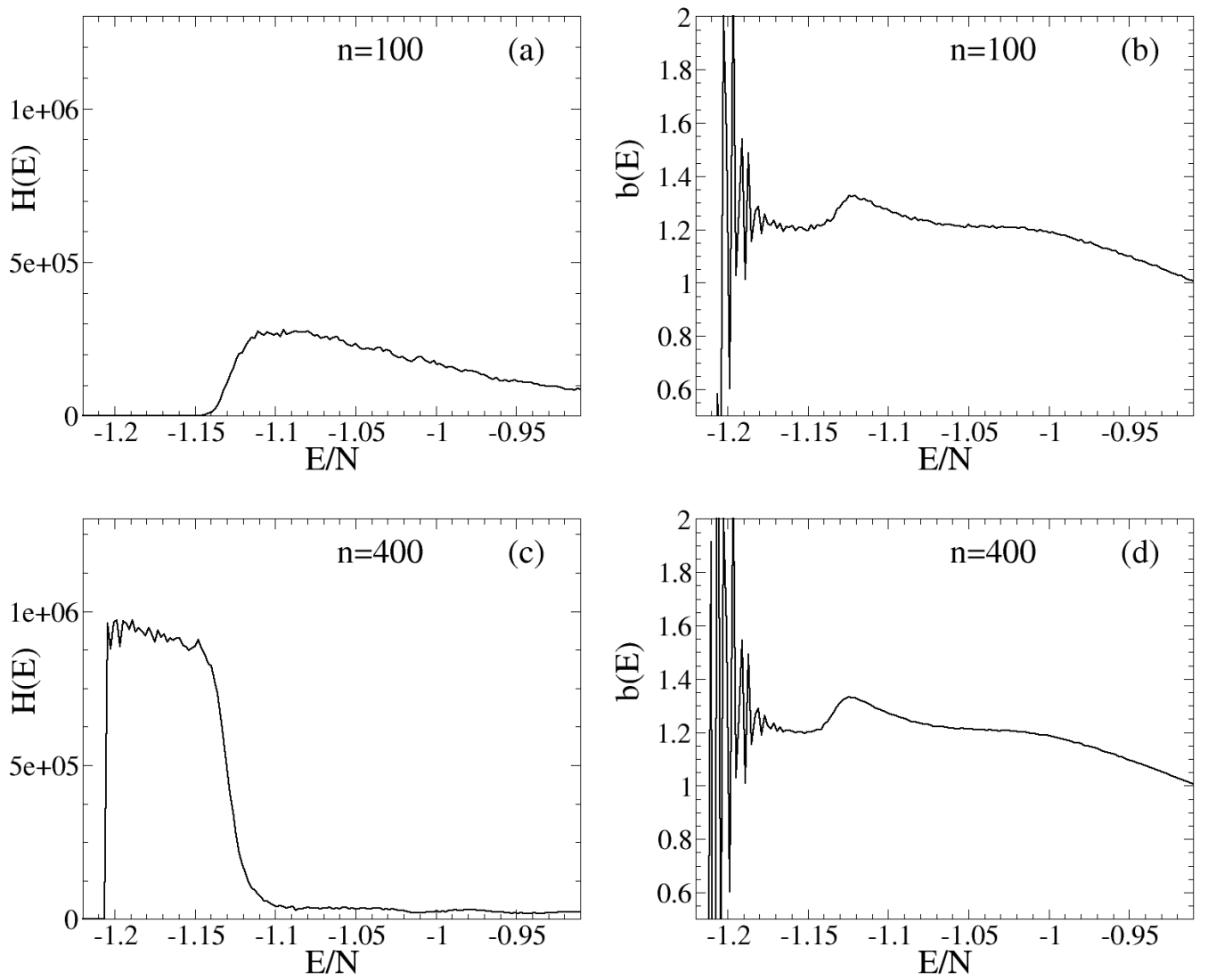

Figura 3.8: Comportamento de $H_{m u}^{n-1}(E)$ e $b^{n}(E)$ para $L=32, \epsilon=2$ e $n_{s}=5 \times 10^{4}$ entradas no histograma em dois estágios diferentes do procedimento de recorrência: $n=100$ nas figuras (a) e (b); $n=400$ nas figuras (c) e (d). Figura retirada da Ref. [75] para o modelo de Ising dipolar 2D. 
calor específico $c(E)$, uma para a energia $E / N \sim-1$, 12 e outra para a energia mais baixa $E / N \sim-1,15$. Pela Eq. 2.14, também conclui-se que o calor específico $c(E)$ é negativo entre essas energias, já que $d b(E) / d E>0$. Na Ref. [80] identificamos o máximo do calor específico canônico em $\langle E / N>\sim-1,13$, que corresponde à temperatura $T \sim 0,7905(3)$. Dessa maneira, é possível concluir que a estimativa canônica para a energia de transição encontra-se em um valor intermediário em relação as estimativas microcanônicas das energias onde ocorrem as divergências em $c(E)$. Além disso, o valor $T^{-1} \sim 1,265$ corresponde à temperatura da transição, a qual pode ser obtida via construção de Maxwell na curva $b(E)$.

A Fig. 3.8(c) mostra que o sistema foi aprisionado na região onde as configurações amostradas possuem energia mais baixas, a qual correspondente à fase de faixas. Percebemos que, mesmo para essa rede de tamanho $L=32$, existe uma supressão da amostragem entre as energias $E / N \sim-1,15$ e $-1,12$, o que dificulta a obtenção dos pesos multicanônicos. Tal supressão ocorre justamente na região onde $c(E)<0$ e é causada pela presença de uma forte barreira de energia livre correspondente à transição de fase faixas-nemática.

Na Fig. 3.9 apresentamos resultados para a rede de tamanho $L=48$. Aqui, nós utilizamos uma discretização menor $(\epsilon=1)$ com a intenção de obter estimativas mais precisas para a derivada de $b(E)$. As Figs. 3.9(a) e 3.9(b) mostram resultados após $n=150$ passos de recorrência. Note que o parâmetro $b(E)$ ainda é bastante ruidoso para esse número de passos de recorrência, embora a curva $b(E)$ já esteja razoavelmente definida. Nesse estágio, o procedimento de recorrência produz configurações com energias principalmente na fase de faixas. Em geral, a simulação não consegue explorar todo espaço de energias para os passos de recorrência posteriores, tal como podemos observar nas Figs. 3.9(a), 3.9(c) e 3.9(e). A Fig. 3.9(f) mostra que nós precisamos aumentar o número de atualizações até $n=550$ passos de recorrência para diminuir o ruído em $b(E)$ na região de energia onde o pico aparece. Note que, nesse caso, duas regiões em formato de S podem ser visualizadas na curva $b(E)$, uma centrada na energia $E / N \sim-1,16$ e a outra na energia $E / N \sim-1,06$. Os pontos onde $d b(E) / d E=0$ correspondem aos picos, localizados em $E / N=-1,155$ e $E / N \sim-1,045$, e aos vales, localizados em $E / N \sim-1,17$ e $E / N \sim-1,08$. 

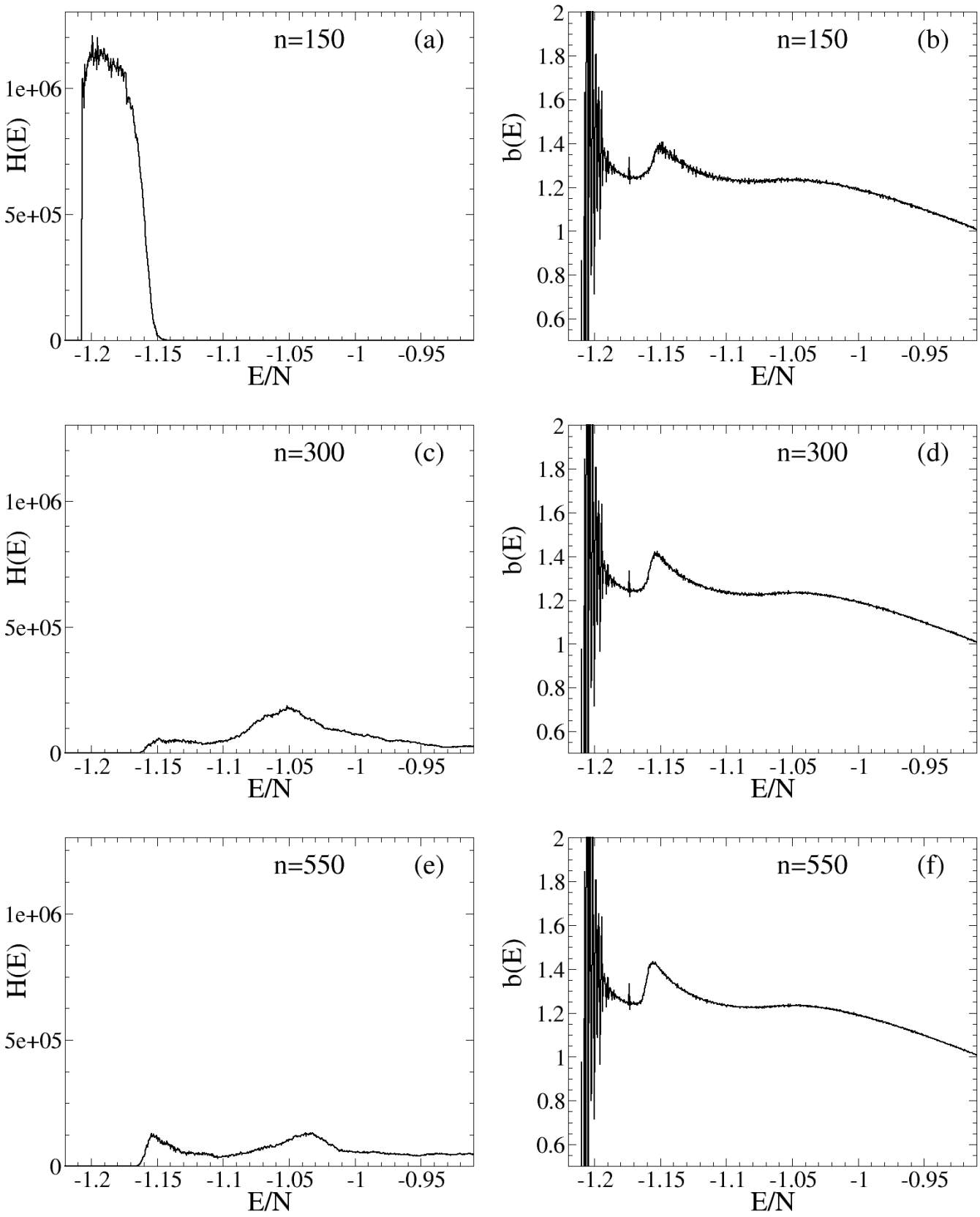

Figura 3.9: Comportamento de $H_{m u}^{n-1}(E)$ e $b^{n}(E)$ para $L=48, \epsilon=1$ e $n_{s}=5 \times 10^{4}$ entradas no histograma em três estágios diferentes do procedimento de recorrência: $n=150$ nas figuras (a) e (b); $n=300$ nas figuras (c) e (d); $n=550$ nas figuras (c) e (d). Figura retirada da Ref. [75] para o modelo de Ising dipolar 2D.

O aparecimento de uma nova transição é um forte efeito de tamanho finito ${ }^{22}$, o qual também foi verificado por nós via simulações canônicas com o algoritmo de

\footnotetext{
${ }^{22} \mathrm{Na}$ Ref. [80] mostramos que apenas para redes de tamanho superior à $L=48$ é possível observar a fenomenologia de duas transições (cenário II).
} 
Metropolis [80]. As temperaturas canônicas onde ocorrem os máximos em $C_{v}$ são $T_{1}=0,7785(7)$ para a transição faixa-nemática e $T_{2}=0,8132(2)$ para a transição nemática-tetragonal, as quais correspondem às seguintes estimativas das energias média de transição $\langle E / N>\sim-1,16$ e $<E / N>\sim-1,06$, respectivamente. Note que os valores $T_{1}^{-1}=1,28$ e $T_{2}^{-1}=1,23$ estão em concordância com estimativas grosseiras para as construções de Maxwell na curva $b(E)$ mostrada na Fig. 3.9(f).

A partir da Fig. 3.9(e), podemos inferir porque as estimativas de $b(E)$ ainda estão ruidosas para energias próximas de $E / N=-1,16$, mesmo após $n=550$ passos de recorrência. Observamos que, assim como no caso anterior para a rede menor, os histogramas para $L=48$ não contém energias amostradas que poderiam resultar em tunelamentos satisfatórios entre as fases. Mesmo com uma estimativa razoável para os parâmetros multicanônicos, os eventos de tunelamento entre as fases são suprimidos em razão da presença de barreiras de energia livre relacionadas às transições de fase faixas-nemática e nemática-tetragonal.

Para $L=56$ a situação foi ainda pior (dados não mostrados) pois, mesmo após $n=800$ passos de atualização, utilizando o protocolo (i) como nos casos acima, o procedimento de recorrência não conseguiu amostrar o intervalo de energias $E / N \lesssim$ $-1,17$ e até o $999^{0}$ passo de recorrência não houve nenhuma melhora na obtenção dos pesos.

Visando explorar uma alternativa que considerasse um número maior de varreduras $n_{s}$ entre as atualizações dos parâmetros multicanônicos, realizamos um estudo utilizando o protocolo (iv), o qual consiste em não zerar o histograma e não atualizar os parâmetros multicanônicos se o sistema não tiver realizado viagens de ida e volta entre as energias extremas (vide subseção 2.3.3). Os resultados para a energia mínima por spin $E_{\min } / N$ em função do número de varreduras $N_{\text {var }}$ utilizado no procedimento de recorrência são apresentados na Tabela 3.4. Incluimos também resultados para o algoritmo entrópico. Diversos tamanho de rede $L$ foram utilizados considerando o acoplamento $\delta=2$. Os valores marcados com asterisco representam procedimentos bem sucedidos em relação a encontrar a energia do estado fundamental. Vemos que, utilizando o protocolo (iv), o procedimento de recorrência não consegue chegar às energias do estado fundamental mesmo para redes pequenas, $L=24$ no caso do algoritmo ES e $L=32$ para o MUCA. Também apresentamos na 


\begin{tabular}{c|ccc|ccc}
\hline \hline & \multicolumn{3}{|c|}{$\mathrm{ES}$} & \multicolumn{3}{c}{ MUCA } \\
\hline \hline$L$ & $N_{\text {var }}\left(10^{6}\right)$ & $E_{\min } / N$ & $\Delta N_{\text {var }}\left(10^{6}\right)$ & $N_{\text {var }}\left(10^{6}\right)$ & $E_{\min } / N$ & $\Delta N_{\text {var }}\left(10^{6}\right)$ \\
\hline 16 & 0,08 & $-1,2083^{*}$ & 0 & 0,33 & $-1,2083^{*}$ & 0 \\
24 & 0,64 & $-1,1922$ & 25,05 & 0,63 & $-1,2095^{*}$ & 0 \\
32 & 1,12 & $-1,1800$ & 11,49 & 1,24 & $-1,1780$ & 32,34 \\
40 & 7,17 & $-1,1900$ & 8,23 & 4,43 & $-1,1881$ & 8,48 \\
48 & 6,81 & $-1,1866$ & 3,96 & 8,66 & $-1,1931$ & 8,04 \\
\hline \hline
\end{tabular}

Tabela 3.4: Estimativa do número de varreduras total $N_{\text {var }}$ (acumulado) para obtenção da densidade de estados até a energia mínimaatingida $E_{\min } / N$. O valor de $\Delta N_{\text {var }}$ fornece o número de varreduras contabilizado entre o sistema ter alcançado $E_{\min } / N$ e nós termos encerrado (arbitrariamente) a simulação, também chamado tempo de estagnação. Os valores marcados com * correspondem aos valores do estado fundamental. Simulações feitas para $\delta=2, \varepsilon=1$ e diferentes tamanhos de rede $L$ utilizando o protocolo (iv) para ambos algoritmos: ES e MUCA.

Tabela 3.4 o número excedente de varreduras $\Delta N_{\text {var }}$ entre o procedimento de recorrência ter ficado estagnado em uma dada energia e as simulações serem abortadas arbitrariamente. Por exemplo, no caso da rede de tamanho $L=32$ e o algoritmo MUCA, após o sistema ter chegado na energia $E / N=-1,1780$ (que não é a energia do estado fundamental), foram realizadas $32,34 \times 10^{6}$ varreduras e mesmo assim não houve nenhuma diminuição na energia mínima alcançada ou alguma melhora nos pesos, então o procedimento de recorrência foi abortado.

Outro teste que fizemos foi no sentido de avaliar a influência da discretização na energia $\epsilon$ na obtenção dos parâmetros multicanônicos para a rede de tamanho $L=48$, também na região $\delta=2$. A Fig. 3.10 mostra resultados para diferentes simulações realizadas com o número de varreduras $n_{s}=2 \times 10^{4}$ por passo de recorrência utilizando várias discretizações. Além das estimativas para $b(E)$ serem ruidosas, vemos uma forte dependência no comportamento de $b(E)$ para os diferentes valores de $\epsilon$. Infelizmente, não há uma tendência definitiva na formação do pico em função de $\epsilon$, sendo que um valor intermediário de $\epsilon=1$ produz o primeiro pico (à direita) em $E / N \sim-1,14$. 

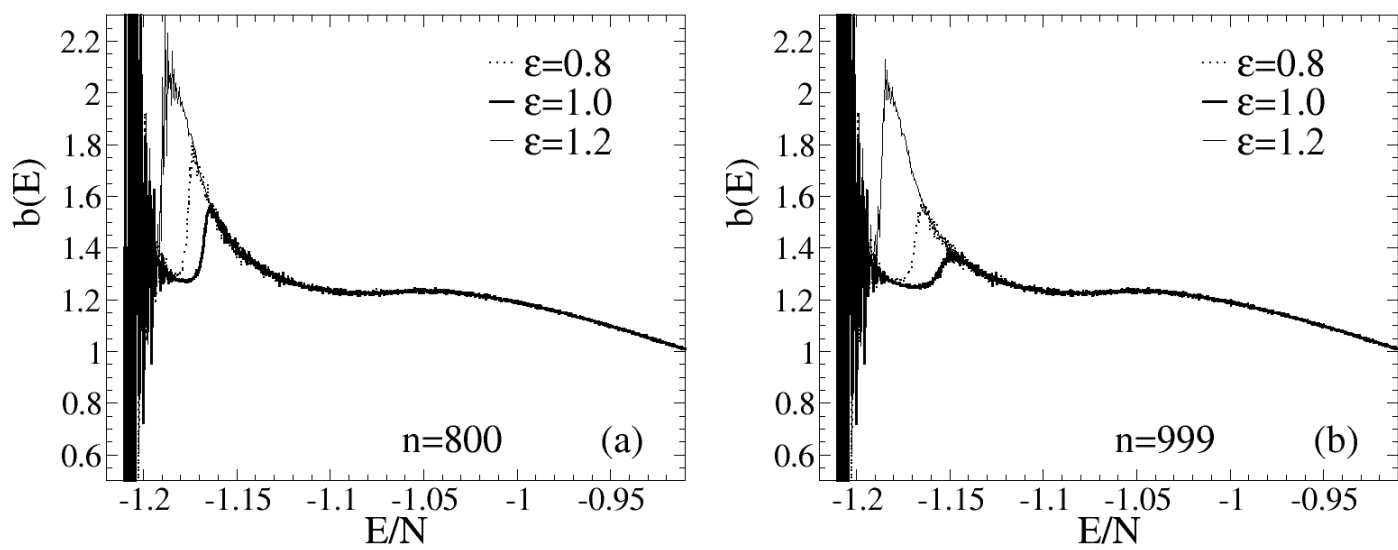

Figura 3.10: Convergência do parâmetro multicanônico $b(E)$ para $L=48$ e $n_{s}=$ $2 \times 10^{4}$ entradas no histograma para diferentes tamanhos de bin $\epsilon$. A Figura (a) mostra resultados para $n=800$ passos de recorrência, e (b) para $n=999$. Figura retirada da Ref. [75].

\subsubsection{Termoestatística microcanônica}

Como vimos na subseção anterior, a presença de uma forte barreira de energia livre influi na presença de uma região com estados metaestáveis com calor específico microcanônico negativo para o acoplamento $\delta=2$. Nessa região a amostragem de configurações ficou bastante prejudicada e frustrou todas as nossas tentativas de obter uma densidade de estados utilizando os algoritmos de amostragem uniforme, mesmo para redes pequenas.

Os fortes efeitos de tamanho finito observados nas curvas calóricas para o modelo de Ising dipolar 2D indicam a necessidade de um algoritmo eficiente para amostrar configurações em grandes tamanhos de rede. Na subseção 2.5.3, mostramos que o método ST-WHAM aplicado à histogramas canônicos obteve resultados equivalentes ao algoritmo MUCA em relação à termoestatística microcanônica na região $\delta=2$ para uma rede de tamanho $L=32$. Além disso, uma das vantagens do método STWHAM em relação ao algoritmo multicanônico é que o tamanho da discretização na energia pode ser alterado para qualquer valor após a produção de dados. Dessa maneira, resolvemos realizar um estudo para avaliar o método ST-WHAM para obter a termoestatística canônica nessa região considerando uma rede de tamanho $L=72$, o qual é apresentado a seguir. Para esse estudo, realizamos duas simulações canônicas utilizando o método de troca entre réplicas (REM), tal como descrito na 
subseção 2.4 .

Primeiramente, utilizamos o método descrito na subseção 2.4 .2 para obter o conjunto de temperaturas. Por uma razão de eficiência computacional ${ }^{23}$, incluimos $M=12$ réplicas de um conjunto maior obtido por 5 realizações considerando $p_{a c}=$ 0,30. Assim, obtivemos o conjunto $\left\{T_{\alpha}\right\}$ utilizado na primeira simulação defindo pelas seguintes temperaturas:

$$
\begin{gathered}
\left\{T_{1}=0,723 ; T_{2}=0,751 ; T_{3}=0,773 ; T_{4}=0,788 ; T_{5}=0,798 ; T_{6}=0,804 ;\right. \\
\left.T_{7}=0,811 ; T_{8}=0,818 ; T_{9}=0,830 ; T_{10}=0,844 ; T_{11}=0,861 ; T_{12}=0,879\right\} .
\end{gathered}
$$

Para cada temperatura foram realizadas $6 \times 10^{6}$ varreduras após o descarte de $10^{6}$ varreduras para termalização. Tentativas de trocas entre réplicas foram feitas a cada $n_{s}=4000$ varreduras. Apresentamos na Fig. 3.11(a) os histogramas obtidos para essa primeira simulação em cada uma das temperaturas. Utilizando uma discretização $\epsilon=1$ calculamos a estimativa para a temperatura estatística via STWHAM, a qual é mostrada na Fig. 3.11(b). As linhas pontilhadas representam o inverso das temperaturas simuladas $\beta_{\alpha}=1 / T_{\alpha}$. Como podemos perceber, duas regiões em forma de $\mathrm{S}$ estão presentes em $b(E)$, as quais correspondem às transições faixas-nemática $(E / N \sim-1,16)$ e nemática-tetragonal $(E / N \sim-1,11)$, tal como já havíamos observado para a rede de tamanho $L=48$ (vide Fig. 3.9(f)). Notamos que a utilização do protocolo de obtenção de temperaturas fornece um conjunto condensado de temperaturas na região de transição nemática-tetragonal porém mais espaçado na transição faixas-nemática. Isso reflete diretamente nos histogramas produzidos, com uma região de energias próximas à $E / N \sim-1,16$ onde observamos uma ausência significativa de configurações amostradas, a qual coincide com a região onde $d b(E) / d E>0$.

A Fig. 3.11(b) fornece fortes indícios de que ambas as transições, faixas-nemática e nemática-tetragonal, sejam transições de fase de primeira ordem. Contudo, por causa da ausência de configurações amostradas na região de energias próximas a $E / N \sim-1,16$, realizamos uma nova simulação, agora dedicada à região de transição

\footnotetext{
${ }^{23} \mathrm{O}$ código em paralelo foi escrito em Fortran90 associado ao OpenMP. Consideramos eficientes simulações que utilizam o número de réplicas $M$ múltiplo de 4, 6 ou 8, em razão do número de núcleos que existem nos computadores atuais.
} 

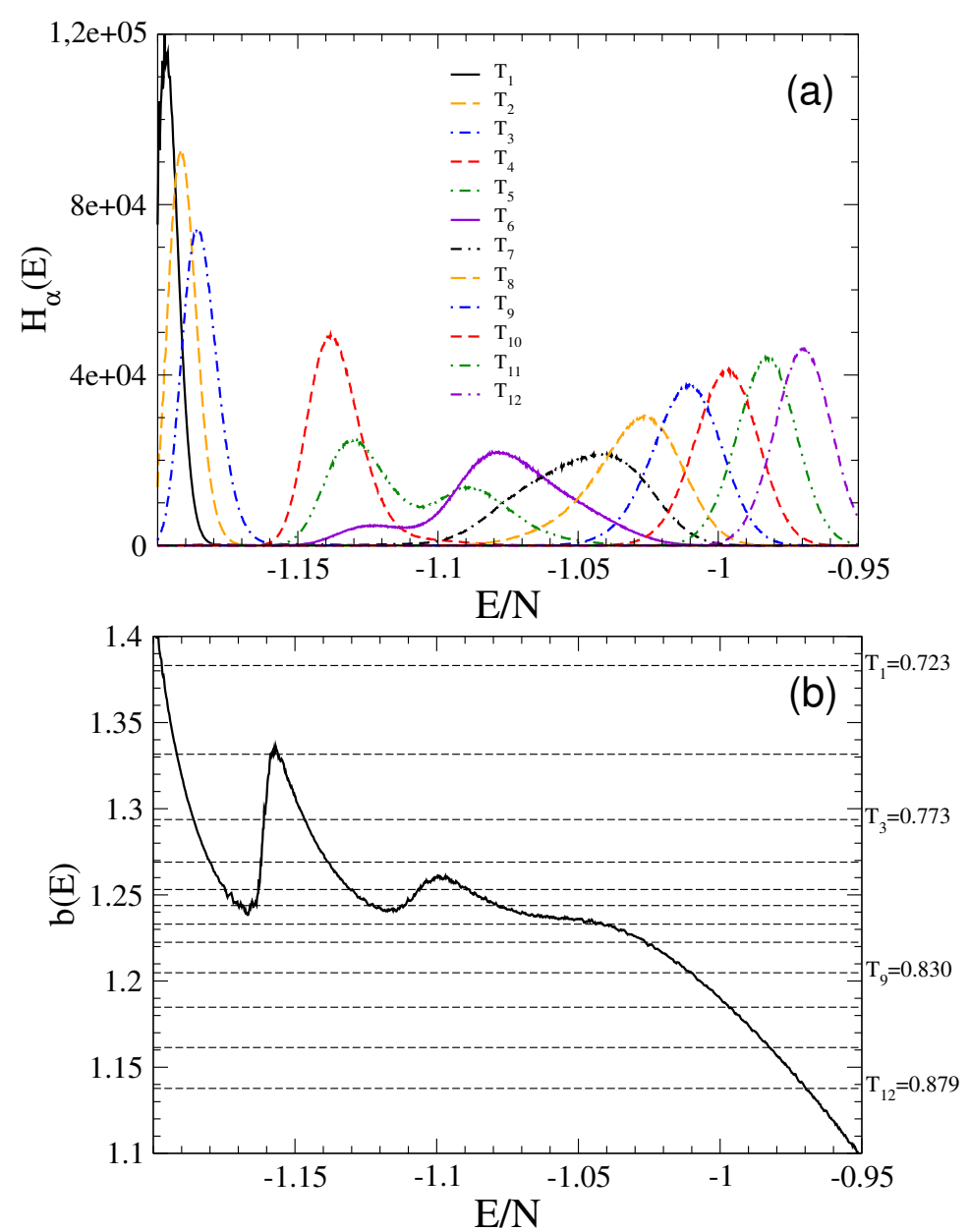

Figura 3.11: Termoestatística microcanônica para o modelo de Ising dipolar 2D para acoplamento $\delta=2$ para uma rede de tamanho $L=72$. Região do cenário II $(h=2)$. (a) Histogramas $H_{\alpha}$ obtidos via simulação REM para as 12 réplicas utilizando o conjunto de temperaturas definido em 3.10); (b) curva calórica $b(E)$ obtida via ST-WHAM em função da energia por volume $E / N$.

faixas-nemática. Para isso utilizamos um conjunto ad hoc baseado numa progressão aritmética no inverso da temperatura $\beta_{\alpha}$. Utilizando $M=6$ réplicas, definimos o conjunto de temperaturas para essa segunda simulação como:

$$
\left\{T_{1}=0,7634 ; T_{2}=0,7752 ; T_{3}=0,7782 ; T_{4}=0,7813 ; T_{5}=0,7937 ; T_{6}=0,8000\right\} .
$$

Nessa nova simulação, amostramos $1,6 \times 10^{7}$ configurações após o descarte de $10^{6}$ varreduras para cada temperatura, também utilizando $n_{s}=4000$ varreduras. Na Fig. 3.12(a) mostramos os histogramas produzidos para cada uma das temperaturas. 

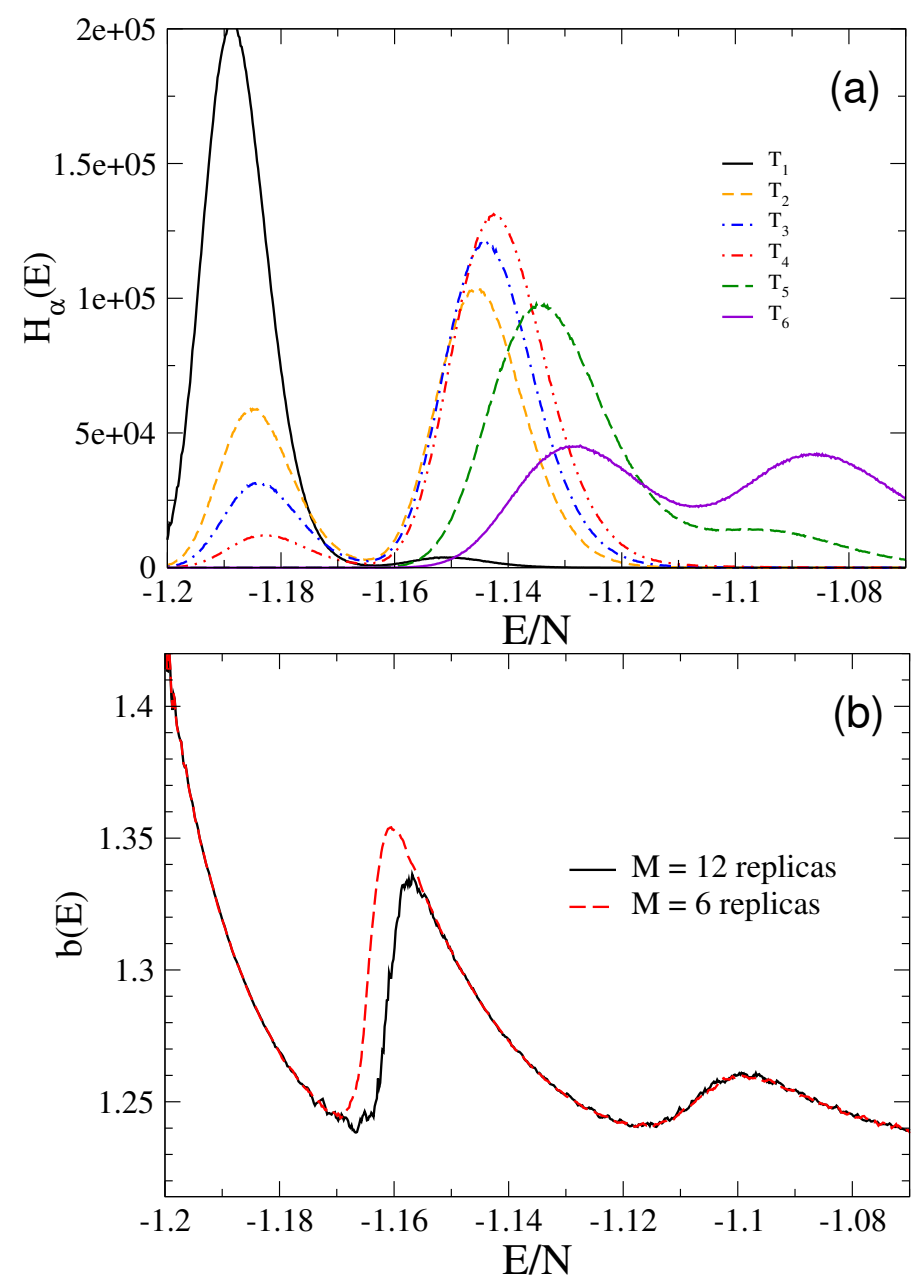

Figura 3.12: Comparação da termoestatística microcanônica para o modelo de Ising dipolar 2D para acoplamento $\delta=2$ para uma rede de tamanho $L=72$ para duas simulações REM. (a) Histogramas $H_{\alpha}$ obtidos via simulação REM para as 6 réplicas utilizando o conjunto de temperaturas definido em 3.11); (b) curvas calóricas $b(E)$ obtidas via ST-WHAM em função da energia por volume $E / N$. A linha preta contínua representa a curva obtida a partir dos dados da simulação REM utilizando 12 temperaturas, enquanto que a linha vermelha tracejada indica a simulação feita com 6 temperaturas.

Notamos que, apesar de também haver uma diminuição nas configurações amostradas em torno da transição faixas-nemática, é possível observar que os histogramas amostraram ambas as fases. O histograma para a temperatura $T_{6}=0,8$ possui picos com alturas praticamente iguais, o que reflete o fato dessa temperatura estar bastante próxima da temperatura de transição entre as fases nemática-tetragonal obtida pelas simulações de Metropolis independentes [80]. As curvas calóricas $b(E)$ 
produzidas por esses histogramas são mostrados na Fig. 3.12(b), onde também incluimos o resultado da primeira simulação para comparação. É interessante notar que, para a transição nemática-tetragonal (em formato de $\mathrm{S}$ na região $E / N \sim-1,1$ ), a nova simulação fornece uma curva calórica equivalentes à obtida pela primeira simulação. Já para a região da transição faixas-nemática, a nova simulação alterou significativamente a curva $b(E)$. O formato de $\mathrm{S}$, no entanto, foi preservado para essa região.

Considerando o resultado da nova simulação, a evidência de que ambas transições, faixas-nemática e nemática-tetragonal, sejam de primeira ordem é mantida. A outra hipótese levantada na literatura seria que tais transições seriam do tipo Kosterlitz-Thouless (KT). O modelo que apresenta o paradigma de transição do tipo KT é o modelo XY bidimensional. Como não encontramos na literatura nenhum trabalho que incluisse a curva calórica para modelo XY na região de transição KT, realizamos tal estudo, que é apresentado no Apêndice A. Mostramos que, diferentemente da curvas calóricas que apresentam formato de S mostradas na Fig. 3.12(b), a curva calórica para o modelo XY é suave e não apresenta nenhum indício de regiões onde $d b(E) / d E>0$ (vide Fig. A.1). Assim, excluimos a possibilidade de transição do tipo KT para o modelo de Ising dipolar 2D na região $\delta=2$. 


\section{Capítulo}

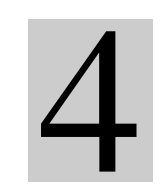

\section{SIMULAÇÕES NUMÉRICAS DE PROTEÍNAS DESCRITAS POR UM MODELO MÍNIMO}

Neste capítulo apresentamos outra importante aplicação dos métodos estudados e desenvolvidos nesta Tese. Em particular, empregamos a análise via ST-WHAMMUCA para obter a termoestatística microcanôcanica a partir de simulações canônicas em diferentes temperaturas que utilizam o método de troca entre réplicas. Trata-se de um estudo realizado em colaboração ${ }^{1}$ e envolve a determinação da estatística microcanônica para descrever os processos de enovelamento de cadeias polipeptídicas, com conhecida propensidade à formação de agregados.

\subsection{Introdução}

Diversas doenças, incluindo as doenças de Alzheimer [149, 150] (AD), de Huntington [151, 152] e de Parkinson [153], são amplamente conhecidas como resultando de processos neurodegenerativos causados pela formação de agregados fibrilares de proteínas. Tais doenças são também chamadas de proteinopatias e ocorrem principalmente em estruturas celulares [154, 155, 156, 157, 158].

Trabalhos recentes sugerem que esses agregados fibrilares são estados termodinâmicos mais estáveis do que o estado nativo [159]. Assim, em muitos casos, o estado nativo seria apenas um estado metaestável das proteínas [160]. Uma vez que tais

\footnotetext{
${ }^{1}$ Esse estudo foi publicado em forma de artigo científico, o qual pode ser encontrado no Anexo VIII.
} 
estruturas fibrilares são formadas, dificilmente as proteínas voltam aos seus estados nativos, o que leva à progressão das doenças causadas em decorrência da formação de agregados.

A formação desses agregados parece ser uma característica comum às cadeias polipeptídicas, já que eles ocorrem mesmo nos casos onde não existe homologia estrutural ou similaridade entre as cadeias das proteínas [161, 155, 157]. Dessa maneira, é plausível argumentar que, para uma caracterização termodinâmica da transição de fase entre estruturas estendidas (desnaturadas) e enoveladas em proteínas com conhecida propensidade a agregarem-se, as propriedades da sua sequência primária desempenhem um papel relevantes. Nesse caso, o uso de potenciais interatômicos detalhados em experimentos computacionais parece desnecessário. Por outro lado, a hidrofobicidade das cadeias laterais correlaciona-se com a taxa de agregação [162, 163], sendo portanto um ingrediente físico-químico bastante importante na nucleação dos agregados fibrilares. Estudos iniciais das propriedades gerais do processo de agregação têm sido realizados com ajuda de modelos simplificados [164]. Aqui, empregamos um modelo mínimo fora da rede [165], também conhecido como modelo AB, para descrever as cadeias polipeptídicas. Para esse modelo, o alfabeto de 20 aminoácidos existentes na natureza é substituito por monômeros de dois tipos, hidrofóbicos (A) ou polares (B). Assim, nossa investigação das propriedades termodinâmicas dessas cadeias considera interações não ligantes as quais são descritas somente pelo caráter hidrofóbico-polar desses monômeros. É importante notar que esse modelo reproduz características complexas apresentadas por proteínas reais $[50,166]$ e tem sido aplicado em estudos para o entendimento do fenômeno de agregação [51, 167].

Estudos mais gerais sobre o fenômeno de agregação mostram que mudanças na taxa de agregação podem depender de vários fatores, agrupados em intrínsecos e extrínsecos [162, 168]. Fatores extrínsecos incluem propriedades físico-químicas relacionadas à vizinhança do polipeptídeo, enquanto que fatores intrínsecos estão associados às características das cadeias polipeptítidicas. Fatores intrínsecos tais como padrões de hidrofobicidade nas sequências primárias, a propensidade para formar estruturas de hélices $\alpha$ e fitas $\beta$ e carga líquida têm demonstrado ter influência na taxa de agregação. A propensidade das cadeias em alterar suas estruturas secun- 
dárias, causando grandes mudanças conformacionais, também pode ser considerado um fator intríseco. Existem fortes evidências de que estados intermediários, onde as proteínas encontram-se em estados parcialmente desenovelados ${ }^{2}$, ou com conformações bastante desestruturadas, têm um papel importante na formação das fibras amilóides [169, 170, 171, 172]. A desestabilização conformacional parece ser um pressuposto natural ${ }^{3}$ para que as cadeias polipetídicas consigam assumir novas conformações, mesmo em condições fisiológicas, as quais culminariam na formação de agregados [175]. Além disso, resultados para mutações da proteína $\beta$-amilóide $(\mathrm{A} \beta)$ mostram que as variantes menos estáveis têm uma cinética de nucleação mais rápida na formação de agregados fibrilares $[176,177]$. Dessa maneira, principalmente com a eventual presença de estados metaestáveis, enfatizamos que as propriedades termodinâmicas de equilíbrio podem ser melhor analisadas no ensemble microcanônico, uma vez que ela fornece a caracterização correta em termos da entropia [32] e permite uma maneira simples de determinar as barreiras de energia livre (veja subseção 2.5.3).

\subsection{Objetivos}

Levando em consideração que: a) o fenômeno de agregação é um fenômeno comum às cadeias polipeptídicas e dessa maneira os detalhes específicos dessas cadeias não são tão importantes; e b) estados intermediários podem desempenhar um papel importante no início da formação de fibrilas, buscamos realizar uma análise comparativa dos aspectos da termoestatística microcanônica que caracterizam a transição de enovelamento ${ }^{4}$ para sistemas representados pelo modelo AB. Esperamos que o conhecimento do processo de enovelamento em proteínas com conhecida propensidade à formação de agregados forneça indícios sobre possíveis causas da formação de agregados. Para isso comparamos as propriedades de heteropolímeros cuja sequência de monômeros AB foi inspirada biologicamente em quatro cadeias polipeptídicas, as quais, por sua vez, possuem conhecida propensidade a formação de agregados:

\footnotetext{
${ }^{2}$ Por exemplo temos o peptídeo A $\beta$ como no caso da doença de Alzheimer.

${ }^{3}$ Vale notar que conformações não estruturadas ou desestabilizadas parecem não ser uma condição necessária para promover agregação [173, 174].

${ }^{4} \mathrm{O}$ termo enovelamento é empregado aqui em um contexto geral e indica que o sistema encontrase em alguma conformação na fase com menor energia que a fase de conformações estendidas.
} 


\begin{tabular}{|c|c|c|c|}
\hline Proteína & Código PDB & $N$ & Sequência \\
\hline $\mathrm{A} \beta$ & 2LFM & 40 & $\begin{array}{l}\text { BABAB BBBBB BABBB BAAAA ABBAB } \\
\text { BBBBA AABAA ABBAA }\end{array}$ \\
\hline $\mathrm{A} \beta$ & $1 Z 0 Q$ & 42 & $\begin{array}{l}\text { BABAB BBBBB BABBB BAAAA ABBAB } \\
\text { BBBBA AABAA ABBAA AA }\end{array}$ \\
\hline Src SH3 & $1 \mathrm{NLO}$ & 56 & $\begin{array}{l}\text { AAAAA BBBBB BABAB ABABB BBBAB } \\
\text { AABBA BBBAA AABBA AABBA BBAAB } \\
\text { BBAAA B }\end{array}$ \\
\hline $\mathrm{hPrP}$ & 1HJM & 104 & $\begin{array}{l}\text { ABBBA ABBAA BBAAA BABBB BBBBB } \\
\text { BBBBA BBBAB BABBB AABBB BBBBB } \\
\text { AABBA ABAAA BBBAA AAAAB BBBAA } \\
\text { BABAB AABBA ABBAA AABBB BBBBA } \\
\text { BBBB }\end{array}$ \\
\hline
\end{tabular}

Tabela 4.1: Códigos PDB, número de aminoácidos $N$ e mapeamento da sequência primária na sequência AB via escala Roseman [178] para os quatro heteropolímeros estudados.

duas isoformas da proteína $\beta$-amilóide, o domínio Src SH3 e a proteína príon humana $(\mathrm{hPrP})$. Na Tabela 4.1 incluimos informações como código PDB, número de aminoácidos $N$ e a sequência $\mathrm{AB}$ das quatro cadeias polipeptídicas.

Como estamos interessados em estudar o comportamento de heteropolímeros inspiradas biologicamente em proteínas com propensidade a agregarem-se e descritos pelo modelo AB, precisamos utilizar alguma informação experimental sobre a hidrofobicidade dos aminoácidos. Para obter a sequências de elementos AB a partir das sequências primárias das proteínas reais (fornecidas pelo PDB), buscamos informações experimentais sobre a hidrofobicidade dos aminoácidos. Tendo em vista a possível comparação dos resultados com o algoritmo de predição de propensidade à agregação chamado Zyggregator [179], realizamos o mapeamento da hidrofobicidade dos 20 aminoácidos em elementos A e B através da escala de hidrofobicidade Roseman [178]. 


\subsection{Descrição do modelo}

Todas as simulações neste Capítulo foram realizadas utilizando o modelo AB, o qual é considerado um modelo mínimo para descrever proteínas pois emprega um potencial de interação simplificado (coarse-grained), o qual, por sua vez, leva em consideração apenas a hidrofobicidade dos seus aminoácidos constituintes. Átomos individuais não são considerados, mas sim uma versão simplificada, sendo a proteína representada apenas por uma cadeia de monômeros de dois tipos, chamados hidrofóbicos (A) e polar ou hidrofílicos (B), localizados na posição dos carbonos alfa $\left(C_{\alpha}\right)$. Algumas conformações ilustrativas para as cadeias polipeptídicas representadas pelo modelo AB são apresentadas na Fig. 4.1. Este é um modelo simplificado e sua utilização tem o intuito de fornecer características globais do processo de enovelamento

(a)

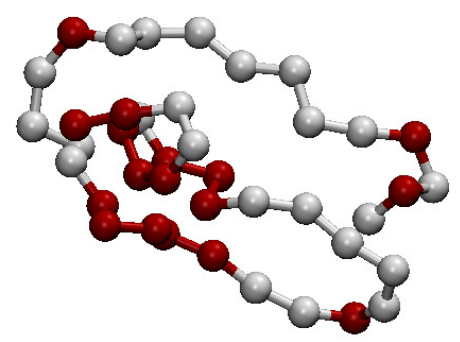

(c)

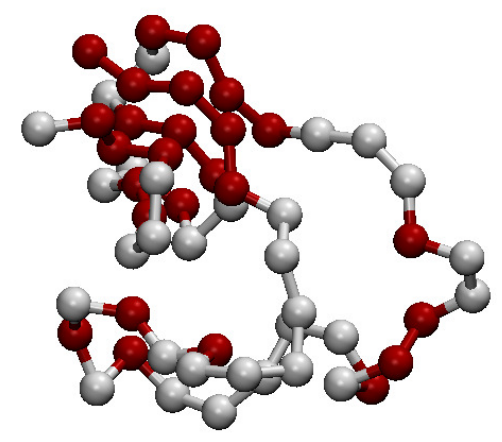

(b)

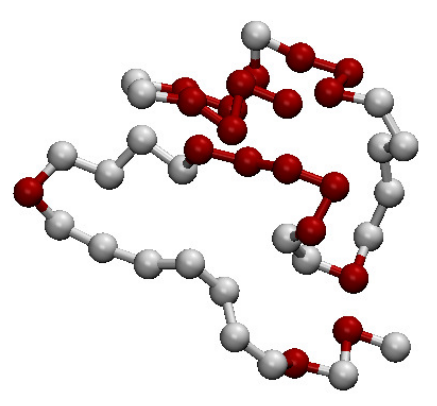

(d)

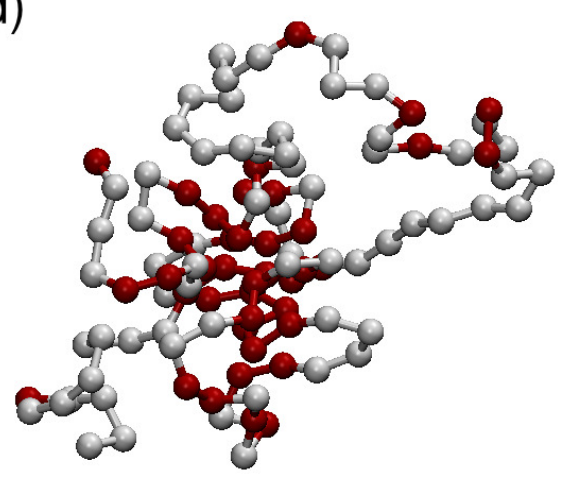

Figura 4.1: Conformações ilustrativas para as sequências AB representando as cadeias (a) A $\beta 40$, (b) A $\beta 42$, (c) Src SH3, e (d) hPrP na região de transição de enovelamento. Esferas escuras (vermelhas) indicam monômeros hidrofóbicos. (Estas figuras foram feitas com ajuda do software VMD [180]). 
dessas cadeias. Dessa maneira, não se espera que conformações nativas (resolvidas experimentalmente) sejam corretamente amostradas por este modelo.

No modelo AB, cadeias com $N$ monômeros são descritas pela seguinte função energia [165],

$$
E=\frac{1}{4} \sum_{k=1}^{N-2}\left(1-\cos \theta_{k}\right)+4 \sum_{i=1}^{N-2} \sum_{j=i+2}^{N}\left(\frac{1}{r_{i j}^{12}}-\frac{C\left(\sigma_{i}, \sigma_{j}\right)}{r_{i j}^{6}}\right),
$$

onde $\theta_{k}$ é o ângulo entre três monômeros consecutivos, e $r_{i j}$ denota a distância entre monômeros $i$ e $j$ da cadeia.

Para definir o ângulo $\theta_{k}$ seguimos a conveção adotada na Ref. [107]. Em termos dos vetores posição $\vec{r}_{k}$ dos três monômeros consecutivos, defini-se $\theta_{k}$ da seguinte maneira,

$$
\cos \theta_{k}=\frac{\left(\vec{r}_{k}-\vec{r}_{k+1}\right) \cdot\left(\vec{r}_{k+1}-\vec{r}_{k+2}\right)}{\left|\vec{r}_{k}-\vec{r}_{k+1}\right| \cdot\left|\vec{r}_{k+1}-\vec{r}_{k+2}\right|}=\left(\vec{r}_{k}-\vec{r}_{k+1}\right) \cdot\left(\vec{r}_{k+1}-\vec{r}_{k+2}\right),
$$

onde consideramos que a distância entre dois monômeros consecutivos $\left|\vec{r}_{k}-\vec{r}_{k-1}\right|$ é igual a 1 (em unidades arbitrárias). O primeiro termo na energia $E$ é um termo de energia de torsão, o qual favorece configurações estendidas para a cadeia.

A constante de acoplamento $C\left(\sigma_{i}, \sigma_{j}\right)$ no potencial tipo Lennard-Jones (LJ) depende dos detalhes de hidrofobicidade dos pares interagentes e é definida por:

$$
C\left(\sigma_{i}, \sigma_{j}\right)=\left\{\begin{array}{cc}
1, & \sigma_{i}=\sigma_{j}=A \\
0.5, & \sigma_{i}=\sigma_{j}=B \\
-0.5, & \sigma_{i} \neq \sigma_{j} .
\end{array}\right.
$$

Como vemos, esses valores favorecem interações entre monômeros de um mesmo tipo. Por exemplo, quanto mais próximos estiverem dois monômeros hidrofóbicos, menor será a energia do termo de LJ. Note que isso insere uma frustração no sistema, onde as energias de torsão e de LJ competem para determinar a energia interna total do sistema.

As configurações são atualizadas em nossas simulações de MC por meio do algoritmo spherical-cap [50]. Este algoritmo utiliza coordenadas esféricas locais (para cada monômero) para a geração de novas posições dos outros monômeros na cadeia 
inteira. Para validar nossa implementação realizamos simulações para cadeias do tipo Fibonacci. Apresentamos os resultados para essas simulações de validação no Apêndice B.

\subsection{Resultados}

\subsubsection{Conjunto de temperaturas}

O conjunto de temperaturas foi determinado a partir do protocolo descrito na seção 2.4.2. Para obter a fração de réplicas aceitas $f_{a c}$, realizamos simulações com $n_{\text {swaps }}=50$ tentativas de troca, com $n_{s}=2000$ varreduras entre cada tentativa. Consideramos a probabilidade de aceitação $p_{a c}$ igual a 0,4 para os heteropolímeros $\beta$ amilóides e 0,3 para os heteropolímeros baseados no domínio Src SH3 e na proteína hPrP. Para todos os sistemas nós consideramos a temperatura inversa inicial igual a $\beta_{1}=0,5$, com acréscimos de $\delta \beta=0,01$. Para cada sistema realizamos cinco simulações independentes para obter uma melhor estimativa de $f_{a c}$ e assim estabelecer o conjunto de temperaturas $\left\{T_{n}\right\}$. A Fig. 4.2 apresenta o gráfico em escala monolog das temperaturas utilizadas nas simulações para cada heteropolímero.

Após a determinação do conjunto de temperaturas, simulações canônicas de MC foram realizadas e configurações foram obtidas em diferentes temperaturas utili-

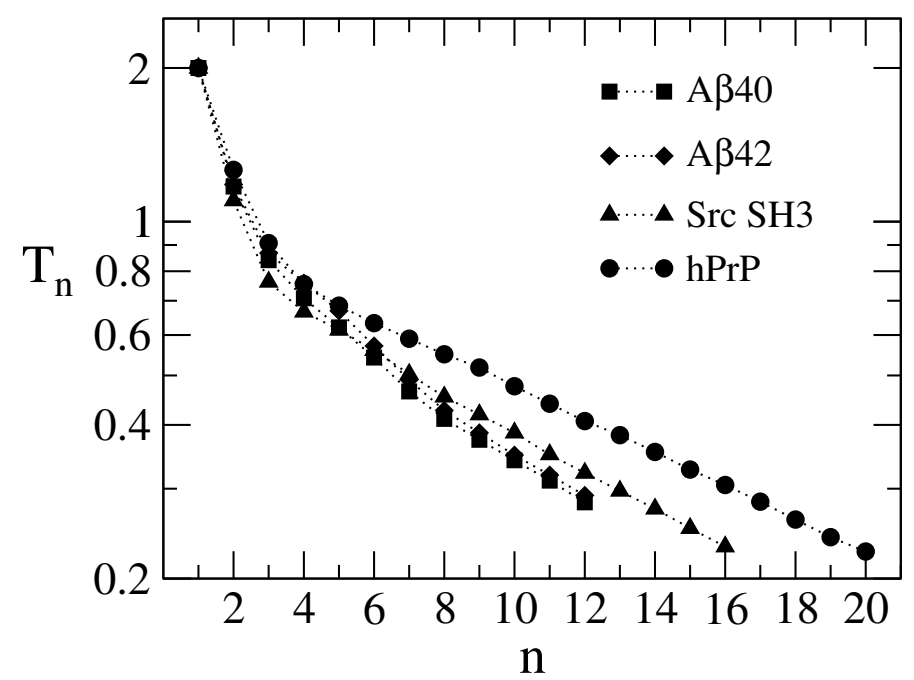

Figura 4.2: Temperaturas utilizadas nas simulações com troca entre réplicas na produção de dados para os quatro heterpolímeros estudados. 
zando REM, tal como descrito na subseção 2.4. A produção final de dados foi obtida com 12 réplicas para os heteropolímeros $\mathrm{A} \beta 40$ e $\mathrm{A} \beta 42,16$ réplicas para o heterpolímero Src SH3, e 20 réplicas para o heterpolímero hPrP. A produção de dados para cada temperatura foi de $10^{7}$ configurações amostradas, obtidas a partir de simulações utilizando REM com $n_{\text {swaps }}=10500$ tentativas de troca entre réplicas e $\operatorname{com} n_{s}=2000$ varreduras. Por causa do tamanho, nós dobramos a estatística para o heteropolímero hPrP, totalizando $n_{\text {swaps }}=21000$ tentativas de trocas. Além disso, as estatísticas acima foram repetidas para cinco simulações independentes, sempre inicializando o sistema de condições iniciais diferentes. Assim, os gráficos apresentados na próxima seção são médias feitas sobre as curvas obtidas para cada uma das cinco simulações. É importante notar que, para cada simulação descartamos $10^{6}$ varreduras iniciais para a termalização do sistema em cada temperatura.

\subsubsection{Termoestatística microcanônica}

Apresentamos nessa subseção os resultados da análise microcanônica do processo de enovelamento para os diferentes heterpolímeros considerados. Tendo obtido as configurações amostradas com $M$ réplicas do sistema via simulações canônicas utilizando REM, as estimativas para o inverso da temperatura estatística $\beta(E)$ seguem da análise via ST-WHAM [71], tal como descrito na seção 2.5.1. A partir das estimativas de $\beta(E)$, calculamos o calor específico microcanônico $C_{v}(E)$ através da Eq. 2.14, utilizando uma regressão linear centrada com estêncil $n_{\text {est }}=51$ para estimar a derivada $d \beta(E) / d E$ numericamente. A entropia microcanônica $S(E)$ foi obtida através do procedimento ST-WHAM-MUCA [70] (vide subseção 2.5.2).

Nos casos onde a curva calórica apresenta regiões em forma de loops de van der Waals, é possível realizar a construção de Maxwell na região limitada pelas energias $E_{a}$ e $E_{b}$ (assim descrito na subseção 2.2) e determinar o inverso da temperatura canônica $\beta_{f}$ como a temperatura em que ocorre uma transição de fase de primeira ordem através da Eq. 2.12. Para esses casos também obtivemos a variação na energia livre $\Delta F(E)$ na temperatura de transição $T_{f}=1 / \beta_{f}$ a partir da entropia deslocada $\Delta S(E)$, tal como na Eq. 2.35. O calor latente por monômero $\ell$ é definido a partir da Eq. 2.13 pela diferença entre as energias $E_{a}$ e $E_{b}$ que definem a região de loop na transição, ou seja, $\ell=\left(E_{b}-E_{a}\right) / N$. 


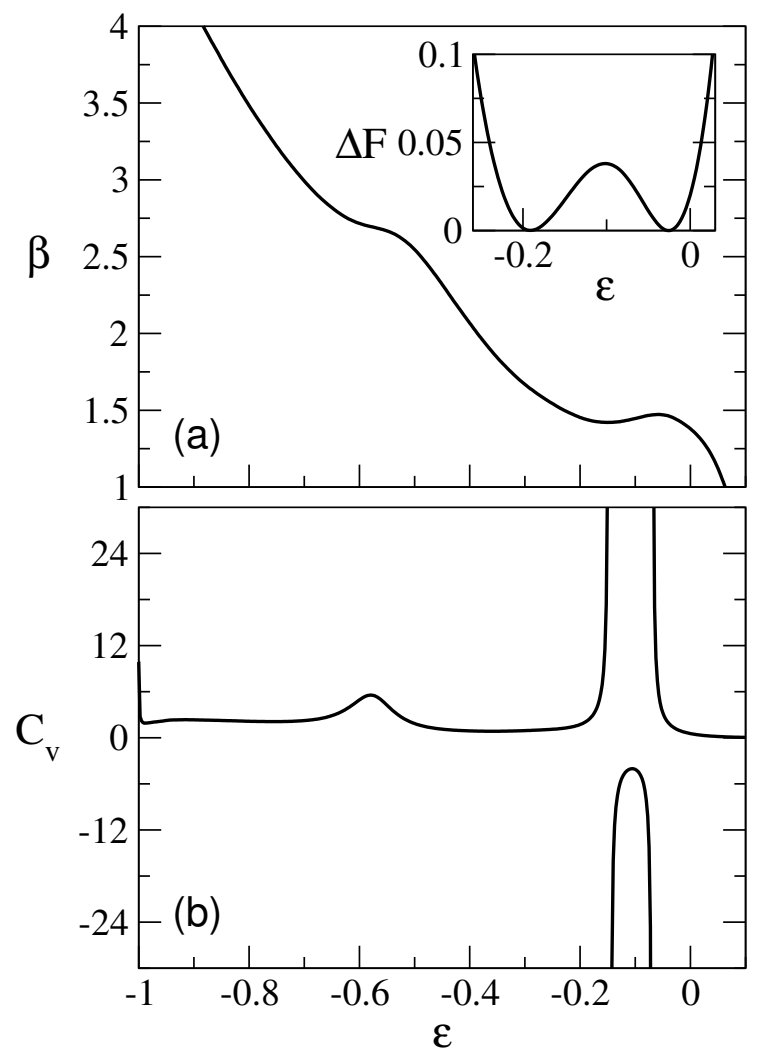

Figura 4.3: (a) Estimativas para o inverso da temperatura microcanônica $\beta(\varepsilon)=$ $1 / T(\varepsilon)$, e (b) calor específico microcanônico $C_{v}(\varepsilon)=-\beta^{2} /(\partial \beta / \partial \varepsilon)$ para o heteropolímero A $\beta 40$. Dentro da Fig. (a) apresentamos as mudanças na energia livre construídas a partir da entropia $S(\varepsilon)$ para a temperatura inversa de enovelamento $\beta_{f}$.

Com o intuito de facilitar eventuais comparações, as quantidades termodinâmicas são fornecidas em termos da energia específica $\varepsilon=E / N$, onde $N$ representa o número de monômeros do sistema.

A Fig. 4.3(a) exibe as estimativas para o inverso da temperatura microcanônica $\beta(\varepsilon)$ para o heteropolímero $\mathrm{A} \beta 40$. Para esse sistema, a entropia apresenta o chamado intruso convexo (figura não mostrada) e produz um calor específico $C_{v}(\varepsilon)$ negativo no intervalo de energias $[-0,15 ;-0,07]$, conforme mostrado na Fig. 4.3(b). Como já discutido, a presença dessa região caracteriza uma transições de fase de enovelamento de primeira ordem. Nessas condições podemos obter a temperatura de transição $T_{f}=0,692(1)$ para A $\beta 40$ realizando a construção de Maxwell entre as energias $\varepsilon_{a}=-0,191$ e $\varepsilon_{b}=-0,026$. Nossos resultados para $\Delta F(\varepsilon)$ são mostrados no gráfico que se encontra dentro da Fig. 4.3(a). Essa curva fornece uma barreira de 
energia livre com altura $\Delta F=0,038(2)$ na temperatura de transição $T_{f}=0,692(1)$. O calor latente é consequência da barreira de energia livre que impede que o sistema se mova de uma fase estável para a outra fase. Dessa maneira, quanto menor o calor latente, maior é a probabilidade de ocorrer uma flutuação espontânea fazendo com que o sistema vá para a outra fase. A estimativa do calor latente por monômero associado a essa transição é $\ell=0,165(3)$. Além disso, um pequeno pico positivo em $C_{v}(\varepsilon)$ é observado para $\varepsilon=-0,579$ na Fig. 4.3(a). Nessa região, a curva calórica $\beta(\varepsilon)$ na Fig. 4.3(a) não apresenta uma curva do tipo van der Waals, assim o pico pode estar associado à uma transição de fase contínua em $\beta_{c}=2,695$, a qual é caracterizada, como veremos, por uma maior compactação da cadeia à baixas temperaturas.

Uma análise similar segue para o heteropolímero obtido a partir da sequência

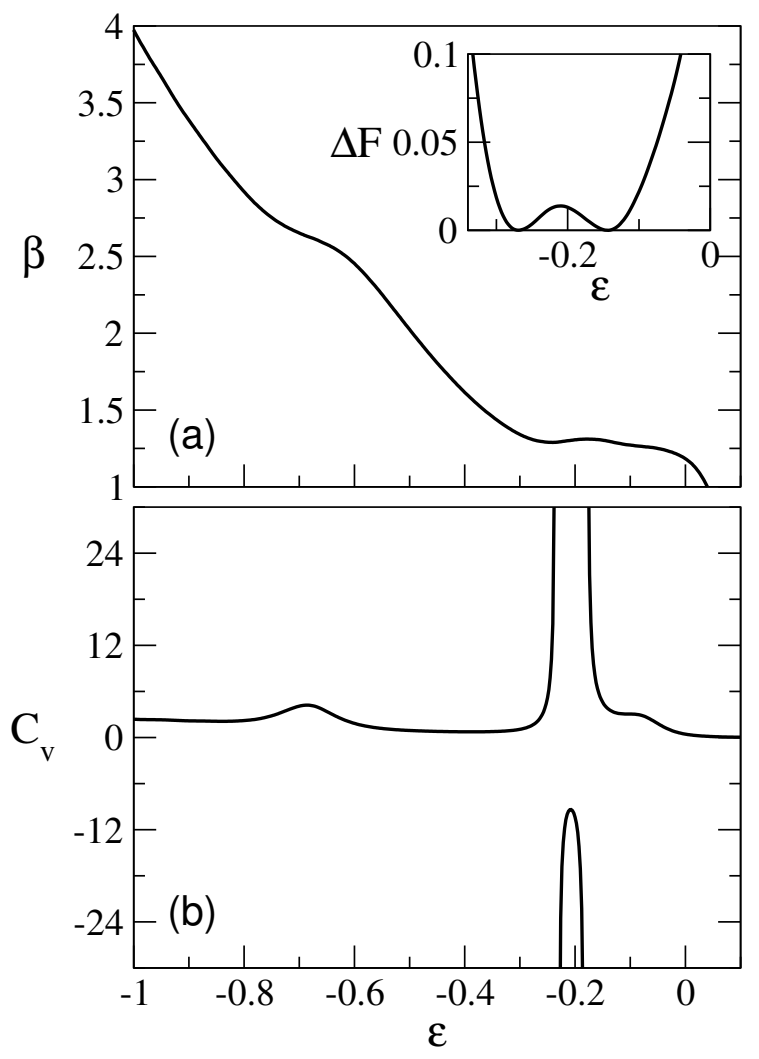

Figura 4.4: (a) Estimativas para o inverso da temperatura microcanônica $\beta(\varepsilon)$, e (b) calor específico microcanônico $C_{v}(\varepsilon)$ para o heteropolímero A $\beta 42$. Dentro da Fig (a) apresentamos as mudanças na energia livre construídas a partir da entropia $S(\varepsilon)$ para a temperatura inversa de enovelamento $\beta_{f}$. 
PDB 1Z0Q para o peptídeo A $\beta 42$. Resultados são apresentados na Fig. 4.4. No entanto, para esse heteropolímero, a curva calórica mostra um comportamento menos pronunciado para o loop de van der Waals em torno energia $\varepsilon=-0,2$ como consequência de uma menor "não concavidade" na entropia microcanônica. Para esse sistema obtemos $\Delta F=0,014(1)$ (veja dentro da Fig. 4.4(a)) e um calor latente $\ell=0,125(2)$. Dessa maneira, a barreira de energia livre separando os estados enovelado e desnaturado para o heterpolímero que descreve o peptídeo A $\beta 42$ é menor quando comparado com o heteropolímero A $\beta 40$. Isso corresponde a uma restrição menos severa à possíveis movimentos de retorno do heterpolímero à conformações intermediárias, dependendo de quão estável as conformações nativas são [159]. Um pequeno pico positivo em $\varepsilon=-0,686$ sinaliza uma transição contínua $\left(\beta_{c}=2,632\right)$ similar àquela observada para o heterpolímero $\mathrm{A} \beta 40$.

Os domínios Src SH3 têm atraido muito interesse porque representam exemplos típicos de proteínas que enovelam-se via um mecanismo de dois estados. É amplamente aceito que o processo físico que ocorre no enovelamento desses domínios é baseado no cenário de nucleação-condensação [181, 182, 183, 184]. De fato, uma transição de fase única entre os estados desenovelados e enovelados foi observada $[181,182]$.

Nossos resultados para o heterpolímero Src SH3, utilizando o modelo AB, são mostrados na Fig. 4.5. Como esperado para esse sistema, uma transição clara de dois estados, representada pelo loop do tipo de van der Waals, pode ser observada na curva calórica (Fig. 4.5(a)). Assim, o calor específico microcanônico apresenta o comportamento típico observado em transições de fase de primeira ordem (Fig. 4.5(b)). A construção de Maxwell é feita entre energias $\varepsilon_{a}=-0,182$ e $\varepsilon_{b}=0,0079$, identificando a temperatura de enovelamento $T_{f}=0,658(1)$. Para esse heteropolímero, nós obtemos a barreira de energia livre $\Delta F=0,068(2)$ (veja na Fig. 4.5(a)) e o calor latente por monômero $\ell=0.190(8)$. Dois pequenos picos positivos são observados em $C_{v}(\varepsilon)$ para energias $\varepsilon=-0,21$ e $\varepsilon=-0,70$. Ambas transições parecem estar relacionadas à compactações.

O próximo heteropolímero representa o domínio globular extracelular da hPrP com 104 monômeros. Comparado com os modelos anteriores, os resultados numéricos não fornecem nenhum intruso convexo na entropia microcanônica $S(\varepsilon)$. O 


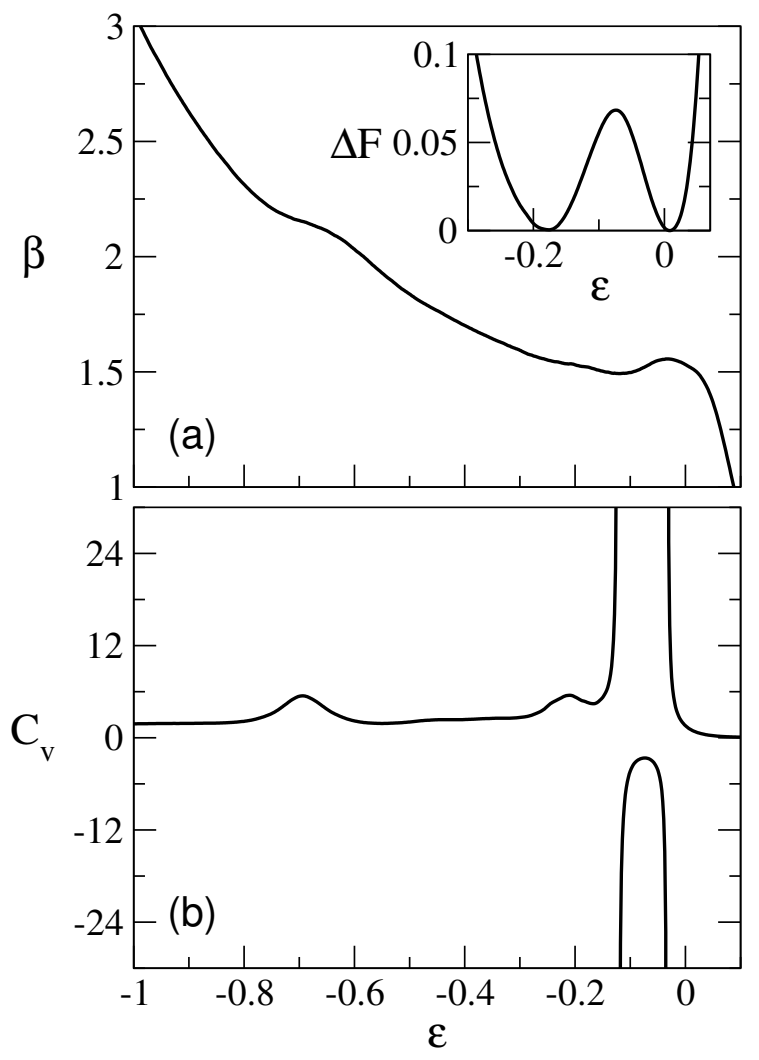

Figura 4.5: (a) Estimativas para o inverso da temperatura microcanônica $\beta(\varepsilon)$, e (b) calor específico microcanônico $C_{v}(\varepsilon)$ para o heteropolímero Src SH3. Dentro da Fig (a) apresentamos as mudanças na energia livre construídas a partir da entropia $S(\varepsilon)$ para a temperatura inversa de enovelamento $\beta_{f}$.

comportamento de $\beta(\varepsilon)$, mostrado na Fig. 4.6(a), não apresenta nenhuma curva de loop do tipo de van der Waals. A análise microcanônica fornece picos positivos no calor específico, os quais podem representar transições de fase contínua (Fig. 4.6(b)). Os máximos de $C_{v}(\varepsilon)$ occorrem em $\varepsilon_{1}=-0,36$ e $\varepsilon_{2}=-0,064$, os quais correspondem às temperaturas $T_{1}=0,596(2)$ e $T_{2}=0,697(1)$, respectivamente.

Desde que nossos resultados para esse heteropolímero não evidenciam a redução da entropia microcanônica à medida que aumenta-se a energia na direção de estados desnaturados, somos levados à argumentação que se segue. Ou a barreira de energia livre que separa as configurações nativas e desnaturadas para esse heteropolímero não é grande o suficiente para ser revelada pela função de energia de interação de define o modelo $\mathrm{AB}$, a qual não contém necessariamente interações que reproduzem contatos nativos, ou, de fato, a transição não ocorre via um mecanismo de dois 


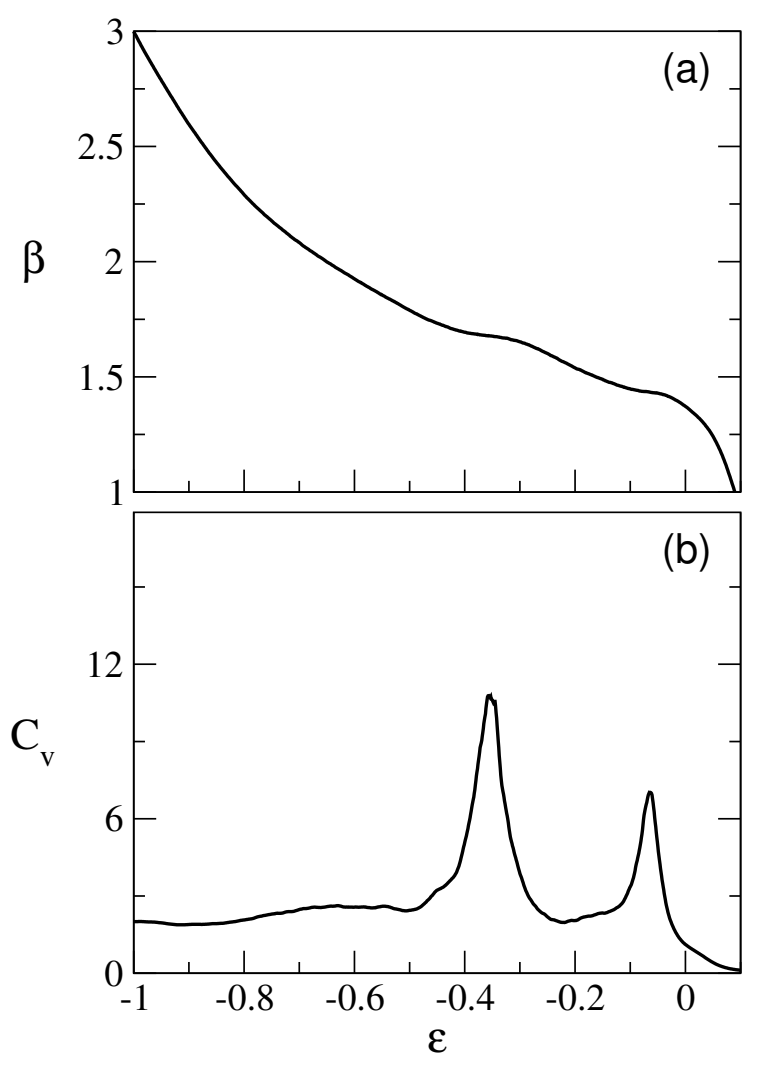

Figura 4.6: (a) Estimativas para o inverso da temperatura microcanônica $\beta(\varepsilon)$, e (b) calor específico microcanônico $C_{v}(\varepsilon)$ para o heteropolímero $\mathrm{hPrP}$.

estados. Curiosamente, observações experimentais contraditórias indicando que o caminho de enovelamento pode envolver um mecanismo de dois estados, apesar de haver evidências contrárias a essa hipótese podem ser encontradas na literatura (veja, por exemplo, a Ref. [185]).

\subsubsection{Raio de giração hidrofóbico}

Como o campo de força (Eq. 4.1) trata as interações hidrofóbicas como a "força" diretora no processo de enovelamento, é importante analisar como a hidrofobicidade dos monômeros comporta-se em função da temperatura. Um estudo recente mostrou que, além das ligações de hidrogênio, a hidrofobicidade é uma componente fundamental nos processos competitivos que levam as proteínas a se enovelar ou se desenovelar [186]. Para analisar o comportamento de enovelamento levando em consideração a distribuição espacial dos monômeros hidrofóbicos, introduzimos um 
raio de giração restrito apenas a esse tipo de monômeros [187],

$$
r_{h}^{2}=\frac{1}{n_{h}^{2}} \sum_{i}^{n_{h}}\left(\vec{r}_{i}-\vec{r}_{0}\right)^{2}
$$

onde $n_{h}$ é o número de monômeros hidrofóbicos da cadeia e $\vec{r}_{0}=\sum_{i} \vec{r}_{i} / n_{h}$. Note que as somas em $i$ são efetuadas apenas sobre os monômeros hidrofóbicos. Foi demonstrado que esse raio de giração hidrofóbico $r_{h}$ é uma função mérito adequada para discriminar estruturas nativas de outras conformações [187].

Os resultados para o raio de giração hidrofóbico $r_{h}$ em função da temperatura canônica $T$, obtidos via repesagem para os quatro heteropolímeros, são mostrados na Fig. 4.7. É esperado que, na transição de enovelamento, ocorra uma rápida mudança na distribuição espacial dos monômeros. Em particular, essa mudança é esperada ser bastante sensível à distribuição espacial dos monômeros hidrofóbicos, como ilustrado na Fig. 4.7(a). Então, nós hipotetizamos que a temperatura onde a

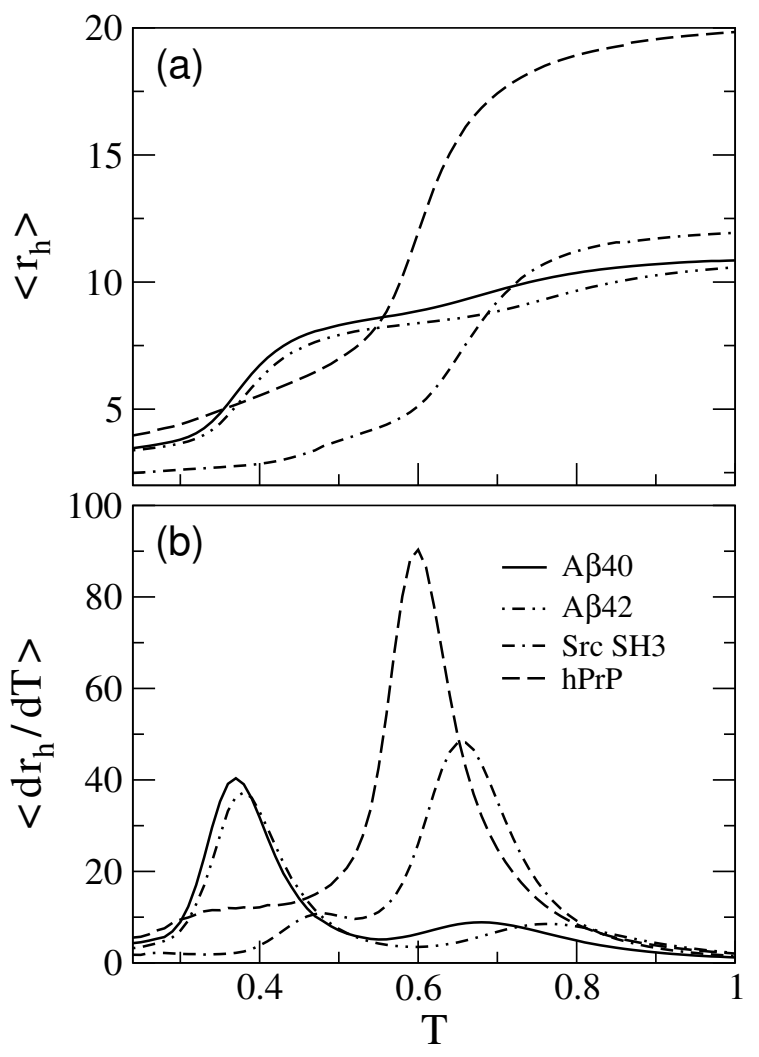

Figura 4.7: Comportamento do raio de giração hidrofóbico $r_{h}$ (a) e a sua derivada $<d r_{h} / d T>$ (b) em função da temperatura. 
derivada $<d r_{h} / d T>$ atinge o seu máximo representa a ocorrência de uma transição termodinâmica. Essas temperaturas, denotadas por $T_{r}$, são facilmente identificadas na Fig. 4.7(b): $T_{r}=0,68(1)$ e $T_{r}=0,76(1)$ para $\mathrm{A} \beta 40$ and $\mathrm{A} \beta 42$, respectivamente. Essas Figs. também identificam as outras transições de compactação nas temperaturas $0,37(1)$ e $0.38(1)$ para A $\beta 40$ e A $\beta 42$, respectivamente. Para o heteropolímero que representa o domínio Src SH3, o máximo de $<d r_{h} / d T>$ occorre na temperatura $T_{r}=0,66(1)$, sendo que a derivada de $r_{h}$ também sinaliza a existência de um segundo pico (menor) para $T_{r}=0,47(3)$, o qual é relacionado a transição observada na Fig. 4.5(a) em $\varepsilon=-0,70$. No caso da hPrP, uma transição clara é observada em $T_{r}=0,60(1)$ e apenas uma pequena mudança na derivada pode ser observada no raio de giração hidrofóbico para $T_{r}=0,32(1)$.

É importante notar que as estimativas para $T_{r}$ concordam muito bem com os valores $T_{f}$ obtidos via construção de Maxwell para todos os heteropolímeros. Isso indica que $r_{h}$ pode ser considerado como um parâmetro de ordem adequado para ilustrar o comportamento do colapso hidrofóbico em função da temperatura em transições de enovelamento.

\subsection{Discussões e conclusões}

A habilidade de cadeias polipeptídicas em formar agregados fibrilares parece surgir da sua propensidade a agregar-se sob condições que permitem o desenovelamento parcial. Essas estruturas fibrilares originam-se a partir cadeias de proteínas mal enoveladas via um processo complexo. Um mecanismo para a formação de fibrilas considera que estados intermediários correspondem à estados metaestáveis com respeito aos estados fibrilares.

Nesse sentido a existência de tais estados metaestáveis podem ser consequência do baixo grau de estabilidade dos estados nativos. Nós realizamos simulações REM para quatro heteropolímeros biologicamente inspirados para relacionar suas propriedades termodinâmicas com suas propensidades à agregação. Considerando os polipeptídeos $\beta$ amilóides, existem evidências experimentais de que $\mathrm{A} \beta 42$ é mais propenso a agregação que A $\beta 40$ [188]. Nossos resultados para a energia livre e calor latente para esses sistemas de heteropolímeros são listados na Tabela 4.2 e indicam 
processos de transição via um mecanismo de dois estados. Menores valores para $\Delta F$ e $\ell$, para o heteropolímero $\mathrm{A} \beta 42$, comparado com os valores respectivos para $\mathrm{A} \beta 40$, indicam que a formação de estados nativos é facilitada para $\mathrm{A} \beta 42$. Esses valores numéricos sinalizam uma transição de primeira ordem mais fraca para para A $\beta 42$. Isso pode oferecer maiores chances para que conformações do tipo nativa da A $\beta 42$ adotem conformações intermediárias parcialmente desenoveladas sobre condições de estabilidade similares. De fato, peptídeos A $\beta$ são considerados intrinsecamente desordenados e assim, A $\beta 42$ pode atravessar a barreira de energia livre em direção às conformações mal enoveladas mais facilmente [176].

Para o heteropolímero Src SH3, nossos resultados mostram uma transição de primeira ordem mais forte, confirmando o caráter de dois estados esperado para esse sistema. Então, comparativamente, é razoável entender os requerimentos experimentais de desestabilizar as conformações nativas [189] para produzir algumas conformações parcialmente desenoveladas como pré-requisito para a auto-montagem das fibrilas.

As evidências conflitantes sobre o mecanismo do processo de enovelamento para a proteína $\mathrm{hPrP}$ reflete o fato de quão difícil é a obter medidas experimentais para essa proteína [185]. Curiosamente, nosso experimento in silico sugere que, se houver alguma barreira de energia livre seperando os estados enovelado e desenovelado para o heteropolímero hPrP, ela não é grande o suficiente para ser revelado pela simples função energias que utilizamos. Nós argumentamos que a ausência da barreira de

\begin{tabular}{cccccc}
\hline \hline Modelo & $T_{f}$ & $\Delta F$ & $\ell$ & $T_{r}$ & Índice $Z_{\text {agg }}[179]$ \\
\hline $\mathrm{A} \beta 40$ & $0,692(1)$ & $0,038(2)$ & $0,165(3)$ & $0,68(1)$ & 0,90 \\
$\mathrm{~A} \beta 42$ & $0,769(1)$ & $0,014(1)$ & $0,125(2)$ & $0,76(1)$ & 0,94 \\
$\mathrm{Src} \mathrm{SH3}$ & $0,658(1)$ & $0,068(2)$ & $0,190(8)$ & $0,66(1)$ & 0,96 \\
$\mathrm{hPrP}$ & $0,596(2)$ & & & $0,60(1)$ & 1,14 \\
\hline \hline
\end{tabular}

Tabela 4.2: Resultados comparativos para os diferentes modelos de heterpolímeros. Temperaturas de enovelamento $T_{f}$ obtidas via construção de Maxweel. Temperaturas de enovelamento $T_{r}$ obtidas via raio de giração hidrofóbicos. Barreiras de energia livre $\Delta F$ e calor latente por monômero $\ell$. Índice de propensidade de agregação $Z_{\text {agg }}$. 
energia livre favorece a presença de conformações parcialmente desenoveladas no heteropolímero hPrP, as quais poderiam explicar o porque ele é mais propenso à agregação do que os outros heteropolímeros. É evidente que nossas conclusões são baseadas em um modelo com campo de forças simples, o qual não foi feito para, por exemplo, reproduzir o estado nativo. No entanto, é esperado que a interação hidrofóbica incorpore os aspectos principais que produzem as configurações dos estados de transição.

Como a propensidade de peptídeos e proteínas a formarem agregados depende bastante da sequência, Pawar e colaboradores [168] definiram uma equação fenomenológica para expressar essa propriedade. Nós calculamos o índice $Z_{a g g}$ de propensidade à agregação para as quatro cadeias polipeptídicas em $\mathrm{pH}=7$ através do algoritmo Zyggregator [179]. Esse algoritmo forneceu os valores apresentados na Tabela 4.2. A observação dos índices $Z_{\text {agg }}$ revela que o polipeptídico hPrP é mais propenso à agregação que as outras cadeias polipeptídicas. Se considerarmos que transições mais fracas facilitam a coexistência de conformações nativas e desnaturadass, essa conclusão concorda com os resultados obtidos para propriedades termodinâmicas listadas na Tabela 4.2 .

Nós também calculamos o raio de giração hidrofóbico e, como pode ser visto na Fig. 4.7, ele é um parâmetro de ordem conveniente para a identificação das temperaturas de enovelamento. O acordo com as estimativas microcanônicas demonstra que o empacotamento espacial dos monômeros hidrofóbicos fornecem informações fundamentais sobre o processo de enovelamento. Mais importante ainda, essa quantidade pode ser facilmente analisada em qualquer estudo de enovelamento de proteínas e não depende de nenhuma outra informação sobre a proteínas, assim como as coordenadas de reação usuais que necessitam de informações sobre os contatos nativos. 


\section{Capítulo}

\section{CONCLUSÕES}

Sistemas complexos que apresentam interações competitivas são ubíquos na natureza. Obter descrições adequadas para as propriedades termodinâmicas desses sistemas é um desafio para o entendimento de uma série de processos químicos e físicos. Soluções analíticas em termos do formalismo teórico da Mecânica Estatística são extremamente difíceis de serem obtidas para esses sistemas, como é o caso dos modelos utilizados para descrever filmes magnéticos ultrafinos e proteínas abordados nesta Tese. Apesar da notável diferença fenomenológica entre esses dois modelos, ambos são descritos por energias contínuas e apresentam o fenômeno de frustração causado pela presença de interações competitivas. Para esses sistemas, as simulações computacionais constituem uma ferramenta essencial para um entendimento mais profundo sobre as suas propriedades termodinâmicas, principalmente com relação a criticalidade. As simulações que utilizam algoritmos de MC generalizados, em particular, são conhecidas por amostrar configurações com grande independência estatística, fornecendo assim resultados de maneira mais eficientes do que as simulações que utilizam o algoritmo usual de Metropolis. Nesta Tese, mostramos resultados de implementações tanto de algoritmos de amostragem uniforme (da classe dos algoritmos seriais) quanto de algoritmos canônicos que utilizam o método de troca entre réplicas (da classe dos algoritmos paralelizáveis). Analisamos como a utilização desses algoritmos ajuda na obtenção das termoestatísticas canônica e microcanônica e, consequentemente, na determinação da natureza das transições de fase nos sistemas estudados. A seguir sumarizamos as principais conclusões desses estudos.

No caso da utilização dos algoritmos de amonstragem uniforme, caracterizamos 
a implementação dos algoritmos MUCA e ES utilizando quatro protocolos para a determinação dos pesos de amostragem. Além do protocolo tradicional que utiliza um número de varreduras $n_{s}$ fixo entre os passos de recorrência, introduzimos três outros protocolos que determinam o número $n_{s}$ a partir da contagem do número de viagens de ida e volta realizadas entre energias extremas. Utilizando o modelo de Ising dipolar 2D com o acoplamento $\delta=1,7$, região na qual ocorre uma transição de primeira ordem entre as fases de faixas $(h=2)$ e tetragonal (Cenário I), realizamos um estudo comparativo entre os algoritmos MUCA e ES. Mostramos que, apesar do algoritmo ES chegar ao estado fundamental mais rapidamente, quantidades termodinâmicas tais como inverso da temperatura microcanônica e diferença de energia livre, calculadas a partir da densidade de estados estimada dos pesos de amostragem, possuiam uma qualidade superior no caso do algoritmo MUCA. Concluimos então que o protocolo (iii) aliado ao algoritmo MUCA seria o mais adequado para a realização de estudos mais amplos relacionados às transição faixas-tetragonal no modelo de Ising dipolar 2D.

Evidências na literatura apontavam para a existência de um ponto trícritico próximo a $\delta \sim 0,9$ no diagrama de fases $(T, \delta)$ do modelo de Ising dipolar $2 \mathrm{D}$ na região $h=1$. A partir de uma grande quantidade de dados produzidos utilizando o algoritmo MUCA para valores do acoplamento $\delta$ na região próxima à 0,9 e redes de tamanho até $L=72$, foi possível realizar uma análise de escala de tamanho finito dos zeros complexos da função de partição no plano das temperaturas. Além da determinação precisa das temperaturas termodinâmicas de transição, obtivemos estimativas para o expoente $d \nu$ para diversos valores de $\delta$, as quais sugerem que a transição faixas-tetragonal seja contínua na região $h=1$, excluindo a existência do ponto tricrítico conforme mencionado. Essa conclusão foi corroborada pelas nossas análises de escala de tamanho finito realizadas para o calor específico e a susceptibilidade do parâmetro de ordem orientacional. O caráter de primeira ordem para a transição de fase faixas-tetragonal parece ocorrer apenas na região com acoplamento $\delta=1,3$, onde o estado fundamental é caracterizado por faixas de largura $h=2$.

Para região $h=2$, onde a fenomenologia do modelo de Ising dipolar 2D é representada pelo o aparecimento da fase nemática entre as fases de faixas e tetragonal (Cenário II), realizamos estudos para o acoplamento $\delta=2$. No primeiro estudo 
mostramos que, tal como observado nas simulações canônicas [80], fortes efeitos de tamanho finito são observados nas curvas calóricas obtidas pelo algoritmo MUCA. As estimativas para os pesos fornecem uma termoestatística microcanônica compatível com a presença de duas barreiras de energia livre para a rede $L=48$, as quais foram associadas às transições de fase faixas-nemática e nemática-tetragonal, em temperaturas compatíveis com aquelas observadas nas simulações canônicas. A presença de uma grande barreira de energia livre entre as fases de faixas e nemática fez com que as simulações amostrassem configurações somente em uma das fases [75], mesmo para redes de tamanho $L=32$, o que, à princípio, não deveria ocorrer quando utilizamos o algoritmo MUCA. Exploramos duas alternativas para tentar solucionar esse problema, uma analisando o efeito da discretização na energia e a outra aumentando a estatística através do uso do protocolo (iv). Para a essa segunda alternativa também incluimos resultados para o algoritmo entrópico. A conclusão foi que os algoritmos de amostragem uniforme falharam na obtenção dos pesos na região onde do acoplamento $\delta=2$, inclusive para as redes pequenas. Resolvemos então combinar simulações canônicas realizadas com método de troca entre réplicas e a análise via ST-WHAM para analisar essa região. Considerando uma rede de tamanho $L=72$, duas simulações foram realizadas para obter estimativas para o inverso temperatura microcanônica. Em relação ao desempenho da obtenção das curvas calóricas, percebemos que, assim como no estudo realizados com algoritmo MUCA para essa região, a amostragem de configurações na região de transição entre as fases de faixas e nemática foi suprimida por causa da presença de uma forte barreira na energia livre, principalmente para a primeira simulação. Isso causou a discrepância entre as curvas calóricas obtidas pelas duas simulações nas regiões onde $d b(E) / d E>0$, contudo, fora das regiões ambas simulações forneceram resultados equivalentes, mesmo com a primeira simulação realizada com uma estatística menor. Concluimos assim que estimativas grosseiras paras as curvas calóricas podem ser obtidas facilmente de simulações canônicas com o método de troca entre réplicas. Em relação à fenomenologia do modelo de Ising dipolar $2 \mathrm{D}$ na região do diagrama de fases representada pelo cenário II em $\delta=2$, nossos resultados para as curvas calóricas sugerem que ambas transições sejam de primeira ordem, excluindo a possibilidade de uma transição do tipo KT. 
A caracterização da termoestatística microcanônica tem sido incorporada em diversos estudos sobre a natureza das transições de fase [190], especialmente no caso de sistemas finitos tais como proteínas [191]. Nesse contexto, apresentamos no Capítulo 4 outra aplicação simulações realizadas com o algoritmo canônico implementado com o REM, a qual corresponde ao estudo da criticalidade em proteínas descritas por um modelo mínimo. Nesse estudo caracterizamos a termoestatística microcanônica das transições de enovelamento de heteropolímeros inspirados biologicamente em quatro polipeptídicas com conhecida propensidade à formação de agregados: duas isoformas da proteína $\beta$ amilóide, o domínio Src SH3 e a proteína príon humana (hPrP). As simulações para os hetepolímeros A $\beta 40$, A $\beta 42$ e Src SH3 indicam que o processo de enovelamento descrito pelo modeo AB é relacionado com a presença de uma região com calor específico negativo, que é um fenômeno que só pode ser verificado no ensemble microcanônico em transições de primeira ordem. Por outro lado, os resultados das simulações para o heteropolímero hPrP sugerem uma transição contínua. Considerando que a ausência de uma barreira de energia livre favorece a presença de conformações parcialmente desenoveladas, esse aspecto termodinâmico poderia explicar porque o heteropolímero hPrP é mais propenso à agregar-se que os outros polímeros considerados, assim como sugerem os resultados do índice $Z_{a g g}$. Além disso, nós introduzimos o raio de giração hidrofóbico como um parâmetro de ordem e mostramos como ele pode ser utilizado para obter informações precisas sobre o empacotamento hidrofóbico e as temperaturas de transição no processo de enovelamento. Essa quantidade é interessante pois não depende de informações sobre o estado nativo das proteínas e pode ser utilizado em simulações de enovelamento em geral.

É interessante notar que, tanto no caso dos algoritmos de amostragem uniforme quanto no método de temperatura estatística, a obtenção da termoestatística microcanônica é feita com base em histogramas. Assim, principalmente no caso de modelos com energia contínuas, a escolha da discretização na energia pode ter uma grande importância. A vantagem de utilizar o ST-WHAM associado à simulações canônicas em paralelo é que, ao contrário do que se faz nos algoritmos de amostragem uniforme, o tamanho da discretização na energia pode ser escolhido após a realização das simulações. Evidências das limitações dos algoritmos de amostragem 
uniforme para modelos com energia contínua podem ser encontradas na literatura. Por exemplo, o problema enfrentado por nós na obtenção dos pesos multicanônicos também foi observado para um modelo de proteínas [63]. Outros exemplos incluem um algoritmo similar ao MUCA, o algoritmo de Wang-Landau (WL), o qual também requer a discretização das energias para a obtensão da densidade de estados. Testando diversas implementações do algoritmo WL, Poulain e colaboradores [192] não conseguiram estimativas adequadas da densidade de estados para baixas energias em modelos de polipeptídeos e clusters de Lennard-Jones, ambos com energia contínua. Além disso, o problema do aprisionamento em uma das fases foi observado em simulações utilizando esse algoritmo para um modelo XY modificado [193, 194, 195]. Outra questão discutida na literatura sobre algoritmos de MC generalizados referese a ser realmente necessário amostrar configurações por todo o espaço de energias [196]. No caso das simulações canônicas implementadas com o REM é possível concentrar a amostragem de configurações em regiões específicas do espaço das energias de maneira simples apenas escolhendo o conjunto de temperaturas.

Finalmente, destacamos que, para os dois modelos empregados nesta Tese, foi verificado ${ }^{1}$ que é possível utilizar o método ST-WHAM para obter o inverso da temperatura estatística a partir resultados obtidos em simulações canônicas, mesmo na região onde a entropia microcanônica apresenta uma região não côncava. Assim como o método de análise ST-WHAM, nossa proposta [70] para calcular a entropia microcanônica, a qual chamamos de ST-WHAM-MUCA, é geral e pode ser aplicada em simulações de MC que utilizem quaiquer pesos de amostragem. Como perspectiva para trabalhos subsequentes, incluimos a possibilidade da extensão do ST-WHAM-MUCA para densidades de estados bidimensionais, no espírito de trabalhos apresentados recentemente na literatura tal como a Ref. [197].

\footnotetext{
${ }^{1}$ Veja resultados na subseção 2.5.2 para o modelo de Ising dipolar $2 \mathrm{D}$ e no Apêndice B para o modelo AB.
} 


\section{REFERÊNCIAS BIBLIOGRÁFICAS}

[1] K. Huang, Statistical Mechanics. Wiley, 1987.

[2] R. J. Pathria, Statistical Mechanics. Butterworth-Heinemann, 1996.

[3] H. B. Callen, Thermodynamics and an Introduction to Thermostatistics. John Wiley \& Sons, 1985.

[4] D. A. McQuarrie, Statistical Mechanics. University Science Books, 2000.

[5] D. Chandler, Introduction to Modern Statistical Mechanics. Oxford University Press, 1987.

[6] C. Chipot e A. Pohorille, Free Energy Calculations: Theory and Applications in Chemistry and Biology. Springer, 2007.

[7] K. S. Novoselov, V. I. Fal'ko, L. Colombo, P. R. Gellert, M. G. Schwab e K. Kim, "A roadmap for graphen", Nature, vol. 490, p. 192, 2012.

[8] M. E. J. Newman e G. T. Barkema, Monte Carlo methods in Statistical Physics. Claredon Press - Oxford, 2001.

[9] D. P. Landau e K. Binder, A guide to Monte Carlo simulations in Statistics Physics. Cambridge University Press, 2000.

[10] N. Metropolis, A. W. Rosenbluth, M. N. Rosenbluth, A. H. Teller e E. Teller, "Equation of state calculations by fast computing machines", J. Chem. Phys., vol. 21, p. 1087, 1953.

[11] K. Binder e D. W. Heerman, Monte Carlo Simulation in Statistical Physics, An Introduction. Springer Series in Solid-State Sciences 80, 1987. 
[12] G. Bhanot, "The Metropolis algorithm", Rep. Prog. Phys., vol. 51, p. 429, 1988.

[13] Z. W. Salsburg, J. D. Jackson, W. Fickett e W. W. Wood, "Application of the Monte Carlo method to the lattice-gas model. i. two-dimensional triangular lattice", J. Chem. Phys., vol. 30, p. 65, 1959.

[14] I. R. McDonald e K. Singer, "Calculation of thermodynamic properties of liquid argon from Lennard-Jones parameters by a Monte Carlo method", Discuss. Faraday Soc., vol. 43, p. 40, 1967.

[15] J. P. Valleau e D. N. Card, "Monte Carlo estimation of the free energy by multistage sampling", J. Chem. Phys., vol. 57, p. 5457, 1972.

[16] C. H. Bennett, "Efficient estimation of free energy differences from Monte Carlo data", J. Comput. Phys., vol. 22, p. 245, 1976.

[17] G. M. Torrie e J. P. Valleau, "Monte carlo free energy estimates using nonBoltzmann sampling: Application to the sub-critical Lennard-Jones fluid", Chem. Phys. Lett., vol. 28, p. 578, 1974.

[18] M. Falcioni, E. Marinari, M. L. Paciello, G. Parisi e B. Taglienti, "Complex zeros in the partition function of the four-dimensional $\mathrm{SU}(2)$ lattice gauge model", Phys. Lett. B, vol. 108, p. 331, 1982.

[19] G. Bhanot, S. Black, P. Carter e R. Salvador, "A new method for the partition function of discrete systems with application to the 3D Ising model", Phys. Lett. B, vol. 183, p. 331, 1987.

[20] G. M. Torrie e J. P. Valleau, "Nonphysical sampling distributions in Monte Carlo free-energy estimation: Umbrella sampling", J. Comput. Phys., vol. 23, p. $187,1977$.

[21] S. Kumar, J. M. Rosenberg, D. Bouzida, R. H. Swendsen e P. A. Kollman, "The weighted histogram analysis method for free-energy calculations on biomolecules. I. The method", J. Comput. Chem., vol. 13, p. 1011, 1992. 
[22] S. Kumar, J. M. Rosenberg, D. Bouzida, R. H. Swendsen e P. A. Kollman, "Multidimensional free-energy calculations using the weighted histogram analysis method", J. Comput. Chem., vol. 16, p. 1339, 1995.

[23] W. Janke, Rugged Free Energy Lanbdscapes: Common Computational Approaches to Spin glasses, Strutural Glasses and Biological Macromolecules. Springer, 2007.

[24] J. J. Binney, N. J. Dowrick, A. J. Fisher e M. E. J. Newman, The theory of critical phenomena. An introduction to the renormalization group theory. Claredon Press - Oxford, New York, 1999.

[25] B. A. Berg, "Introduction to multicanonical Monte Carlo simulations", Fields Inst. Commun., vol. 26, p. 1, 2000.

[26] L. G. Rizzi e R. B. Frigori, "Termodinâmica do modelo de Ising com interações de alcance infinito via ensemble canônico generalizado", Rev. Bras. Ens. Fís., vol. 34, p. 1306, 2012.

[27] U. H. E. Hansmann e Y. Okamoto, "Generalized-ensemble approach for protein folding simulations", Annual Reviews of Computational Physics VI, edited by D. Stauffer (World Scientific, Singapore), p. 129, 1999.

[28] A. Mitsutake, Y. Sugita e Y. Okamoto, "Generalized-ensemble algorithms for molecular simulations of biopolymers", Biopolymers, vol. 60, p. 96, 2001.

[29] Y. Sugita e Y. Okamoto, "Free-energy calculations in protein folding by generalized-ensemble algorithms", Lecture Notes in Computational Science and Engineering (T. Schlick, H. H. Gan; Springer-Verlag, Berlin), p. 304, 2002.

[30] B. A. Berg, "Generalized ensemble simulations for complex systems", Comput. Phys. Commun., vol. 147, p. 52, 2002.

[31] D. H. E. Gross, Microcanonical thermodynamics: phase transitions in small systems. Lecture Notes in Physics 66. World Scientific. Singapore, 2001. 
[32] D. H. E. Gross e J. F. Kenney, "The microcanonical thermodynamics of finite systems: The microscopic origin of condensation and phase separations, and the conditions for heat flow from lower to higher temperatures", J. Chem. Phys., vol. 122, p. 224111, 2005.

[33] J. Barré, D. Mukamel e S. Ruffo, "Inequivalence of ensembles in a system with long-range interactions", Phys. Rev. Lett., vol. 87, p. 030601, 2001.

[34] F. Bouchet e J. Barré, "Classification of phase transitions and ensemble inequivalence in systems with long range interactions", J. Stat. Phys., vol. 118, p. 1073, 2005.

[35] M. Costeniuc, R. S. Ellis, H. Touchette e B. Turkington, "Generalized canonical ensembles and ensemble equivalence", Phys. Rev. E, vol. 73, p. 026105, 2006.

[36] H. Touchette, M. Costeniuc, R. Ellis e B. Turkington, "Metastability within the generalized canonical ensemble", Physica A, vol. 365, p. 132, 2006.

[37] B. A. Berg e T. Neuhaus, "Multicanonical algorithms for first order phase transitions", Phys. Lett. B, vol. 267, p. 249, Set 1991.

[38] B. A. Berg e T. Neuhaus, "Multicanonical ensemble: a new approach to simulate first-order phase transitions", Phys. Rev. Lett., vol. 68, no. 1, p. 9, 1992.

[39] W. Janke, "Multicanonical Monte Carlo simulations", Physica A, vol. 254, p. 164, 1998.

[40] J. Lee, "Erratum: New Monte Carlo algorithm: entropic sampling", Phys. Rev. Lett., vol. 71, no. 2, p. 2353, 1993.

[41] B. A. Berg, U. H. E. Hansmann e Y. Okamoto, "Comment on 'Monte Carlo simulation of a first-order transition for protein folding"', J. Phys. Chems., vol. 99, p. 2236, 1995.

[42] M. H. Hao e H. A. Scheraga, "Reply to comment on 'Monte Carlo simulation of a first-order transition for protein folding"', J. Phys. Chems., vol. 99, p. 2238, 1995. 
[43] J. Lee, "New Monte Carlo algorithm: entropic sampling", Phys. Rev. Lett., vol. 71, no. 2, p. 211, 1993.

[44] B. A. Berg e T. Celik, "New approach to spin glass simulation", Phys. Rev. Lett., vol. 69, p. 2292, 1992.

[45] B. A. Berg, U. H. E. Hansmann e T. Neuhaus, "Simulation of an ensemble with varying magnetic field: a numerical determination of the order-order interface tension in the $\mathrm{D}=2$ Ising model", Phys. Rev. B, vol. 47, p. 497, 1993.

[46] W. Janke e S. Kappler, "Multibondic cluster algorithm for monte carlo simulations of first-order phase transition", Phys. Rev. Lett., vol. 74, p. 212, 1995.

[47] B. A. Berg e W. Janke, "Multi-overlap simulations of the 3d Edwards-Anderson Ising spin glass", Phys. Rev. Lett., vol. 80, p. 4771, 1998.

[48] N. Hatano e J. E. Gubernatis, "A multicanonical Monte Carlo study of the 3D 士J spin glass,", Prog. Theor. Phys. Suppl., vol. 138, p. 442, 2000.

[49] B. A. Berg, A. Billoire e W. Janke, "Spin glass overlap barriers in three and four dimensions", Phys. Rev. B, vol. 61, p. 12143, 2000.

[50] M. Bachmann, H. Arkin e W. Janke, "Multicanonical study of coarse-grained off-lattice models for folding heteropolymers,", Phys. Rev. E, vol. 71, p. 031906 , 2005.

[51] C. Junghans, M. Bachmann, H. Arkin e W. Janke, "Microcanonical analyses of peptide aggregation processes", Phys. Rev. Lett., vol. 97, p. 218103, 2006.

[52] J. V. Lopes, M. D. Costa, J. M. B. L. dos Santos e R. Toral, "Optimized multicanonical simulations: A proposal based on classical fluctuation theory", Phys. Rev. E, vol. 74, p. 046702, 2006.

[53] T. Neuhaus e J. S. Hager, "Free-energy calculations with multiple gaussian modified ensembles", Phys. Rev. E, vol. 74, p. 036702, 2006. 
[54] F. Wang e D. P. Landau, "Efficient, multiple-range random walk algorithm to calculate the density of states", Phys. Rev. Lett., vol. 86, no. 10, p. 2050, 2001.

[55] F. Wang e D. P. Landau, "Determining the density of states for classical statistical models: A random walk algorithm to produce a flat histogram", Phys. Rev. E, vol. 64, p. 056101, 2001.

[56] J.-S. Wang e R. H. Swendsen, "Transition matrix Monte Carlo method", J. Stat. Phys., vol. 106, p. 245, 2002.

[57] P. M. C. de Oliveira, "Broad histogram: An overview", Braz. J. Phys., vol. 30, p. $195,2000$.

[58] R. H. Swendsen e J. Wang, "Replica Monte Carlo simulation of spin-glasses", Phys. Rev. Lett., vol. 57, p. 2607, 1986.

[59] K. Hukushima e K. Nemoto, "Exchange Monte Carlo method and application to spin glass simulations", J. Phys. Soc. Japan, vol. 65, p. 1604, 1996.

[60] E. Marinari e G. Parisi, "Simulated tempering: a new Monte Carlo scheme", Europhys. Lett., vol. 19, p. 451, 1992.

[61] Y. Sugita e Y. Okamoto, "Replica-exchange multicanonical algorithm and multicanonical replica-exchange method for simulating systems with rough energy landscape", Chem. Phys. Lett., vol. 329, p. 261, 2000.

[62] A. Mitsutake, Y. Sugita e Y. Okamoto, "Replica-exchange multicanonical and multicanonical replica-exchange monte carlo simulations of peptides. i. formulation and benchmark test", J. Chem. Phys., vol. 118, p. 6664, 2003.

[63] M. Nanias, C. Czaplewski e H. A. Scheraga, "Replica exchange and multicanonical algorithms with the coarse-grained united-residue (UNRES) force field", J. Chem. Theory Comput., vol. 2, p. 513, 2006.

[64] T. Neuhaus, M. P. Magiera e U. H. E. Hansmann, "Efficient parallel tempering for first-order phase transitions", Phys. Rev. E, vol. 76, p. 045701, 2007. 
[65] J. Kim e J. E. Straub, "Optimal replica exchange method combined with Tsallis weight sampling", J. Chem. Phys., vol. 130, p. 144114, 2009.

[66] J. Kim, T. Keyes e J. E. Straub, "Generalized replica exchange method", J. Chem. Phys., vol. 132, p. 224107, 2010.

[67] J. Kim e J. E. Straub, "Generalized simulated tempering for exploring strong phase transitions", J. Chem. Phys., vol. 133, p. 154101, 2010.

[68] R. B. Frigori, L. G. Rizzi e N. A. Alves, "The extended gaussian ensemble and metastabilities in the Blume-Capel model", J. Phys.: Conf. Ser., vol. 246, p. 012018, 2010.

[69] R. B. Frigori, L. G. Rizzi e N. A. Alves, "Extended gaussian ensemble solution and tricritical points of a system with long-range interactions", Eur. Phys. J. $B$, vol. 75, p. 311, 2010.

[70] L. G. Rizzi e N. A. Alves, "Multicanonical entropy-like solution of statistical temperature weighted histogram analysis method", J. Chem. Phys., vol. 135, p. 141101, 2011.

[71] J. Kim, T. Keyes e J. E. Straub, "Iteration-free, weighted histogram analysis method in terms of intensive variables", J. Chem. Phys., vol. 135, p. 061103, 2011.

[72] S. A. Pighín e S. A. Cannas, "Phase diagram of an Ising model for ultrathin magnetic films: Comparing mean field and Monte Carlo predictions", Phys. Rev. B, vol. 75, no. 22, 2007.

[73] A. Abanov, V. Kalatsky, V. L. Pokrovsky e W. M. Saslow, "Phase diagram of ultrathin ferromagnetic films with perpendicular anisotropy", Phys. Rev. B, vol. 51, no. 2, p. 1023, 1995.

[74] J. S. M. Fonseca, G. Rizzi e N. A. Alves, "Stripe-tetragonal phase transition in the two-dimensional Ising model with dipole interactions: Partition function zeros approach", Phys. Rev. E, vol. 86, p. 011103, 2012. 
[75] L. G. Rizzi e N. A. Alves, "Multicanonical simulation and trapping due to high free-energy barriers in an Ising model for ultrathin magnetic films", J. Comp. Int. Sci., vol. 2, p. 79, 2011.

[76] W. Nadler e U. H. E. Hansmann, "Generalized ensemble and tempering simulations: A unified view", Phys. Rev. E, vol. 75, p. 045701, 2007.

[77] A. M. Ferrenberg e R. H. Swendsen, "New Monte Carlo technique for studying phase transitions", Phys. Rev. Lett., vol. 61, no. 23, p. 2635, 1988.

[78] T. Bereau e R. H. Swendsen, "Optimized convergence for multiple histogram analysis", J. Comput. Phys., vol. 228, p. 6119, 2009.

[79] L. G. Rizzi, "Simulações numéricas de Monte Carlo aplicadas no estudo das transições de fase do modelo de Ising dipolar bidimensional", Dissertação de Mestrado, Universidade de São Paulo, 2009.

[80] L. G. Rizzi e N. A. Alves, "Phase transitions and autocorrelation times in two-dimensional Ising model with dipole interactions", Physica B, vol. 405, p. $1571,2010$.

[81] N. A. Alves, B. A. Berg e R. Villanova, "Ising-model Monte Carlo simulations: density of states and mass gap", Phys. Rev. B, vol. 41, p. 383, 1990.

[82] N. A. Alves, B. A. Berg e S. Sanielevici, "Spectral density study of the SU(3) deconfining phase transition", Nucl. Phys. B, vol. 376, no. 1, p. 218, 1992.

[83] A. D. Sokal, Monte Carlo methods in statistical mechanics: foundations and new algorithms. Lecture notes of the cours de troisime cycle de la physique en suisse romande. Lausanne, 1989.

[84] H. K. Janssen, B. Schaub e B. Schmittmann, "Optimization with extremal dynamics", Zeitschrift für Physik B Condensed Matter, vol. 73, p. 539, 1989.

[85] B. A. Berg, "Double jackknife bias-corrected estimators", Comput. Phys. Commun., vol. 69, p. 7, 1992. 
[86] B. A. Berg, Markov Chain Monte Carlo Simulations And Their Statistical Analysis: With Web-based Fortran Code. World Scientific Publishing Co. Pte. Ltd., 2004.

[87] F. Reif, Fundamentals of Statistical and Thermal Physics. McGraw Hill, 1965.

[88] R. S. Johal, A. Planes e E. Vives, "Statistical mechanics in the extended gaussian ensemble", Phys. Rev. E, vol. 68, p. 056113, 2003.

[89] A. R. Lima, J. S. S. Martins e T. J. P. Penna, "Monte Caril simulation of magnetic systems in the Tsallis statistics", Physica A, vol. 268, p. 553, 1999.

[90] C. Tsallis, Introduction to Nonextensive Statistical Mechanics. Springer, 2009.

[91] M. S. S. Challa e J. H. Hetherington, "Gaussian ensemble: an anternate Monte Carlo scheme", Phys. Rev. A, vol. 38, p. 6324, 1988.

[92] T. Morishita e M. Mikami, "Enhanced sampling via strong coupling to a heat bath: Relationship between Tsallis and multicanonical algorithms", J. Chem. Phys., vol. 127, p. 034104, 2007.

[93] R. S. Ellis, K. Haven e B. Turkington, "Large deviation principles and complete equivalence and nonequivalence results for pure and mixed ensembles", J. Stat. Phys., vol. 101, p. 999, 2000.

[94] F. Leyvraz e S. Ruffo, "Ensemble inequivalence in systems with long-range interactions", J. Phys. A: Math. Gen., vol. 35, p. 285, 2002.

[95] L. Casetti e M. Kastner, "Partial equivalence of statistical ensembles and kinetic energy", Physica A, vol. 384, p. 318, 2007.

[96] S. Ruffo, "Equilibrium and nonequilibrium properties of systems with longrange interactions", Eur. Phys. J. B, vol. 64, p. 355, 2008.

[97] A. Campa, T. Dauxois e S. Ruffo, "Statistical mechanics and dynamics of solvable models with long-range interactions", Phys. Rev., vol. 480, p. 57, 2009. 
[98] R. S. Ellis, H. Touchette e B. Turkington, "Thermodynamic versus statistical nonequivalence of ensembles for the mean-yield blume-emery-griffiths model", Physica A, vol. 335, p. 518, 2004.

[99] L. Velazquez e S. Curilef, "On the thermodynamic stability of macrostates with negative heat capacities", J. Stat. Mech., p. P03027, 2009.

[100] L. Velazquez e S. Curilef, "Geometrical aspects and connections of the energytemperature fluctuation relation", J. Phys. A: Math. Theor., vol. 42, p. 335003, 2009.

[101] L. Velazquez e S. Curilef, "A thermodynamic fluctuation relation for temperature and energy", J. Phys. A: Math. Theor., vol. 42, p. 095006, 2009.

[102] C. Cohen-Tannoudji, B. Diu e F. Laloe, Quantum Mechanics, Vol. 1. John Wiley \& Sons, 1977.

[103] L. Velazquez e S. Curilef, "Extending canonical monte carlo methods", J. Stat. Mech., p. P02002, 2010.

[104] L. Velazquez e S. Curilef, "Extending canonical monte carlo methods II", J. Stat. Mech., p. P04026, 2010.

[105] H. Touchette, "Methods for calculating nonconcave entropies", J. Stat. Mech., p. P05008, 2010.

[106] B. A. Berg, "Multicanonical simulations step by step", Comput. Phys. Commun., vol. 153, no. 3, p. 397, 2003.

[107] C. Junghans, "Aggregation of mesoscopic protein-like heteropolymers", Dissertação de Mestrado, University of Leipzig, 2006.

[108] C. E. Fiore, "Comparing different protocols of temperature selection in the parallel tempering method", J. Chem. Phys., vol. 135, p. 114107, 2011.

[109] M. Lingenheil, R. Denschlag, G. Mathias e P. Tavan, "Efficiency of exchange schemes in replica exchange", Chem. Phys. Lett., vol. 478, p. 80, 2009. 
[110] A. B. MacIsaac, J. P. Whitehead, M. C. Robinson e K. De'Bell, "Striped phases in two-dimensional dipolar ferromagnets", Phys. Rev. B, vol. 51, no. 22, p. 16033, 1995.

[111] I. Booth, A. B. MacIsaac, J. P. Whitehead e K. De'Bell, "Domain structures in ultrathin magnetic films", Phys. Rev. Lett., vol. 75, no. 5, p. 950, 1995.

[112] K. De'Bell, A. B. MacIsaac e J. P. Whitehead, "Dipolar effects in magnetic thin films and quasi-two-dimensional systems", Rev. Mod. Phys., vol. 72, no. 1, p. $225,2000$.

[113] D. P. Pappas, K. P. Kämper e H. Hopster, "Reversible transition between perpendicular and in-plane magnetization in ultrathin films", Phys. Rev. Lett., vol. 64, no. 26, p. 3179, 1990.

[114] R. Allenspach, M. Stampanoni e A. Bischof, "Magnetic domains in thin epitaxial Co/Au(111) films", Phys. Rev. Lett., vol. 65, no. 26, p. 3344, 1990.

[115] R. Allenspach e A. Bischof, "Magnetization direction switching in $\mathrm{Fe} / \mathrm{Cu}(100)$ epitaxial films: temperature and thickness dependence", Phys. Rev. Lett., vol. 69 , no. 23, p. 3385, 1992.

[116] O. Portmann, A. Vaterlaus e D. Pescia, "An inverse transition of magnetic domain patterns in ultrathin films", Nature, vol. 422, p. 701, 2003.

[117] S. A. Cannas, D. A. Stariolo e F. A. Tamarit, "Stripe-tetragonal first-order phase transition in ultrathin magnetic films", Phys. Rev. B, vol. 69, no. 9, p. 092409, 2004.

[118] A. B. Kashuba e V. L. Pokrovsky, "Stripe domain structures in a thin ferromagnetic film", Phys. Rev. B, vol. 48, no. 14, p. 10335, 1993.

[119] M. Biskup, L. Chayes e S. Kivelson, "On the absence of ferromagnetism in typical 2D ferromagnets", Commun. Math. Phys., vol. 274, p. 217, 2007.

[120] E. Rastelli, S. Regina e A. Tassi, "Phase diagram of a square Ising model with exchange and dipole interactions: Monte C simulations", Phys. Rev. B, vol. 76, no. 5, p. 054438, 2007. 
[121] A. Giuliani, J. L. Lebowitz e E. H. Lieb, "Ising models with long-range antiferromagnetic and short-range ferromagnetic interactions", Phys. Rev. B, vol. 74, no. 6, p. 064420, 2006.

[122] A. Giuliani, J. L. Lebowitz e E. H. Lieb, "Striped phases in two-dimensional dipole systems", Phys. Rev. B, vol. 76, no. 18, p. 184426, 2007.

[123] A. D. Stoycheva e S. J. Singer, "Stripe melting in a two-dimensional system with competing interactions", Phys. Rev. Lett., vol. 84, no. 20, p. 4657, 2000.

[124] A. D. Stoycheva e S. J. Singer, "Scaling theory for two-dimensional systems with competing interactions", Phys. Rev. E, vol. 64, no. 1, p. 016118, 2001.

[125] A. Giuliani, J. L. Lebowitz e E. H. Lieb, "Checkerboards, stripes, and corner energies in spin models with competing interactions", Phys. Rev. B, vol. 84, p. 064205, 2011.

[126] E. Rastelli, S. Regina e A. Tassi, "Phase transitions in a square Ising model with exchange and dipole interactions", Phys. Rev. B, vol. 73, p. 144418, 2006.

[127] A. B. MacIsaac, J. P. Whitehead, K. De'Bell e K. S. Narayanan, "Monte carlo study of two-dimensional Ising dipolar antiferromagnets as a model for rareearth ordering in the R-Ba-Cu-o compounds ( $\mathrm{R}=$ rare earth)", Phys. Rev. B, vol. 46, p. 6387, 1992.

[128] S. A. Cannas, M. F. Michelon, D. A. Stariolo e F. A. Tamarit, "Ising nematic phase in ultrathin magnetic films: a Monte Carlo study", Phys. Rev. B, vol. 73, p. $184425,2006$.

[129] P. M. Gleiser, F. A. Tamarit e S. A. Cannas, "Metastable states in a twodimensional Ising model with dipolar interactions", Physica D, vol. 73, p. 168, 2002.

[130] P. M. Gleiser, F. A. Tamarit, S. A. Cannas e M. A. Montemurro, "Slow dynamics in a two-dimensional Ising model with competing interactions", Phys. Rev. B, vol. 68, p. 134401, 2003. 
[131] R. M. Fernandes, Propriedades físicas de sistemas com interações competitivas. Tese de Doutorado, Instituto de Física "Gleb Wataghin" da Universidade Estadual de Campinas, UNICAMP, 2008.

[132] P. M. Chaikin e T. C. Lubensky, Principles of condensed matter physics. Cambridge University Press. Cambridge, New York, 1995.

[133] J. Lee e J. M. Kosterlitz, "New numerical method to study phase transitions", Phys. Rev. Lett., vol. 65, p. 137, 1990.

[134] J. Lee e J. M. Kosterlitz, "Three-dimensional $q$-state Potts model: Monte Carlo study near $q=3$ ", Phys. Rev. B, vol. 43, p. 1268, 1991.

[135] J. Lee e J. M. Kosterlitz, "Finite-size scaling and Monte Carlo simulations of first-order phase transitions", Phys. Rev. B, vol. 43, p. 3265, 1991.

[136] J. S. M. Fonseca, "Zeros de Fisher e aspectos críticos do modelo de Ising dipolar", Dissertação de Mestrado, Universidade de São Paulo, 2011.

[137] M. E. Fisher, Lectures in Theoretical Physics, vol. 7c. University of Colorado Press, Boulder, 1965.

[138] C. Itzykson, R. B. Pearson e J. B. Zuber, "Distribution of zeros in Ising and gauge models", Nucl. Phys. B, vol. 220, p. 415, 1983.

[139] G. Bhanot, R. Salvador, S. Black, P. Carter e R. Toral, "Accurate estimate of $\nu$ for the three-dimensional Ising model from a numerical measuremente of its partition function", Phys. Rev. Lett., vol. 59, p. 803, 1987.

[140] N. A. Alves, B. A. Berg e R. Villanova, "Potts models: Density of states and mass gap from Monte Carlo calculations", Phys. Rev. B, vol. 43, p. 5846, 1991.

[141] N. A. Alves, B. A. Berg e S. Sanielevici, "Partition function zeros and the SU(3) deconfining phase transition", Phys. Rev. Lett., vol. 64, p. 3107, 1990.

[142] N. A. Alves e U. H. E. Hansmann, "Partition function zeros and finite size scaling of helix-coil transitions in a polypeptide", Phys. Rev. Lett., vol. 84, p. $1836,2000$. 
[143] N. A. Alves, J. P. N. Ferrite e U. H. E. Hansmann, "Numerical comparison of two approaches for the study of phase transitions in small systems", Phys. Rev. E, vol. 65, p. 036110, 2002.

[144] N. A. Alves, J. R. D. Felicio e U. H. E. Hansmann, "A new look at the 2D Ising model from exact partition function zeros for large lattice sizes", Int. J. Mod. Phys. C, vol. 8, p. 1063, 1997.

[145] C. Itzkson, R. B. Pearson e J. B. Zuber, "Distribution of zeros in Ising and gauge models", Nuclear Physics B, vol. 220, p. 415, 1983.

[146] M. Fukugita, H. Mino, M. Okawa e A. Ukawa, "Finite-size scaling of the threestate Potts model on a simple cubic lattice", J. Stat. Phys., vol. 59, p. 1397, 1990.

[147] M. E. Fisher e A. N. Berker, "Scaling for first-order phase transitions in thermodynamic and finite system", Phys. Rev. B, vol. 26, p. 2507, 1982.

[148] K. Decker, A. Hasenfratz e P. Hasenfratz, "Singular renormalization group transformations and first order phase transitions", Nucl. Phys. B, vol. 295, p. 21, 1988.

[149] D. J. Selkoe, "Alzheimer's disease: genes, proteins, and therapy", Physiolog. Rev., vol. 81, p. 741, 2001.

[150] J. Hardy e D. J. Selkoe, "The amyloid hypothesis of Alzheimer's disease: progress and problems on the road to therapeutics", Science, vol. 297, p. 353, 2002.

[151] S. Ramaswamy, K. M. Shannon e J. H. Kordower, "Huntington's disease: pathological mechanisms and therapeutic strategies", Cell Transplantation, vol. 16, p. 301, 2007.

[152] S. Imarisio, J. Carmichael, V. Korolchuk, C.-W. Chen, S. Saiki, C. Rose, G. Krishna, J. E. Davies, E. Itofi, B. R. Underwood e D. C. Rubinsztein, "Huntington's disease: from pathology and genetics to potential therapies", Biochem. J., vol. 412, p. 191, 2008. 
[153] M. R. Cookson, "The biochemistry of Parkinson's disease", Ann. Rev. Biochem., vol. 74, p. 29, 2005.

[154] R. M. Murphy, "Peptide aggregation in neurodegenerative disease", Annu. Rev. Biomed. Eng., vol. 4, p. 155, 2002.

[155] D. Thirumalai, D. K. Klimov e R. I. Dima, "Emerging ideas on the molecular basis of protein and peptide aggregation", Curr. Opin. Struct. Biol., vol. 13, p. $146,2003$.

[156] S. Ohnishi e K. Takano, "Amyloid fibrils from the viewpoint of protein folding", Cellular and Molecular Life Sciences, vol. 61, p. 511, 2004.

[157] F. Chiti e C. M. Dobson, "Protein misfolding, functional amyloid, and human disease", Ann. Rev. Biochem., vol. 75, p. 333, 2006.

[158] A. Espargaró, V. Castillo, N. S. D. Groot e S. Ventura, "The in vivo and in vitro aggregation properties of globular proteins correlate with their conformational stability: the SH3 case", J. Mol. Biol., vol. 378, p. 1116, 2008.

[159] D. Thirumalai e G. Reddy, "Are native proteins metastable?", Nature Chem., vol. 3, p. 910, 2011.

[160] A. J. Baldwin, T. P. J. Knowles, G. G. Tartaglia, A. W. Fitzpatrick, G. L. Devlin, S. L. Shammas, C. A. Waudby, M. F. Mossuto, S. Meehan, S. L. Gras, J. Christodoulou, S. J. Anthony-Cahill, P. D. Barker, M. Vendruscolo, e C. M. Dobson, "Metastability of native proteins and the phenomenon of amyloid formation", J. Am. Chem. Soc., vol. 133, p. 14160, 2011.

[161] M. Bucciantini, E. Giannoni, F. Chiti, F. Baroni, L. Formigli, J. Zurdo, N. Taddei, G. Ramponi, C. M. Dobson e M. Stefan, "Inherent toxicity of aggregates implies a common mechanism for protein misfolding diseases", $\mathrm{Na}$ ture, vol. 416, p. 507, 2002.

[162] K. F. DuBay, A. P. Pawar, F. Chiti, J. Zurdo, C. M. Dobson e M. Vendruscolo, "Prediction of the absolute aggregation rates of amyloidogenic polypeptide chains", J. Mol. Biol., vol. 341, p. 1317, 2004. 
[163] M. Belli, M. Ramazzotti e F. Chiti, "Prediction of amyloid aggregation in vivo", EMBO Reports, vol. 12, p. 657, 2011.

[164] B. Ma e R. Nussinov, "Simulations as analytical tools to understand protein aggregation and predict amyloid conformation", Curr. Opin. Chem. Biol., vol. 10, p. $445,2006$.

[165] F. H. Stillinger e T. Head-Gordon, "Collective aspects of protein folding illustrated by a toy model", Phys. Rev. E, vol. 52, p. 2872, 1995.

[166] S. Schnabel, M. Bachmann e W. Janke, "Two-state folding, folding through intermediates, and metastability in a minimalistic hydrophobic-polar model for proteins", Phys. Rev. Lett., vol. 98, p. 048103, 2007.

[167] C. Junghans, M. Bachmann, H. Arkin e W. Janke, "Thermodynamics of peptide aggregation processes: An analysis from perspectives of three statistical ensembles", J. Chem. Phys., vol. 128, p. 085103, 2008.

[168] A. P. Pawar, K. F. DuBay, J. Zurdo, F. Chiti, M. Vendruscolo e C. M. Dobson, "Prediction of aggregation-prone and aggregation-susceptible regions in proteins associated with neurodegenerative diseases", J. Mol. Biol., vol. 350, p. 379,2005 .

[169] V. N. Uversky e A. L. Fink, "Conformational constraints for amyloid fibrillation: the importance of being unfolded", Biochim. Biophys. Acta, vol. 1698, p. 131, 2004.

[170] D. Hamada, T. Tanaka, G. G. Tartaglia, A. Pawar, M. Vendruscolo, M. Kawamura, A. Tamura, N. Tanaka e C. M. Dobson, "Competition between folding, native-state dimerisation and amyloid aggregation in $\beta$-lactoglobulin", J. Mol. Biol., vol. 386, p. 878, 2009.

[171] P. Neudecker, P. Robustelli, A. Cavalli, P. Walsh, P. Lundström, A. ZarrineAfsar, S. Sharpe, M. Vendruscolo e L. E. Kay, "Structure of an intermediate state in protein folding and aggregation", Science, vol. 336, p. 362, 2012. 
[172] J. R. Kumita, L. Helmfors, J. Williams, L. M. Luheshi, L. Menzer, M. Dumoulin, D. A. Lomas, D. C. Crowther, C. M. Dobson e A.-C. Brorsson, "Diseaserelated amyloidogenic variants of human lysozyme trigger the unfolded protein response and disturb eye development in drosophila melanogaster", FASEB J., vol. 26, p. 192, 2012.

[173] S. Liemann e R. Glockshuber, "Influence of amino acid substitutions related to inherited human prion diseases on the thermodynamic stability of the cellular prion protein", Biochem., vol. 38, p. 3258, 1999.

[174] G. Soldi, F. Bemporad, S. Torrassa, A. Relini, M. Ramazzotti, N. Taddei e F. Chiti, "Amyloid formation of a protein in the absence of initial unfolding and destabilization of the native state", Biophys. J., vol. 89, p. 4234, 2005.

[175] J. E. Straub e D. Thirumalai, "Toward a molecular theory of early and late events in monomer to amyloid fibril formation", Annu. Rev. Phys. Chem., vol. 62 , p. 437, 2011.

[176] C.-L. Ni, H.-P. Shi, H.-M. Yu, Y.-C. Chang e Y.-R. Chen, "Folding stability of amyloid- $\beta 40$ monomer is an important determinant of the nucleation kinetics in fibrillization", FASEB J., vol. 25, p. 1390, 2011.

[177] G. Bitan, M. D. Kirkitadze, A. Lomakin, S. S. Vollers, G. B. Benedek e D. B. Teplow, "Amyloid $\beta$-protein (a $\beta$ ) assembly: $\mathrm{A} \beta 40$ and a $\beta 42$ oligomerize through distinct pathways", Proc. Natl. Acad. Sci. USA, vol. 100, p. 330, 2003.

[178] M. A. Roseman, "Hidrophilicity of polar amino acid side-chais is markedly reduced by flanking peptide bonds", J. Mol. Biol., vol. 200, p. 513, 1988.

[179] A. P. Pawar, K. F. DuBay, J. Zurdo, F. Chiti, M. Vendruscolo e C. M. Dobson, "The intrinsic aggregation propensity score algorithm at Vendrusculo's group page". http://www-vendruscolo.ch.cam.ac.uk/zyggregator . php, ago 2012.

[180] VMD, "Theoretical e computational biophysics group. VMD - Visual Molecular Dynamics". http://www.ks.uiuc.edu/Research/vmd/, nov 2012. 
[181] F. Ding, N. V. Dokholyan, S. V. Buldyrev, H. E. Stanley e E. I. Shakhnovich, "Direct molecular dynamics observation of protein folding transition state ensemble", Biophys. J., vol. 83, p. 3525, 2002.

[182] J. M. Borreguero, N. V. Dokholyan, S. V. Buldyrev, E. I. Shakhnovich e H. E. Stanley, "Thermodynamics and folding kinetics analysis of the SH3 domain from discrete molecular dynamics", J. Mol. Biol., vol. 318, p. 863, 2002.

[183] J. M. Borreguero, F. Ding, S. V. Buldyrev, H. E. Stanley e N. V. Dokholyany, "Multiple folding pathways of the SH3 domain", Biophys. J., vol. 87, p. 521, 2004.

[184] I. A. Hubner, K. A. Edmonds e E. I. Shakhnovich, "Nucleation and the transition state of the SH3 domain", J. Mol. Biol., vol. 349, p. 424, 2005.

[185] H. Yu, X. Liu, K. Neupane, A. N. Gupta, A. M. Brigley, A. Solanki, I. Sosova e M. T. Woodside, "Direct observation of multiple misfolding pathways in a single prion protein molecule", Proc. Natl. Acad. Sci. USA, vol. 109, p. 5283, 2012.

[186] A. W. Fitzpatrick, T. P. J. Knowles, C. A. Waudby, M. Vendruscolo e C. M. Dobson, "Inversion of the balance between hydrophobic and hydrogen bonding interactions in protein folding and aggregation", PLoS Comput. Biol., vol. 7, p. e1002169, 2011.

[187] N. A. Alves, V. Aleksenko e U. H. E. Hansmann, "A simple hydrophobicitybased score for profiling protein structures", J. Phys.: Condens. Matt., vol. 17, p. S1595, 2005.

[188] J. D. Harper e P. T. Lansbury, "Models of amyloid seeding in Alzheimer's disease and scrapie: Mechanistic truths and physiological consequences of the time-dependent solubility of amyloid proteins", Annu. Rev. Biochem., vol. 66, p. $385,1997$.

[189] Z. Liu, G. Reddy e D. Thirumalai, "Theory of the molecular transfer model for proteins with applications to the folding of the src-SH3 domain", J. Phys. Chem. B, vol. 116, p. 6707, 2012. 
[190] S. Schnabel, D. T. Seaton, D. P. Landau e M. Bachmann, "Microcanonical entropy inflection points: Key to systematic understanding of transitions in finite systems", Phys. Rev. E, vol. 84, p. 011127, 2011.

[191] J. Hernandez-Rojas e J. M. G. Llorente, "Microcanonical versus canonical analysis of protein folding", Phys. Rev. Lett., vol. 100, p. 258104, 2008.

[192] P. Poulain, F. Calvo, R. Antoine, M. Broyer e P. Dugourd, "Performances of Wang-Landau algorithms for continuous systems", Phys. Rev. E, vol. 73, p. 056704, 2006.

[193] J. Xu e H.-R. Ma, "Density of states of a two-dimensional XY model from the Wang-Landau algorithm", Phys. Rev. E, vol. 75, p. 041115, 2007.

[194] S. Sinha e S. K. Roy, "Performance of Wang-Landau algorithm in continuous spin models and a case study: modified XY-model", Phys. Lett. A, vol. 373, p. 308, 2009.

[195] S. Sinha e S. K. Roy, "Finite size scaling and first-order phase transition in a modified XY model", Phys. Rev. E, vol. 81, p. 022102, 2010.

[196] P. Dayal, S. Trebst, S. Wessel, D. Würtz, M. Troyer, S. Sabhapandit e S. N. Coppersmith, "Performance limitations of flat-histogram methods", Phys. Rev. Lett., vol. 92, p. 097201, 2004.

[197] A. Mitsutake e Y. Okamoto, "Multidimensional generalized-ensemble algorithms for complex systems", J. Chem. Phys., vol. 130, p. 214105, 2009.

[198] R. Gupta e C. F. Baillie, "Critical behavior of the two-dimensional XY model", Phys. Rev. B, vol. 45, p. 2883, 1992.

[199] J. M. Kosterlitz, "The critical properties of the two-dimensional XY model", J. Phys. C, vol. 7, p. 1046, 1974.

[200] F. C. Poderoso, J. J. Arenzon e Y. Levin, "New ordered phases in a class of generalized XY models", Phys. Rev. Lett., vol. 106, p. 067202, 2011. 
[201] U. Wolff, "Collective Monte Carlo updating for spin systems", Phys. Rev. Lett., vol. 62, p. 361, 1989.

[202] M. Hasenbusch, "The two-dimensional XY model at the transition temperature: a high precision Monte Carlo study", J. Phys. A: Math. Gen., vol. 38, p. 5869, 2005. 


\section{APÊNDICE}

\section{CURVA CALÓRICA PARA O MODELO XY BIDIMENSIONAL}

Tendo em vista a possibilidade da ocorrência de transições do tipo KosterlitzThouless [198, 199] (KT) no diagrama de fases do modelo de Ising dipolar bidimensional, resolvemos estudar a termoestatística microcanônica do modelo XY, também em duas dimensões. Esse modelo apresenta o paradigma de transição do tipo KT [132]. Os resultados apresentados a seguir foram obtidos em colaboração com o Dr. Fábio C. Poderoso (trabalho em preparação), quem desenvolveu o programa para simular o modelo XY [200].

O Hamiltoniano para o modelo XY pode ser escrito como

$$
\mathcal{H}=-\sum_{\langle i, j\rangle} \cos \left(\theta_{i}-\theta_{j}\right),
$$

onde a notação $\langle i, j\rangle$ indica que a soma é feita somente sobre os primeiros vizinhos. As variáveis $\theta_{i}$ representam ângulos entre a direção dos spins e uma direção principal (por exemplo, o eixo das abcissas).

A produção de dados foi obtida em temperaturas independentes utilizando o algoritmo de cluster de Wolff [201]. Ao todo foram $10000 \times L^{2}$ configurações amostradas para cada temperatura e consideramos redes de tamanho $L=48$ e $L=128$. Realizamos simulações independentes para temperaturas indo de $T_{\min }=0,75\left(\beta_{\max }=1,33\right)$ até $T_{\max }=1,05\left(\beta_{\min }=0,95\right)$. Para ambas as redes utilizamos temperaturas intermediárias igualmente espaçadas de $\delta T$, sendo empregado $\delta T=0,05$ para a rede menor, resultando num total de sete temperaturas, enquanto que para a rede maior dez temperaturas igualmente espaçadas $\delta T=0,02$ foram simuladas. Na Fig. A.1 


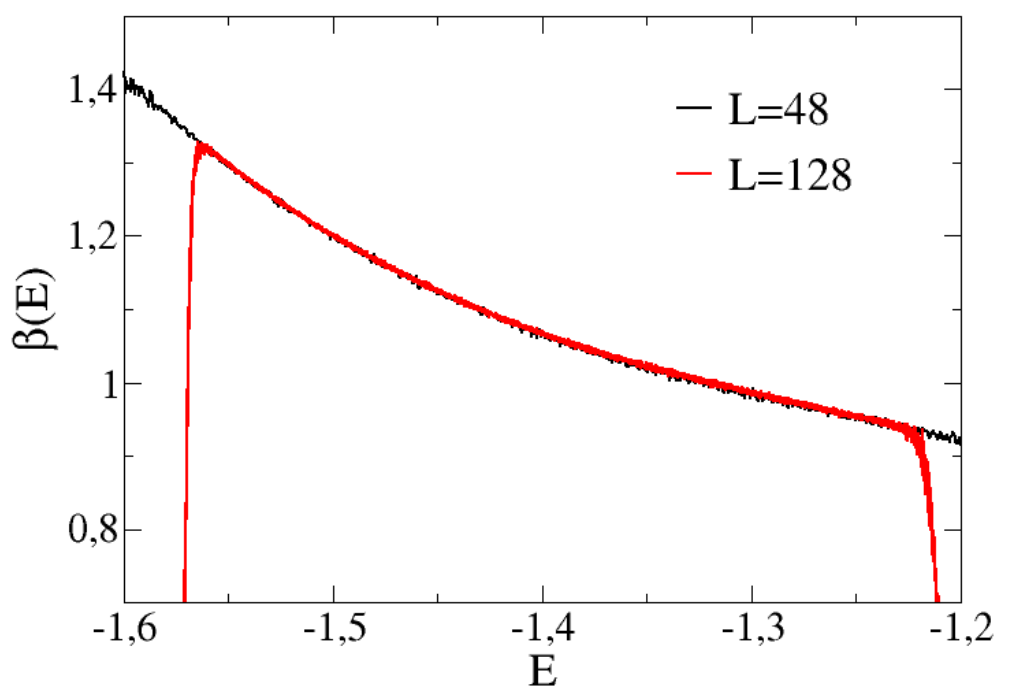

Figura A.1: Curvas calóricas obtidas via ST-WHAM para o modelo XY bidimensional na região de transição $\mathrm{KT}$ para dois tamanhos de rede $L=48$ e $L=128$.

são apresentadas as curvas para a temperatura estatística obtidas via ST-WHAM utilizando a discretização na energia com $\epsilon=1$. Como vemos, as curvas calóricas não apresentam indícios de uma região metaestável, sugerindo assim que a termoestatística microcanônica da transição KT assemelha-se à das transições contínuas. O valor mais preciso obtido para o inverso da temperatura da transição KT é $\beta_{K T}=1,1199$ [202]. Notamos ainda que a variação de tamanho da rede não produz qualquer efeito observável nas curvas calóricas. 


\section{APÊNDICE}

\section{VALIDAÇÃO DA IMPLEMENTAÇÃO DO MODELO AB}

Apresentamos aqui resultados utilizados na validação da implementação das simulações do modelo AB, estudado no Capítulo 4.

Primeiramente consideramos um heteropolímero que já havia sido abordado na literatura [107], o qual consiste em uma sequência com 13 monômeros definida por ABBABBABABBAB, também conhecida como sequência de Fibonacci. Para comparação, realizamos tanto simulações utilizando o método de troca entre réplicas (REM) quanto simulações de Metropolis independentes. Ambas simulações foram realizadas utilizando o mesmo número de varreduras, $10^{7}$ para cada temperatura. Para todas as temperaturas, $10^{6}$ varreduras iniciais foram descartadas para a termalização. Na simulação utilizando o REM, as tentativas de trocas ocorreram a cada 2000 varreduras. Utilizamos o mesmo conjunto de doze temperaturas para as duas simulações, o qual consistiu das seguintes temperaturas: $\{0,05 ; 0,07 ; 0,09 ; 0,11 ; 0,13 ; 0,14 ; 0,15 ; 0,16 ; 0,18 ; 0,20 ; 0,23 ; 0,27\}$.

Na Fig. B.1 apresentamos resultados para a energia média por monômero em função da temperatura para esse sistema. Como vemos, para temperaturas próximas e abaixo da transição $(T \sim 0,15)$, os resultados das duas simulações apresentam uma discrepância significativa. Na Ref. [107] esta mesma cadeia foi estudada utilizando o algoritmo multicanônico (MUCA) e o mesmo gráfico da energia média por monômero foi obtido. A concordância entre os resultados apresentados na Ref. [107] e a nossa implementação do REM indica que as simulações de Metropolis estão fornecendo resultados inadequados, viesando a média térmica da energia. Outra 


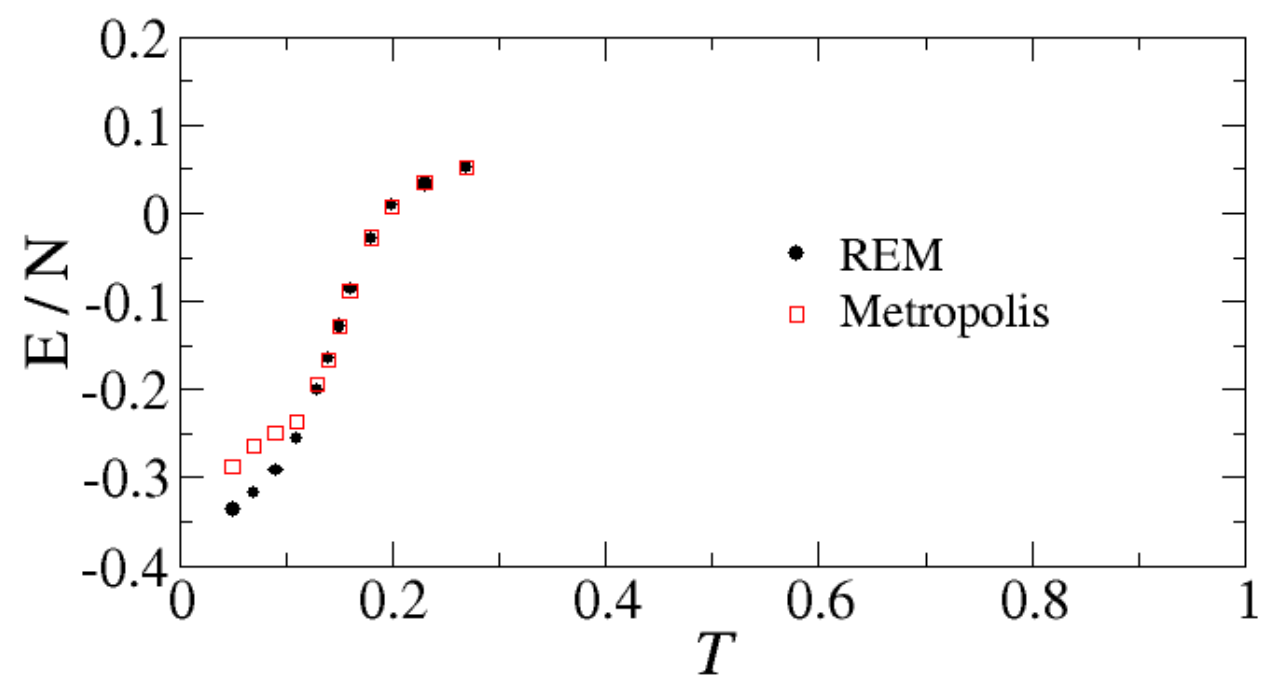

Figura B.1: Comparação entre simulações de Metropolis independentes e utilizando o método de troca entre réplicas para o modelo $A B$. Energia média por monômero em função da temperatura para a sequência Fibonacci (ABBABBABABBAB) com 13 monômeros.

questão pertinente que podemos concluir dessa validação é que, mesmo utilizando apenas uma atualização dita global, como é o caso do algoritmo spherical cap ${ }^{1}$, obtemos resultados iguais aos obtidos quando utiliza-se também atualizações locais tais como crank shaft (vide Ref. [107]).

Para complementar a validação da implementação do modelo AB, também resolvemos incluir resultados para a termoestatística microcanônica no caso onde de duas cadeias de Fibonacci com 13 aminoácidos. Nesse caso também é possível comparar com resultados apresentados na literatura [51]. Tais resultados foram utilizados para o fenômeno de agregação. Além do termo de interação de monômeros na mesma cadeia, inclui-se uma interação da mesma natureza (do tipo Lennard-Jones levando em consideração o caráter hidrofóbico ou polar) entre monômeros de cadeias distintas, tal como descrito na Ref. [51, 167]. As simulações foram feitas utilizando o REM, com o número de varreduras total para cada temperatura igual a $10^{7}$, sendo as tentativas de trocas realizadas a cada $10^{4}$ varreduras. O conjunto de oito temperaturas foi determinado utilizando-se a progressão aritmética para o inverso da temperatura $\beta$, resultando em: $\{3,8 ; 4,2 ; 4,6 ; 5,0 ; 5,4 ; 5,8 ; 6,2 ; 6,6\}$

\footnotetext{
${ }^{1}$ Utilizamos um ângulo máximo de atualização igual a $\theta_{\max }=0,14154$, que corresponde à $\cos \left(\theta_{\max }\right)=0.99$, como utilizado na Ref. [50].
} 


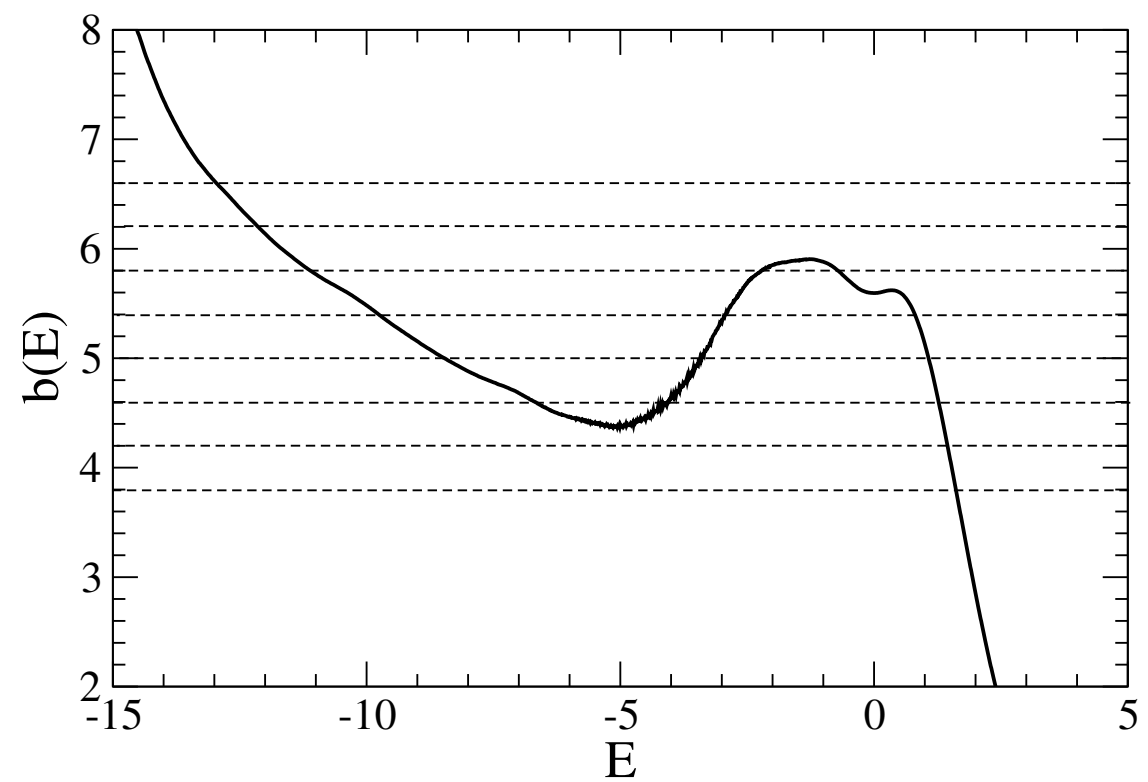

Figura B.2: Curva calórica microcanônica para o sistema de duas sequências de Fibonacci com 13 aminoácidos cada obtida a partir de simulações de Metropolis com troca entre réplicas aliadas ao ST-WHAM. As linhas pontilhas representam as temperaturas inversas utilizadas na simulações.

No caso do sistema com duas cadeias, consideramos também rotações e translações de corpo rígido. Cada varredura inclui a possibilidade de rotações em torno de três eixos principais de no máximo $\phi_{\max }=0,261799\left(15^{\circ}\right)$ cada e translações para as três direções de no máximo 0,1 (unidades arbitrárias) cada, para ambas cadeias.

A Fig. B.2 mostra a curva calórica $(b(E)$ versus $E)$ para nossa implementação do modelo $\mathrm{AB}$ utilizando dois heteropolímeros. A curva calórica foi obtida com o método ST-WHAM, onde utilizamos a discretização na energia com $\epsilon=0,01$. As linhas pontilhadas representam as temperaturas inversas para cada uma das oito réplicas. Comparando essa figura com a figura apresentadas para esse sistema na referência [167] (obtida utilizando o algoritmo multicanônico), é possível concluir que estão em estrita concordância. Mesmo o loop pequeno próximo da energia $E \sim 0$ pode ser observado. Além de validar a nossa implementação do modelo $\mathrm{AB}$, a concordância entre os resultados obtidos aqui com os resultados obtidos via algoritmo multicanônico também contribui para validar o método ST-WHAM na obtenção da termoestatística microcanônica em regiões de transição de fase onde a entropia apresenta uma região não côncava. 


\section{ANEXOS: ARTIGOS}

Anexo I $\quad$ Artigo publicado: Physica B 405 (2010) 1571-1579.

http://dx.doi.org/10.1016/j.physb.2009.12.041

Anexo II Artigo publicado: Eur. Phys. J. B 75 (2010) 311-318.

http://dx.doi.org/10.1140/epjb/e2010-00161-y

Anexo III Artigo publicado: J. Phys.: Conf. Ser 246 (2010) 012018.

http://dx.doi.org/10.1088/1742-6596/246/1/012018

Anexo IV Artigo publicado: J. Comp. Int. Sci. 2 (2011) 79.

http://dx.doi.org/10.6062/jcis.2011.02.02.0034

Anexo V $\quad$ Artigo publicado: J. Chem. Phys. 135 (2011) 141101.

http://dx.doi.org/10.1063/1.3651627

Anexo VI Artigo publicado: Rev. Bras. Ens. Fis. 34 (2012) 1306.

http://www.sbfisica.org.br/rbef/pdf/341306.pdf

Anexo VII $\quad$ Artigo publicado: Phys. Rev. E 86 (2012) 011103.

http://dx.doi.org/10.1103/PhysRevE.86.011103

Anexo VIII Artigo publicado: J. Chem. Phys. 138 (2013) 015102.

http://dx.doi.org/10.1063/1.4773007

Os artigos originais listados acima foram suprimidos na versão digital desta Tese com o intuito de evitar eventuais problemas com violações de direitos autorais na sua reprodução on-line na Biblioteca Digital de Teses e Dissertações da Universidade de São Paulo. 